\title{
An Admittance Meter Technique to Measure the Complex Permeability at VHF
}

\author{
A. L. Rasmussen* and C. M. Allred** \\ Institute for Basic Standards, National Bureau of Standards, Boulder, Colo. 80302
}

(October 24, 1967)

\begin{abstract}
An admittance meter technique may be used in evaluating and comparing accurately and conveniently the complex permeability of magnetic materials from $30 \mathrm{MHz}$ to $\sim 100 \mathrm{MHz}$. The admittance meter has three coaxial lines fed from a common source at a common junction point, two lines being terminated by shorts and the third by $50 \Omega$. The currents in the lines are detected by three electrically connected parallel loops each located close to the common junction point of the lines. The loops are adjustable to one minute of rotation and follow closely a sine law. The complex permeability of a sample is derived from measurements with a sample in and out of one of the shorted coaxial lines. The estimated error from $30 \mathrm{MHz}$ to $100 \mathrm{MHz}$ is from $\sim 1$ to $\sim 10$ percent for sample inductance from $3 \cdot 10^{-9}$ to $10^{-7} \mathrm{H}$ and sample resistance $5 \cdot 10^{-1}$ to $10^{2} \Omega$. Error of inductance is $\sim 1$ percent from $30 \mathrm{MHz}$ to $200 \mathrm{MHz}$ for low-loss samples using calibrated sample data. Using precision $50 \Omega$, low-contact resistance lines, the sample impedance error attainable is estimated as $\sim 1$ percent for the above limits of impedance and measurements can be extended to above $100 \mathrm{MHz}$. The equations for the inductance and the resistance of the sample are expressed in terms of calibrated values for the settings of two loops, the calibrated resistance value of the $50 \Omega$ termination, the calibrated or calculated impedance components of the sample line, and the inductance of an equivalent air core.
\end{abstract}

Key Words: Admittance meter, attenuation calibration, lossy magnetic materials, magnetic measurement methods, permeability, rf magnetic materials, VHF bridge, VHF magnetic materials.

\section{Definitions of Symbols}

$Y_{1}=$ Line 1 admittance terminated by a short.

$Y_{2}=$ Line 2 admittance terminated by $50 \Omega$.

$Y_{3}=$ Line 3 admittance terminated by a short.

$K_{1}=$ Relative loop output which is a function of the angle of loop rotation in the corresponding numbered line.

$K_{2}=$ Same as above. A primed symbol refers to data with a sample in line 3 .

$K_{3}=$ Same as above. A primed symbol refers to data with a sample in line 3.

$L=$ Sample inductance.

$R=$ Sample resistance.

$\omega=$ Angular frequency.

$L_{3}=$ Inductance of line 3 without a sample inside.

$R_{2}=$ Resistance of line 2 .

$L_{a}=$ Calculated inductance of an equivalent air core.

$R_{3}=$ Resistance of line 3 without a sample inside.

$\mu^{\prime}=$ Real component of initial permeability.

$\mu^{\prime \prime}=$ Imaginary component of initial permeability.

$\tan \delta=\mu^{\prime \prime} / \mu^{\prime}=R / \omega L$. 


\section{Introduction}

A technique based on the principles of a familiar admittance meter [1] ${ }^{1}$ may be used in evaluating and comparing accurately and conveniently the complex permeability of magnetic materials from $30 \mathrm{MHz}$ to $\sim 100 \mathrm{MHz}$. Such an instrument is relatively simple to calibrate; and, utilizing a null method, "lossy" materials are easier to evaluate than they would be if resonant cavity techniques were used. The technique is evaluated and data discussed.

\section{The Admittance Meter and Its Calibration}

The admittance meter discussed here (see fig. 1) has three coaxial lines fed from a common source at a common junction point, two lines being terminated by shorts and the third by $50 \Omega$. In the commercially available model one line is terminated by its characteristic impedance $(50 \Omega)$, another by a reactance, and the third by the unknown admittance. The current in each line in these instruments is sampled near the common junction point by a loop through the mutual coupling between the loop and the center conductor of the line. The mutual coupling which closely follows a sine law, is adjustable by rotating the loop about an axis perpendicular to the center conductor of its respective line. The outputs of the loops are connected in parallel and fed into a sensitive tuned null detector.

The experimental model used in the technique described here was originally designed and constructed at NBS for use in some very special rf power measurements, and a more stable instrument with better impedance matching could easily be designed to better meet the needs required in the technique under discussion if the time and funds were available. Nevertheless, in spite of some difficulties, the technique was adequately evaluated and found to have merit.

In order to explain the measurement technique and loop calibration, the basic equations for the admittance meter are developed and discussed. As shown in figure 1, the two shorted lines are designated as 1 and 3 , and the $50 \Omega$ line as 2 . The currents in lines 1,2 , and 3 are

$$
\begin{aligned}
& i_{1}=V Y_{1} \\
& i_{2}=V Y_{2} \\
& i_{3}=V Y_{3} .
\end{aligned}
$$

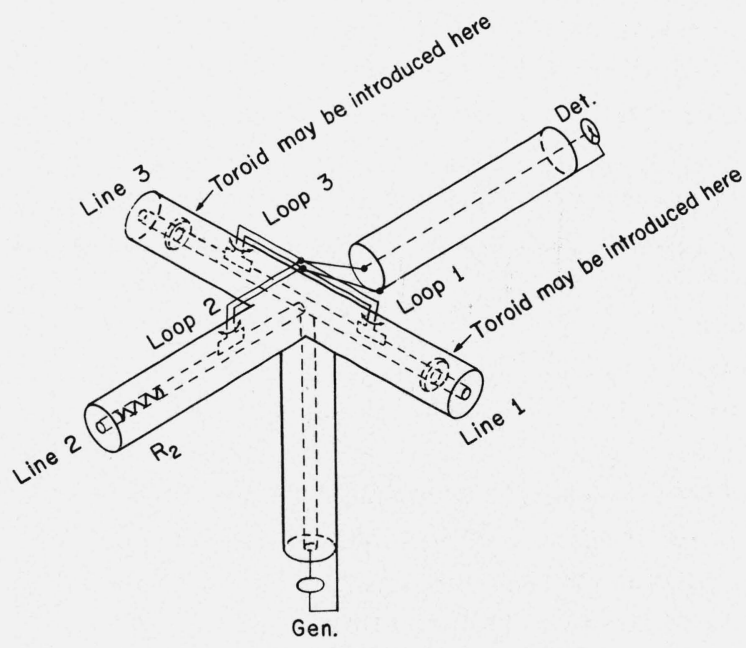

FIGURE 1. Schematic of the admittance meter circuit used.

\footnotetext{
${ }^{1}$ Figures in brackets indicate the literature references on page 87.
} 
The outputs of the loops are, respectively,

$$
\begin{aligned}
& v_{1}=K_{1} i_{1} \\
& v_{2}=K_{2} i_{2} \\
& v_{3}=K_{3} i_{3}
\end{aligned}
$$

where the proportionality constant $K$ is a function of the angle of loop rotation. The functional relationship is to a close approximation, $K=k \sin \theta$. The three outputs are combined and the $K$ 's are adjusted for a null where

$$
v_{1}+v_{2}+v_{3}=0
$$

and hence

$$
K_{1} Y_{1}+K_{2} Y_{2}+K_{3} Y_{3}=0
$$

The $K_{1}$ values for the instrument used are proportional to the sines of angles of $+90^{\circ}$ to $-90^{\circ}$; $K_{2}$, from $+5^{\circ}$ to $-90^{\circ}$; and $K_{3}$ from $-5^{\circ}$ to $+90^{\circ}$. Angles are adjustable to one minute of rotation.

Measurements of a sample can be made by (1) holding $K_{1}$ constant and adjusting loops 2 and 3 for the conditions with and without a sample in line 3, or (2) a sample in one line can be compared with a sample in the other coaxial line. We chose to use method (1). Method (2) is especially useful if the two coaxial lines are identical both electrically and physically.

It can be shown (see appendix A) that the equations for the inductance and the resistance of a sample in line 3 are

$$
\begin{gathered}
L=\frac{\left(K_{3}^{\prime} / K_{3}\right)\left(1 / \omega L_{3}\right)}{\omega\left[\left(\left(K_{2}^{\prime}-K_{2}\right) / K_{3}\right)^{2}\left(1 / R_{2}\right)^{2}+\left(1 / \omega L_{3}\right)^{2}\right]}-L_{3}+L_{a}, \\
R=\frac{-\left(K_{3}^{\prime} / K_{3}\right)\left(\left(K_{2}^{\prime}-K_{2}\right) / K_{3}\right)\left(1 / R_{2}\right)}{\left(\left(K_{2}^{\prime}-K_{2}\right) / K_{3}\right)^{2}\left(1 / R_{2}\right)^{2}+\left(1 / \omega L_{3}\right)^{2}}-R_{3}
\end{gathered}
$$

when the following assumptions are made:

1. $K_{1} Y_{1}=$ constant during the measurement with and without a sample in line $3 . K_{1}$ may have a wide range of values. Setting loop 1 determines the setting of loop 3 and vice versa.

2. $R_{2}=50 \Omega$ and its VSWR $\approx 1.005$. See appendix A.

3. Precision $50 \Omega$ lines with low contact resistance terminations are used. The lines used did not have these characteristics; therefore, the term $R_{3} / \omega^{2} L_{3}^{2}$ should be added to $-\left(\left(K_{2}^{\prime}-K_{2}\right) / K_{3}\right)\left(1 / R_{2}\right)$ whenever this expression appears in eqs (2) and (3). See appendix A. In addition to the correction from $R_{3}$, other corrections for transformed impedances should be made. However, none were necessary for the accuracy of the data in this paper.

For a low-loss sample where $\omega L \gg R$, we can simplify the equations to

$$
\begin{gathered}
L=L_{3}\left[\left(K_{3}^{\prime} / K_{3}\right)-1\right]+L_{a} \\
R=-\left(K_{3}^{\prime} / K_{3}\right)\left(\left(K_{2}^{\prime}-K_{2}\right) / K_{3}\right)\left(1 / R_{2}\right)\left(\omega L_{3}\right)^{2}-R_{3}
\end{gathered}
$$

when the expression $\left(\left(K_{2}^{\prime}-K_{2}\right) / K_{3}\right)^{2}\left(1 / R_{2}\right)^{2} \ll\left(1 / \omega L_{3}\right)^{2}$. As in assumption 3 above, $R_{3} / \omega^{2} L_{3}^{2}$ must be added to $-\left(\left(K_{2}^{\prime}-K_{2}\right) / K_{3}\right)\left(1 / R_{2}\right)$ in eq (5). If $L$ and $K^{\prime \prime}$ of a high-or low-loss sample are known, one can find $L_{3}$ and $R_{3}$ using eqs (2) and (3) or (4) and (5). $L_{3}$ can also be calculated from the dimensions of a precision line. 
Finally, the complex permeability is (using the $L$ and $R$ values of eqs (2) and (3) or (4) and (5)):

$$
\begin{aligned}
& \mu^{\prime}=\frac{L}{L_{a}} \\
& \mu^{\prime \prime}=\frac{R}{\omega L_{a}}
\end{aligned}
$$

and the loss tangent

$$
\tan \delta=\frac{\mu^{\prime \prime}}{\mu^{\prime}}=\frac{R}{\omega L}
$$

Calibration of the loop outputs shows they closely follow a sine law, deviating somewhat when the angles are $\widetilde{\gtrless} 10^{\circ}$. "Calibrated values" include the relative outputs of the loops to each other. In general data are a little more accurate using a sine law and the relative output calibration. However, results on samples reported in this paper come from completely calibrated loop data.

Calibration of the voltage output of the loops is performed using the circuit shown in figure 2 . To a first order approximation, the voltage in each loop is proportional to the admittance in the corresponding numbered line.

A signal in Branch 1 is matched to a signal in Branch 2 by balancing a loop output to the attenuator output of opposite phase. This loop is terminated in $50 \Omega$. The two other loops are set to zero output and their corresponding lines to infinite impedance. The zero output angle of each loop is found electrically.

Angles are calibrated by reading the angle to a resolution of one minute and the attenuator to $\pm 0.001 \mathrm{~dB}$ accuracy. Voltage ratios are derived from measuring the decibel change from a reference angle. Calibration of the loop output may be calculated from the voltage ratios. Relative output is found by measuring the change in attenuation from one loop to another.

Loop calibration was checked at $30 \mathrm{MHz}$ using two $50 \Omega$ terminations accurate to \pm 0.5 percent. They were compared to each other using lines 1 and 2,1 and 3 , and 2 and 3 with the loops set at several different angles, and generally agreed within 0.5 percent.

The precision of loop 3 measurements when evaluating samples was $\sim 0.1$ percent, and for loop 2, 1 percent for "lossy" samples. Sample data are independent of the loop angles used (except when they were close to zero). At $30 \mathrm{MHz}$, the input power was $\sim 0.25 \mathrm{~W}$ and at $100 \mathrm{MHz}$, $\sim 0.1 \mathrm{~W}$.

\section{Interpretation of Measurements}

Using the instrument described and treating line 3 impedances as lumped circuit quantities, the estimated error from 30 to $100 \mathrm{MHz}$ is from $\sim 1$ percent to $\sim 10$ percent for sample inductance

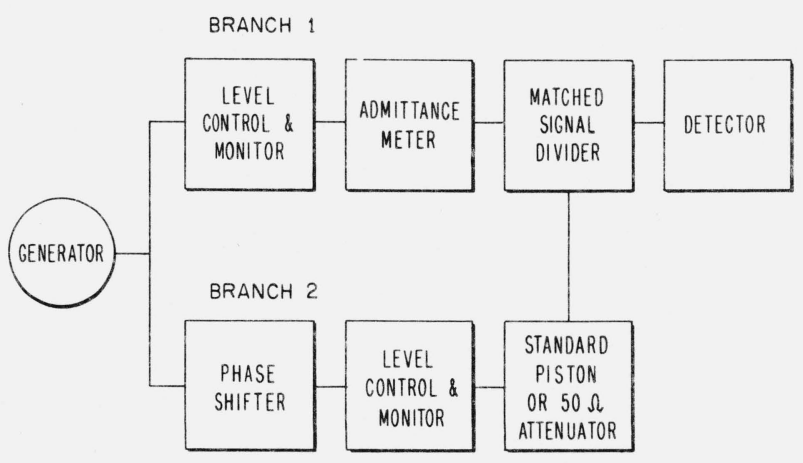

FIGURE 2. Schematic of circuit used to calibrate loops.

Standard piston attenuator used at $30 \mathrm{MHz}$ only. $50 \Omega$ attenuator used at $30 \mathrm{MHz}$ and $100 \mathrm{MHz}$. 
from $3 \cdot 10^{-9}$ to $10^{-7} \mathrm{H}$ and sample resistance $5 \cdot 10^{-1}$ to $10^{2} \Omega$. Error for inductance is $\sim 1$ percent from 30 to $200 \mathrm{MHz}$ for low-loss samples using calibrated sample data, figure 3 . Using precision $50 \Omega$ lines with low contact resistance terminations in place of the present lines, it is estimated the effect of the present mismatch could be reduced from the observed $\sim 10$ percent to $\sim 1$ percent. It is also estimated that measurements could be extended to lower resistances and higher frequencies.

Low-loss sample data $\left(\mu^{\prime} \sim 10\right.$ and $\left.\tan \delta \sim 10^{-2}\right)$ are shown in table 1 and figure 3 . In table 1 , sample inductance at $30 \mathrm{MHz}, \Delta L=\left(\mu^{\prime}-1\right) L_{a}$, or from eq (4), $\Delta L=\left(L-L_{a}\right)$, is compared to calibrated sample inductance values. These are constant over the frequency range used. The samples were calibrated using an adjustable length precision coaxial line functioning at a small fraction of a wavelength at low frequency and as a half wavelength cavity at high frequencies [2]. The losses, $\sim 5 \cdot 10^{-3} \Omega$, are not reported because of the poor precision in the contact resistance of line 3 . Inductance data shown in table 1 agree within 1 percen., the estimated error of the calibrated samples.

Figure 3 may be used to evaluate the inductance of low-loss samples from loop data. A sample may be identified as having low loss by showing only a small change in loop 2 when placing a sample in line 3. Transformed line impedances cause the curves shown to decrease their slope with frequency.

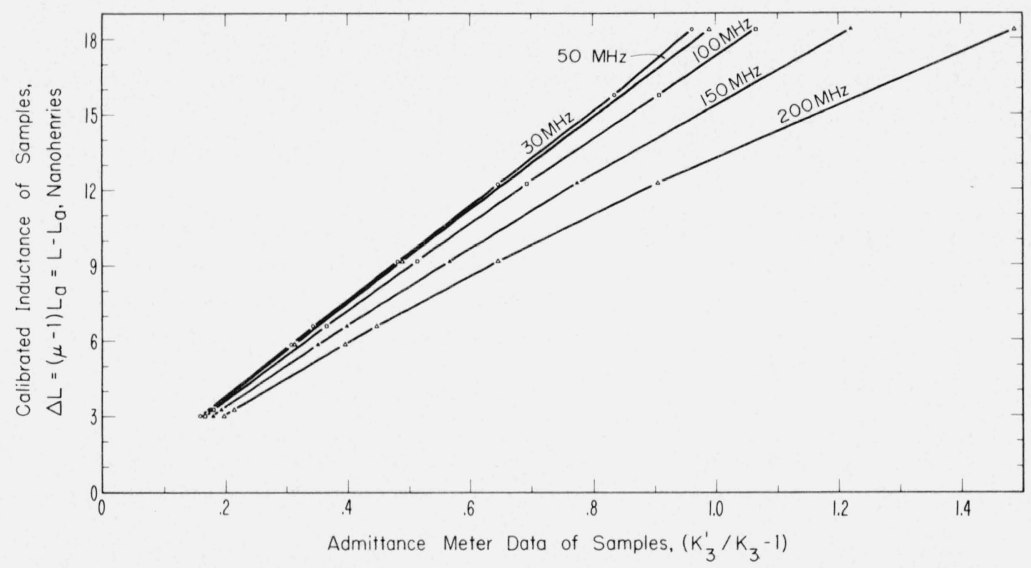

Figure 3. Calibrated inductance $\left(\mu^{\prime}-1\right) \mathrm{L}_{\mathrm{a}}$ of low-loss samples versus $\left[\left(\mathrm{K}_{3}^{\prime} / \mathrm{K}_{3}\right)-1\right]$, admittance meter loop data of samples, at 30,50,100,150, and $200 \mathrm{MHz}$.

Table 1 data are used to get $\Delta L$. The graph may be used to find the permeability of a low-loss sample using admittance meter data.

TABLE 1. Inductance data of samples using the admittance meter at $30 \mathrm{MHz}$ compared to data using an adjustable length precision coaxial line $(1 \mathrm{MHz})$ or coaxial cavity $(100 \mathrm{MHz})$ for samples whose permeability is constant to several hundred $\mathrm{MHz}$.

\begin{tabular}{|c|c|c|c|}
\hline \multicolumn{4}{|c|}{ Inductance $\Delta L_{u}=\left(L-L_{u}\right)=\left(\mu^{\prime}-1\right) L_{u}$} \\
\hline Sample & $\begin{array}{c}\text { Admittance } \\
\text { meter* } \\
\left(30 \mathrm{MHz}^{*}\right)\end{array}$ & $\begin{array}{c}\text { Adjustable } \\
\text { length coaxial } \\
\text { line }(1 \mathrm{MHz})^{* *} \\
\text { or coaxial } \\
\text { cavity } \\
(100 \mathrm{MHz})^{* *}\end{array}$ & $\begin{array}{l}\text { Coaxial } \\
\text { line or } \\
\text { cavity } \\
\text { frequency }\end{array}$ \\
\hline 1 & $3.05 \cdot 10^{-9} \mathrm{H}$ & $3.03 \cdot 10^{-9} \mathrm{H}$ & $1 \mathrm{MHz}$ \\
\hline 2 & 3.27 & 3.27 & $1 \mathrm{MHz}$ \\
\hline 3 & 5.61 & 5.66 & $1 \mathrm{MHz}$ \\
\hline 4 & 6.21 & 6.22 & $1 \mathrm{MHz}$ \\
\hline 5 & 6.56 & 6.59 & $100 \mathrm{MHz}$ \\
\hline 6 & 9.12 & 9.17 & $100 \mathrm{MHz}$ \\
\hline 7 & 12.25 & 12.25 & $100 \mathrm{MHz}$ \\
\hline 8 & 18.52 & 18.35 & $100 \mathrm{MHz}$ \\
\hline
\end{tabular}

${ }^{*}$ Using $\left(L-L_{a}\right)=L_{3}\left[\left(K_{3}^{\prime} / K_{3}\right)-1\right]$, eq (4) of the text. Sample with $\Delta L=5.87 \cdot 10^{-9} \mathrm{H}$ (1 $\mathrm{MHz}$ ) was used to calibrate $L_{3}$.

$* * \Delta L=\left(\mu^{\prime}-1\right) L_{a}$, the change in length of the line equivalent to the inductance change introduced by the sample placed at the end of the line. The cavity operates at $1 / 2$ wavelength. 
High-loss sample data using the admittance meter and other techniques are shown in table 2, and figure 4, parts a, b, c, and d. Techniques used for comparison to admittance meter data are the rf permeameter [3] (a calibrated transformer in which the sample is part of the secondary) on a Schering bridge or the $Q$-meter and the adjustable length coaxial cavity operating at a $1 / 2$ wavelength [2]. Since the latter is a resonance technique, it is not particularly adaptable to measuring
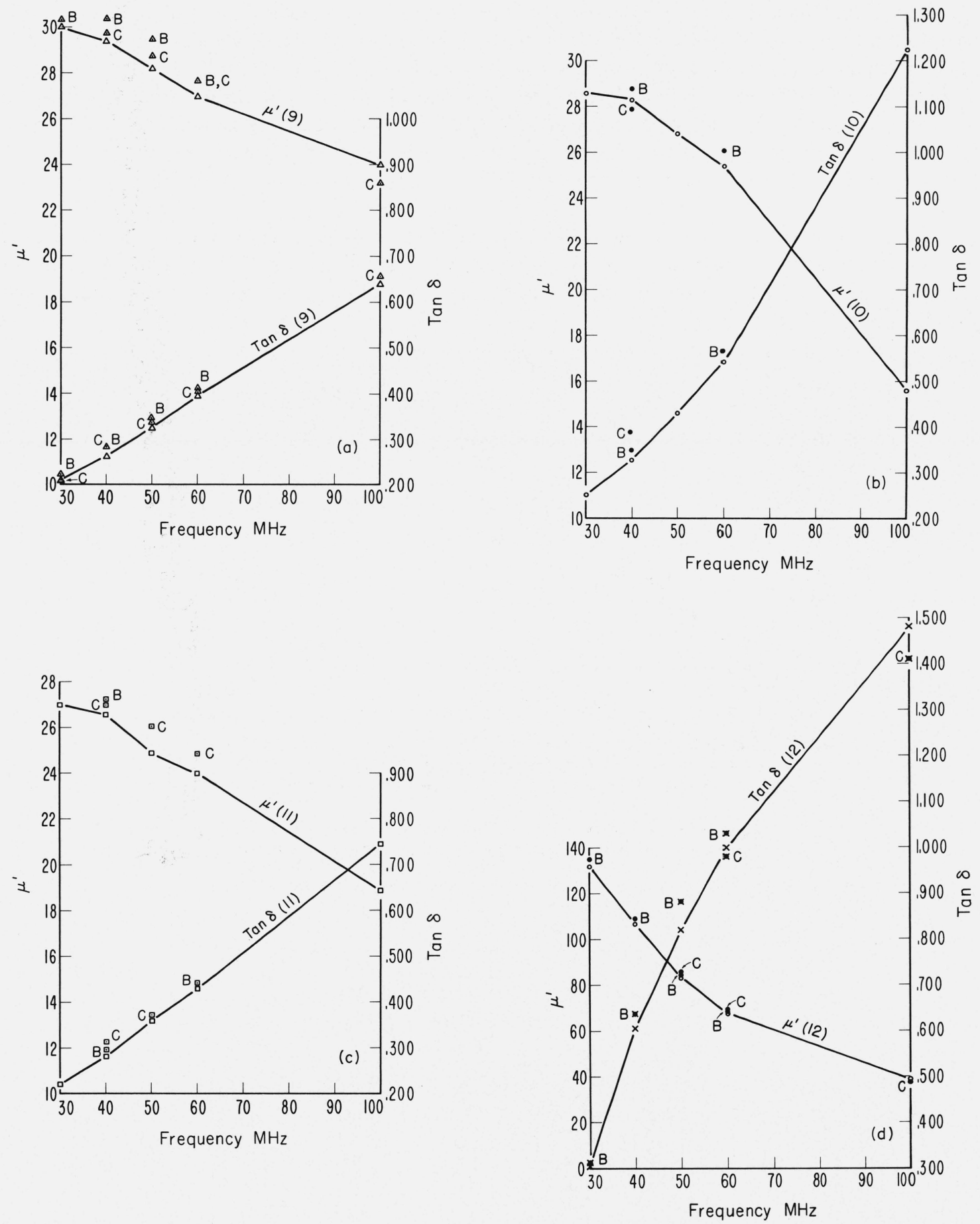

FIGURE 4. Permeability $\left(\mu^{\prime}\right)$ and loss tangent (tan $\left.\delta=\mu^{\prime \prime} / \mu^{\prime}\right)$ versus frequency $(M H z)$ of lossy materials using the admittance meter $(A)$, the permeameter $(B)$, and coaxial cavity $(C)$.

These data are also found in table 2. 
TABLE 2. Initial permeability $\left(\mu^{\prime}\right)$ and loss tangent (tan $\left.\delta=\mu^{\prime \prime} / \mu^{\prime}\right)$ of "lossy" materials using the admittance meter compared to other techniques

Equations (2), (3), (6), and (8) of the text were used with the changes of eqs (2) and (3) indicated in assumption 3. The $L_{3}$ value calibrated at $30 \mathrm{MHz}$ was used for all the admittance meter data.

\begin{tabular}{|c|c|c|c|c|c|c|c|c|c|}
\hline \multirow{2}{*}{ Frequency } & \multirow{2}{*}{ Method* } & \multicolumn{2}{|c|}{ Sample 9} & \multicolumn{2}{|c|}{ Sample 10} & \multicolumn{2}{|c|}{ Sample 11} & \multicolumn{2}{|c|}{ Sample 12} \\
\hline & & $\mu^{\prime}$ & $\tan \delta$ & $\mu^{\prime}$ & $\tan \delta$ & $\mu^{\prime}$ & $\tan \delta$ & $\mu^{\prime}$ & $\tan \delta$ \\
\hline $30 \mathrm{MHz}$ & $\begin{array}{l}\mathrm{A} \\
\mathrm{B} \\
\mathrm{C}\end{array}$ & $\begin{array}{l}30.0 \\
30.4 \\
30.9 \\
(28 \mathrm{M}\end{array}$ & $\begin{array}{r}0.212 \\
.221 \\
.206 \\
. z z\end{array}$ & 28.6 & 0.252 & 27.0 & 0.222 & $\begin{array}{l}132 \\
135\end{array}$ & $\begin{array}{r}0.302 \\
.310\end{array}$ \\
\hline 40 & $\begin{array}{l}\mathrm{A} \\
\mathrm{B} \\
\mathrm{C}\end{array}$ & $\begin{array}{l}29.4 \\
30.4 \\
29.8\end{array}$ & $\begin{array}{l}.262 \\
.281 \\
.283\end{array}$ & $\begin{array}{r}28.3 \\
* * 28.8 \\
27.9\end{array}$ & $\begin{array}{r}.327 \\
* * .349 \\
.390\end{array}$ & $\begin{array}{r}26.6 \\
* * 27.2 \\
27.0\end{array}$ & $\begin{array}{r}.283 \\
* * .296 \\
.314\end{array}$ & $\begin{array}{l}107 \\
109\end{array}$ & $\begin{array}{l}.605 \\
.635\end{array}$ \\
\hline 50 & $\begin{array}{l}\mathrm{A} \\
\mathrm{B} \\
\mathrm{C}\end{array}$ & $\begin{array}{r}28.2 \\
29.5 \\
\text { (1) } 28.8 \\
\text { (2) } 28.7\end{array}$ & \begin{tabular}{l|}
.326 \\
.345 \\
.332 \\
.344
\end{tabular} & 26.8 & .431 & $\begin{array}{l}24.9 \\
26.1\end{array}$ & $\begin{array}{l}.360 \\
.371\end{array}$ & $\begin{array}{l}83.4 \\
84.8 \\
85.7\end{array}$ & $\begin{array}{l}.819 \\
.881 \\
.816\end{array}$ \\
\hline 60 & $\begin{array}{l}\mathrm{A} \\
\mathrm{B} \\
\mathrm{C}\end{array}$ & $\begin{array}{l}27.0 \\
27.7 \\
27.7\end{array}$ & $\begin{array}{l}.395 \\
.406 \\
.400\end{array}$ & $\begin{array}{r}25.4 \\
* * 26.1\end{array}$ & $\begin{array}{r}.543 \\
* * .566\end{array}$ & $\begin{array}{r}24.0 \\
* * 24.9\end{array}$ & $\begin{array}{r}.431 \\
* * .442\end{array}$ & $\begin{array}{l}68.1 \\
68.3 \\
69.2\end{array}$ & $\begin{array}{l}.999 \\
1.03 \\
0.983\end{array}$ \\
\hline 100 & $\begin{array}{l}\mathrm{A} \\
\mathrm{B} \\
\mathrm{C}\end{array}$ & $\begin{array}{ll} & 24.0 \\
& \\
\text { (1) } & 23.2 \\
\text { (2) } & 23.25\end{array}$ & $\begin{array}{l}.640 \\
.646 \\
.666\end{array}$ & 15.6 & 1.22 & 18.9 & .747 & $\begin{array}{l}38.8 \\
37.2 \\
39.8\end{array}$ & $\begin{array}{l}1.48 \\
1.47 \\
1.36\end{array}$ \\
\hline
\end{tabular}

*Method A-Admittance meter.

** Method B-RF permeameter-Schering bridge or $Q$-meter (the permeameter is a calibrated transformer in which the sample is part of the secondary).

Method $\mathrm{C}$-Adjustable length coaxial cavity. See second footnote of table 1 .

"lossy" materials. It is seen that there is relatively good agreement between the admittance meter data and data using the other techniques from 30 to $100 \mathrm{MHz}$. At $100 \mathrm{MHz}$, the impedance transformation affecting $\mu^{\prime}$ and $\tan \delta$ values of sample 12 in a precision $50 \Omega$ line of equivalent length to the coupling loop is $\sim 10$ percent and $\sim 5$ percent, respectively. It is pointed out that the $30 \mathrm{MHz}$ calibration of $L_{3}$ was used to $100 \mathrm{MHz}$. The agreement of the data is better than the percentages just given implying that some errors cancel in the system described.

The authors thank Clarence C. Cook and Robert A. Lawton for valuable discussions with them, and Leonard B. Schmidt for making some measurements.

\section{References}

[1] R. A. Soderman, Impedance measurements in the 50 to 2000 Mc range, Radio \& Television News 46, Radio-Electronic Engineering Section, 3-6, 25 (July 1951).

[2] R. D. Harrington, Cavity techniques for permeability measurements in the VHF region, Proc. Electronic Components Conf., 27-29 (May 1955).

[3] R. D. Harrington and A. L. Rasmussen, Magnetic core permeability measurement techniques, Magnetic Core Conf., Proc. 7, 11-24 (June 1965).

\section{Appendix A}

Assuming lumped circuit conditions, eqs (2) and (3) in the text for the sample inductance $(L)$ and sample resistance $(R)$ are derived as follows. $K_{1}$ and $Y_{1}$ are held constant and loops 2 and 3 are adjusted for the conditions with and without a sample in line 3.

Without a sample in line 3 , we have

$$
K_{1} Y_{1}+K_{2} Y_{2}+K_{3} Y_{3}=0 .
$$

With a sample in line 3 , we have

$$
K_{1} Y_{1}+K_{2}^{\prime} Y_{2}+K_{3}^{\prime} Y_{3}^{\prime}=0 .
$$


Subtracting eq (A1) from eq (A2), we have

$$
\left(K_{2}^{\prime}-K_{2}\right) Y_{2}+K_{3}^{\prime} Y_{3}^{\prime}-K_{3} Y_{3}=0
$$

where

$$
\begin{aligned}
Y_{2}=\frac{1}{R_{2}+j \omega L_{2}}=\frac{R_{2}-j \omega L_{2}}{R_{2}^{2}+\omega^{2} L_{2}^{2}} \\
Y_{3}=\frac{1}{R_{3}+j \omega L_{3}}=\frac{R_{3}-j \omega L_{3}}{R_{3}^{2}+\omega^{2} L_{3}^{2}} \\
Y_{3}^{\prime}=\frac{1}{\left(R_{3}+R\right)+j \omega\left(L_{3}+L-L_{a}\right)}=\frac{R_{3}+R-j \omega\left(L_{3}+L-L_{a}\right)}{\left(R_{3}+R\right)^{2}+\omega^{2}\left(L_{3}+L-L_{a}\right)^{2}} .
\end{aligned}
$$

Separating the real and imaginary parts in eqs (A4), (A5), and (A6) and substituting them in eq (A3), we have

$$
\left(K_{2}^{\prime}-K_{2}\right) \frac{R_{2}}{R_{2}^{2}+\omega^{2} L_{2}^{2}}+K_{3}^{\prime} \frac{\left(R_{3}+R\right)}{\left(R_{3}+R\right)^{2}+\omega^{2}\left(L_{3}+L-L_{a}\right)^{2}}-K_{3} \frac{R_{3}}{R_{3}^{2}+\omega^{2} L_{3}^{2}}=0
$$

and

$$
\left(K_{2}^{\prime}-K_{2}\right) \frac{L_{2}}{R_{2}^{2}+\omega^{2} L_{2}^{2}}+K_{3}^{\prime} \frac{\left(L_{3}+L-L_{a}\right)}{\left(R_{3}+R\right)^{2}+\omega^{2}\left(L_{3}+L-L_{a}\right)^{2}}-K_{3} \frac{L_{3}}{R_{3}^{2}+\omega^{2} L_{3}^{2}}=0 .
$$

From eqs (A7) and (A8) we get

$$
K_{3}^{\prime} \frac{\left(R_{3}+R\right)}{\left(R_{3}+R\right)^{2}+\omega^{2}\left(L_{3}+L-L_{a}\right)^{2}}=K_{3} \frac{R_{3}}{R_{3}^{2}+\omega^{2} L_{3}^{2}}-\left(K_{2}^{\prime}-K_{2}\right) \frac{R_{2}}{R_{2}^{2}+\omega^{2} L_{2}^{2}}
$$

and

$$
K_{3}^{\prime} \frac{\left(L_{3}+L-L_{a}\right)}{\left(R_{3}+R\right)^{2}+\omega^{2}\left(L_{3}+L-L_{a}\right)^{2}}=\frac{K_{3} L_{3}}{R_{3}^{2}+\omega^{2} L_{3}^{2}}-\left(K_{2}^{\prime}-K_{2}\right) \frac{L_{2}}{R_{2}^{2}+\omega^{2} L_{2}^{2}} .
$$

Equations (A9) and (A10) yield

$$
\frac{R_{3}+R}{K_{3} \frac{R_{3}}{R_{3}^{2}+\omega^{2} L_{3}^{2}}-\left(K_{2}^{\prime}-K_{2}\right) \frac{R_{2}}{R_{2}^{2}+\omega^{2} L_{2}^{2}}}=\frac{L_{3}+L-L_{a}}{K_{3} \frac{L_{3}}{R_{3}^{2}+\omega^{2} L_{3}^{2}}-\left(K_{2}^{\prime}-K_{2}\right) \frac{L_{2}}{R_{2}^{2}+\omega^{2} L_{2}^{2}} .}
$$

Solving for $\left(L_{3}+L-L_{a}\right)$ in eq (A10) after substituting the expression for $\left(R_{3}+R\right)$ found from eq (A11), we have

$$
L_{3}+L-L_{a}=\frac{\frac{K_{3}^{\prime}}{K_{3}}\left(\frac{L_{3}}{R_{3}^{2}+\omega^{2} L_{3}^{2}}-\frac{\left(K_{2}^{\prime}-K_{2}\right)}{K_{3}} \frac{L_{2}}{R_{2}^{2}+\omega^{2} L_{2}^{2}}\right)}{\left(\frac{R_{3}}{R_{3}^{2}+\omega^{2} L_{3}^{2}}-\frac{\left(K_{2}^{\prime}-K_{2}\right)}{K_{3}} \frac{R_{2}}{R_{2}^{2}+\omega^{2} L_{2}^{2}}\right)^{2}+\omega^{2}\left(\frac{L_{3}}{R_{3}^{2}+\omega^{2} L_{3}^{2}}-\frac{\left(K_{2}^{\prime}-K_{2}\right)}{K_{3}} \frac{L_{2}}{R_{2}^{2}+\omega^{2} L_{2}^{2}}\right)^{2}} .
$$

Substituting $\left(L_{3}+L-L_{a}\right)$ from eq (A12) into eq (A11) we get

$$
R_{3}+R=\frac{\frac{K_{3}^{\prime}}{K_{3}}\left(\frac{R_{3}}{R_{3}^{2}+\omega^{2} L_{3}^{2}}-\frac{\left(K_{2}^{\prime}-K_{2}\right)}{K_{3}} \frac{R_{2}}{R_{2}^{2}+\omega^{2} L_{2}^{2}}\right)}{\left(\frac{R_{3}}{R_{3}^{2}+\omega^{2} L_{3}^{2}}-\frac{\left(K_{2}^{\prime}-K_{2}\right)}{K_{3}} \frac{R_{2}}{R_{2}^{2}+\omega^{2} L_{2}^{2}}\right)^{2}+\omega^{2}\left(\frac{L_{3}}{R_{3}^{2}+\omega^{2} L_{3}^{2}}-\frac{\left(K_{2}^{\prime}-K_{2}\right)}{K_{3}} \frac{L_{2}}{R_{2}^{2}+\omega^{2} L_{2}^{2}}\right)^{2}} .
$$


If line 3 without a sample has low-loss, $\omega L_{3} \gg R_{3}$ and $\omega^{2} L_{3}^{2} \gg R_{3}^{2}$, the latter being a correct approximation for even a lossy line; consequently, $R_{3}$ and $R_{3}^{2}$ may be neglected.

If line 2 and $R_{2}$ have a VSWR $\approx 1.005, L_{2}$ and $\omega^{2} L_{2}^{2}$ may be neglected for $R_{2}^{2} \gg \omega^{2} L_{2}^{2}$.

Therefore eqs (Al2) and (Al3) become

$$
\begin{gathered}
L_{3}+L-L_{a}=\frac{\frac{K_{3}^{\prime}}{K_{3}}\left(\frac{1}{\omega L_{3}}\right)}{\omega\left[\left(\left(\frac{K_{2}^{\prime}-K_{2}}{K_{3}}\right) \frac{1}{R_{2}}\right)^{2}+\left(\frac{1}{\omega L_{3}}\right)^{2}\right]} \\
R_{3}+R=\frac{-\frac{K_{3}^{\prime}}{K_{3}}\left(\frac{K_{2}^{\prime}-K_{2}}{K_{3}}\right) \frac{1}{R_{2}}}{\left(\left(\frac{K_{2}^{\prime}-K_{2}}{K_{3}}\right) \frac{1}{R_{2}}\right)^{2}+\left(\frac{1}{\omega L_{3}}\right)^{2}}
\end{gathered}
$$

which are eqs (2) and (3) in the text.

It should be noted that if $R_{3}$ cannot be neglected, but if $\omega^{2} L_{3}^{2} \gg R_{3}^{2}$ then

$$
\frac{R_{3}}{R_{3}^{2}+\omega^{2} L_{3}^{2}} \approx \frac{R_{3}}{\omega^{2} L_{3}^{2}}
$$

which is the approximation leading to the correction mentioned in assumption (3) in the text following eqs (2) and (3).

(Paper 72C1-270) 


\section{Publications of the National Bureau of Standards*}

\section{Selected Abstracts}

\begin{abstract}
Analytical coordination chemistry; titrimetry, gravimetry, flame photometry, spectrophotometry, gas evolution and isotopic preparations, July 1965 to June 1966, Ed. O. Menis, Tech. Note 402 (July 21, 1967), 50 cents. Studies in four areas of analytical chemistry: titrimetry, gravimetry, flame emission and atomic absorption, and solution spectrophotometry, are described from the standpoint of analytical coordination chemistry and applications to NBS standard reference materials. In the first two competences these investigations dealt with spectrophotometric titrations and homogeneous precipitation methods. Advances are described in the latter two areas through the unique applications of ternary complexes, displacement reactions in metal-ligand systems and the use of complexing media as "releasing agents." This approach is described for the determination of nanogram quantities of $\mathrm{Sb}, \mathrm{Cu}, \mathrm{Ni}$, and $\mathrm{Au}$ in very high purity zine by both spectrophotometric and flame procedures. Also in flame emission and atomic absorption a current table is presented for the detection limits of 70 elements. Progress of a new method is reported for the simultaneous determination of $\mathrm{Ni}, \mathrm{Cu}$, and Co by the dimethylglyoxime method. Descriptive tables of results are also given for ferrous, non-ferrous and ceramic materials which were analyzed by one of the four competences. In Another analytical area dealing with the analysis of gases in metals results of homogeneity and precision studies lead to certification of three new ferrous SRM's for their oxygen content. Also reported are the initial investigations of pyrohydrolytic separatıons of fluoride, nitrides and boron, separations of molybdenum from tungsten, controlled potential coulometric titration of molybdenum, and a description of improved instrumentation in flame emission and atomic absorption. Finally data are given on the preparation of stoichiometric mixtures of uranium oxide of varied isotopic composition and a list describing the variety of special analyses is included.
\end{abstract}

Key Words: Spectrophotometric titration, controlled potential coulometric, molybdenum, homogeneous precipitation, aluminum, beryllium, thermoanalytical standards, tricalcium silicate, spectrophotometry, antimony, high precision determination of nickel, simultaneous determination copper, cobalt, "releasing agents" in flame emission and atomic absorption, magnesium, ferrous SRM's, stoichiometric mixtures uranium oxide, isotope ratio determination.

Calorimetry, (,. T. Armstrong, 1967 McGraw-Hill Yearbook of Science and Technology, pp. 124-127 (1967).

The present status of calorimetry is reviewed. Several new and promising instruments for accurate calorimetry and the development of new or improved techniques for calorimetric processes are discussed. The relationship of calorimetry to the U.S. fuel technology, to the rocket propellant program, and to molecular biophysics is briefly discussed.

Key Words: Calorimetry, international, calorimetry, review, fuel calorimetry, calorimetry: biological, calorimetry: new developments.

*Publications for which a price is indicated are available by purchase from the Superintendent of Documents, U.S. Government Printing Office, Washington, D.C. 20402 (foreign postage, one-fourth additional). The NBS nonperiodical series are also available from the Clearinghouse for Federal Scientific and Technical Information, Springfield, Va. 22151. Reprints from outside journals and the NBS Journal of Research may often be obtained directly from the authors.
Drawings of micrometer U-tube manometers for the ranges up to $100 \mathrm{~mm}$ of mercury, A. M. Thomas and J. L. Cross, Tech. Note 420 (Aug. 26, 1967), 15 cents.

Drawings with sufficient detail are presented so that micrometer $U$-tube manometers for use with mercury, oil, and water may be constructed. Measurements made with the oil manometer have an uncertainty of about $4 \times 10^{-4} \mathrm{~mm}$ of $\mathrm{Hg}$ plus one part in $10^{4}$ of the reading. Measurements made with the mercury manometer have an uncertainty of about $4 \times 10^{-3} \mathrm{~mm}$ of $\mathrm{Hg}$ plus eight parts in $10^{5}$ of the reading. The operation and an error analysis are described elsewhere.

Key Words: Manometer, micrometer, $U$-tube, vacuum, medium vacuum measurements.

NBS standard frequency and time services, radio stations WWV, WWVH, WWVB, WWVL, Misc. Publ. 236, 1967 Edition (1967), 15 cents.

Detailed descriptions are given of eight technical services provided by the National Bureau of Standards radio stations WWV WWVH, WWVB, and WWVL. These services are: 1. Standard radio frequencies; 2. Standard audio frequencies; 3. Standard musical pitch; 4 . Standard time intervals; 5 . Time signals; 6 . UT2 corrections; 7. Radio propagation forecasts; and 8. Geophysical alerts. In order to provide users with the best possible services, occasional changes in the broadcasting schedules are required. This publication shows the schedules in effect on June 1, 1967. Annual revisions will be made. Advance notices of changes occurring between revisions will be sent to regular users of these services upon request. Current data relating to standard frequencies and time signals are also available monthly in the Time and Frequency Services Bulletin.

Key Words: Broadcast of standard frequencies, high frequency, low frequency, standard frequencies, time signals, very low frequency.

Standard Reference Materials: Mössbauer spectroscopy standard for the chemical shift of iron compounds, J. J. Spijkerman, D. K. Snediker, F. C. Ruegg, and J. R. DeVoe, Misc. Publ. 260-13 (July 28, 1967), 40 cents.

The preparation, calibration, and use of the Standard Reference Material for chemical shift of iron compounds in Mössbauer Spectroscopy is described. This standard is a properly oriented single crystal of sodium pentacyanonitrosylferrate (II) dihydrate (sodium nitroprusside). Primary standards were calibrated with a high accuracy optical Mössbauer spectrometer and secondary calibrations were made with a tandem Mössbauer spectrometer. The midpoint between the two absorption peaks in the spectrum at $25.0{ }^{\circ} \mathrm{C}$ provide a useful velocity scale calibration of the spectrometer. Descriptions of the spectrometers used and the error analysis associated with the data are given. Suggested format for reporting Mössbauer spectra and their parameters is also presented.

Key Words: Mössbauer, spectroscỏpy, standard, differential chemical shift, quadrupole splitting, random error, systematic error, sodium nitroprusside, iron compounds, optical Mössbauer spectrometer, tandem Mössbauer spectrometer, velocity calibration.

Standard Reference Materials: Recommended method of use of standard light-sensitive paper for calibrating carbon arcs used in testing textiles for colorfastness to light, E. Passaglia and P. J. Shouse, Misc. Publ. 260-15 (July 21, 1967), 20 cents. 
The use of NBS light-sensitive paper and NBS booklets of standard faded strips in the standardization of fading lamps is described. These lamps are used to determine the fading characteristics of textiles, and the light-sensitive paper is thus useful in standardizing this procedure.

Key Words: Light-sensitive paper; Booklets of faded strips; fading characteristics; textiles; fading standardization.

Revision of the NBS tables of spectral-line intensities below 2450 Å, C. H. Corliss, Mono. 32 Supplement (July 7, 1967), 30

A calibration is applied to the intensity measurements of the 1400 lines below $2450 \AA$ in the NBS Tables of Spectral-Line Intensities. Tables of the new values are presented with the lines arranged by elements and by wavelengths.

Key Words: Atomic spectra, intensities, spectral lines, ultraviolet.

Thermal-shock resistance for built-up membranes, W. C. Cullen and T. H. Boone, Bldg. Sci. Series 9 (Aug. 21, 1967), 20 cents. The resistance of bituminous built-up roofing membranes to thermally induced forces is considered in terms of their strength properties such as breaking load in tension, modulus of elongation and apparent linear thermal expansion coefficient. The development of a Thermal-Shock Resistance Factor is described and values are given for three bituminous built-up membranes at temperatures of $-30{ }^{\circ} \mathrm{F}\left(-34.4{ }^{\circ} \mathrm{C}\right), 0{ }^{\circ} \mathrm{F}\left(-17.8^{\circ} \mathrm{C}\right), 30^{\circ} \mathrm{F}\left(-1.1^{\circ} \mathrm{C}\right)$ and $73^{\circ} \mathrm{F}$ $\left(22.8^{\circ} \mathrm{C}\right)$. The apparent relation between the values obtained in the laboratory and the observed performance of roofing membranes in service is considered. The utilization of the Thermal-Shock Resistance Factor in the reduction of potential failures of bituminous built-up roofing membranes in service from thermally induced forces is also discussed.

Key Words: Development, roofing membrane, strength properties, thermally induced forces, thermal-shock resistance factor.

The single-engine Claude cycle as a $4.2{ }^{\circ} \mathrm{K}$ refrigerator, R. C. Muhlenhaupt and T. R. Strobridge, Tech. Note 354 (June 1, 1967), 45 cents.

The performance of the $4.2^{\circ} \mathrm{K}$ Claude-cycle refrigerator has been computed taking into account the efficiencies of the various components. The results are presented in graphical form. These charts give the input power requirements, mass flow rates for both the compressor and expander, pertinent temperatures, and allow selection of the optimum high pressure for a given set of component characteristics.

Key Words: Claude, cyrogenics, refrigeration.

Part 1. The solid system. II. Numeric compression, P.A.D deMaine, K. Kloss, and B. A. Marron, Tech. Note 413 (Aug. 15 1967), 30 cents.

This part of NBS Technical Note 413 describes the general NU. MERIC COMPRESSOR (NUPAK) Algorithm for automatically compressing (encoding) or decoding compressed numerical information, which may of course have come from graphical information. The amount of compression achieved is determined by the "lowest limit of significance," the range, and the sequential patterns of the data to be stored. The encoded information can be stored in memory or on external storage devices in a small fraction of the space normally required, and can be expanded (decoded) item-by. item whenever needed by the system.

Key Words: Numeric compression, information handling, highspeed information transmission, information storage and retrieval, systems analysis.

Part 2. The solid system. III. Alphannmeric compression, P. A. D. deMaine, K. Kloss, and B. A. Marron, Tech. Note 413 (Aug. 15, 1967), 30 cents.

An algorithm for compressing alphanumeric information is described. Unlike other methods which depend upon frequency of occurrence of words in a particular class of publications, this scheme is language and content independent since the information for compression is obtained from the text itself. The compressed bit stream is preceded by sufficient information for auto- matic reconstruction of the original bit stream whenever the system requires it. Even with this additional information required for expansion, compression rates approaching $40 \%$ have been achieved. Because this ALPHANUMERIC COMPRESSOR (ANPAK) is fully automatic and self-organizing, it can operate on information which has already been compressed via the NUMERIC COMPRESSOR (NUPAK).

Key Words: Alphanumeric compression, information handling, high-speed information transmission, information storage and retrieval, systems analysis.

Determination of trace elements in standard reference materials by neutron activation analysis, G. W. Smith, D. A Becker, G. J. Lutz, L. A. Currie, and J. R. DeVoe, Anal. Chim. Acta 38, 333-340 (1967).

Neutron activation analysis with its high sensitivity and accuracy in trace analysis, is being used at the NBS for analysis of Standard Reference Materials. Problems affecting precision and accuracy have been encountered and solutions to four problems are discussed First, the positive bias introduced by induced radioactivity of similar gamma-ray energy was found in the determination of interstitial argon in ultra-pure silicon. A decay curve resolution technique was used to compensate for the error. Secondly, errors due to differences in geometrical location between sample and standard during irradiation were observed. Flux gradients were determined by copper foil flux monitoring to give necessary means of correction. Thirdly, errors are caused by differences in neutron selfshielding between sample and standard during irradiation. An empirical correction method was used and computer program written for calculation. Examples are given. Finally, the problem of gamma-ray attenuation during counting of sample and standard has been explored. A theoretical and experimental study gives the necessary corrections. It is concluded that careful study is vital to assure accurate analyses by neutron activation analysis on trace elements in complex matrices such as many Standard Reference Materials.

Key Words: Neutron, activation, analysis, trace, Standard Reference Materials, accuracy, precision, similar gamma-ray energy, decay curve resolution, geometrical location, neutron self-shielding, gamma-ray attenuation.

Distillation as a tool for purification of research quantities of material, R. T. Leslie, Ann. N. Y. Acad. Sci. 13 7, 19-29 (1966). Distillation can increase the purity of nearly any vaporizable mixture if sufficient effort is made. The method is invaluable for purifying relatively small quantities of material for research purposes.

The selection of the proper still column for a particular problem can be based on a knowledge of the characteristics of a few basic types of columns. Some operating procedures which favor good results can be outlined in a general way, but testing of stills by the operator using mixtures whose behaviors can be predicted under various conditions is recommended.

Some possibilities for the improvement of still columns is suggested.

Key Words: Distillation, material, purification of research quantities of materials, research quantities.

Gas phase radiolysis of cyclobutane, R. D. Doepker and P. Ausloos, J. Chem. Phys. 44, 1641-1647 (Feb. 1966).

The gas phase radiolysis of cycle- $\mathrm{C}_{4} \mathrm{H}_{8}$ and cyclo- $\mathrm{C}_{4} \mathrm{D}_{8}$ has been investigated in the presence of $\mathrm{O}_{2}, \mathrm{NO}, \mathrm{H}_{2} \mathrm{~S}, \mathrm{NH}_{3}$, and several organic compounds. From the products formed, it could be inferred that the following fragmentation processes occur:

$$
\begin{aligned}
& \mathrm{C}_{4} \mathrm{H}_{8}^{+}-\mathrm{C}_{3} \mathrm{H}_{5}^{+}+\mathrm{CH}_{3} \\
& \mathrm{C}_{4} \mathrm{H}_{3}^{+}-\mathrm{C}_{2} \mathrm{H}_{4}^{+}+\mathrm{C}_{2} \mathrm{H}_{4} \\
& \mathrm{C}_{4} \mathrm{H}_{8}^{+}-\mathrm{C}_{2} \mathrm{H}_{5}^{+}+\mathrm{C}_{2} \mathrm{H}_{3} \\
& \mathrm{C}_{4} \mathrm{H}_{8}^{+}-\mathrm{C}_{3} \mathrm{H}_{4}^{+}+\mathrm{CH}_{4} .
\end{aligned}
$$

At 20 torr, the ion pair yields which can be ascribed to some of these processes are lower than the corresopnding ion pair yields observed in the mass spectrometer at a pressure of $10^{-5}$ torr.

When compounds such as NO (I.E. $=9.25 \mathrm{eV})$ or $\left(\mathrm{CH}_{3}\right)_{3} \mathrm{~N}(\mathrm{I} . \mathrm{E} .=7.8$ $\mathrm{eV})$ are added to cyclobutane, butene (I.E. $=9.13-9.58 \mathrm{eV}$ ) is a major product. On the other hand, when organic or inorganic compounds whose ionization energy is higher than that of butene 
are added to cyclobutane, the yield of butene is, in most cases, negligibly small. The formation of butene can be tentatively accounted for by a ring opening of the parent ion followed by charge transfer. On the basis of this mechanism, a minimum value of 0.42 with an estimated possible deviation of \pm 0.02 can be ascribed to $\mathrm{M}\left(\mathrm{C}_{\mathbf{4}} \mathrm{H}_{8}^{+}\right) / \mathrm{N}$.

When an electrical field is applied in the saturation current region, during radiolysis of cyclobutane-NO mixtures, the yields of me thane, ethane and butene which have the parent ion or fragments thereof as precursors, remain unchanged. On the other hand, the yields of products such as ethylene, allene, acetylene, and 1,3 butadiene whose formation is, in part, attributed to the decomposi tion of neutral excited molecules, are seen to increase due to in creased excitation by electron impact. In the absence of an elec trical field, the number of neutral excited molecule decompositions per ion pair is estimated to be $\leqslant 0.65 \pm 0.05$.

Key Words: Cycloalkanes; ion-molecular reactions; ion-pair yields: radiolysis; unimolecular decomposition.

Investigating ion-molecule reactions by analyzing neutral products formed in the radiolysis and photoionization of hydrocarbons, P. Ausloos, S. G. Lias, and A. A. Scala, Adv Chem. Ser. 58, 264-277 (1966)

The analysis of neutral products produced in the radiolysis and photoionization of suitable deuterium labeled hydrocarbons or hydrocarbon mixtures provides information concerning: a) the relative rates of $\mathrm{H}^{+}, \mathrm{H}^{-}, \mathrm{H}_{2}^{-}$, and $\mathrm{H}_{2}$-transfer reactions; and $b$ ) the structure of the reacting ion or reaction complex. The reaction cross section of a given ion with various alkalanes is generally seen to increase with increasing polarizability of the neutral molecule. The actual increase in rate is, however, faster than that of the collision cross section given by the expression: $2 \pi e(\alpha / \mu)^{1 / 2}$. Good quantitative and qualitative correspondence is seen between the information on reactions of parent ions obtained from gas phase radiolysis studies and that derived from photoionization experiments carried out at wavelengths slightly above the ionization energy of the molecule.

Key Words: Analysis of neutral products, ion-molecule reactions, neutral products, photoionization of hydrocarbons, radiolysis and photoionization of hydrocarbons.

Microtexture and composition of reaction products in the system kaoline-lime-water, W. C. Ormsby and L. A. Bolz, J. Am. Ceram. Soc. 49, No. 7, 364-366 (July 1966).

Textural and compositional features of reaction products in the kaolin-lime-water system were examined by electron microscopy and electron diffraction. Electron micrographs of replicas of fracture surfaces of compacted mixtures and transmission electron micrographs of powdered compacts showed considerable attack of kaolinite particles by hydrated lime and indicated the formation of significant amounts of calcium silicate hydrate phases. Electron diffraction of reaction products confirmed the presence of calcium silicate hydrates. The presence of these hydrates is undoubtedly responsible for the stabilizing effects of lime which have previously been reported in the literature.

Key Words: Calcium silicate hydrates, composition, electron diffraction, electron microscopy, kaolin-lime-water, microtexture.

Microwave spectroscopy, D. R. Lide, Jr., Encyclopedia of Industrial Analysis 2, 600-611 (John Wiley \& Sons, Inc., New York, N.Y., 1966).

The experimental techniques used in microwave spectroscopy are described. A brief outline of the theory of rotational spectra is given. The information on molecular structure which can be obtained from microwave studies is discussed. Some comments are made on the use of microwave spectroscopy in chemical analysis.

Key Words: Chemical analysis, microwave spectroscopy, microwave studies, molecular structure, rotational spectra, spectrarotational, spectroscopy-microwave.

Mösbauer spectroscopy: applications to aerospace, J. R. DeVoe and J. J. Spijkerman, Book, Radioisotopes for Aerospace, Part 2, Systems and Applications, pp. 254-269 (Plenum Press, Inc., New York, N.Y., 1966).
The principle of the Mössbauer Effect will be discussed. A few possible applications of the technique with respect to physics and engineering in aerospace will be outlined. Of greater interest are the possible applications of the technique for determining chemical structure and solid state properties of materials. Solid phase transitions of materials subjected to severe conditions similar to that existing in space can be measured by M̈̈ssbauer Effect.

The National Bureau of Standards' Mössbauer spectrometer will be discussed and some data taken on a number of materials (such as tecktites, steels, glasses, and metal alloys) will be presented.

Key Words: Aerospace, applications, materials structure analysis, Mïssbauer effect, spectrometer, standards.

Needs of American Chemical Society members for property data, H. M. Weisman, J. Chem. Doc. 7, No. 1, 10-14 (Feb. 1967). In August of 1965 the American Chemical Society, on behalf of the NBS Office of Standard Reference Data, sent a questionnaire to its membership asking for information on their needs for compilations of critically evaluated data. Through this questionnaire, the Office of Standard Reference Data obtained information on the preferences and needs of the chemical profession for data com pilations, and equally importantly, located a substantial number of compilation activities of which it was not aware. Further, the Office of Standard Reference Data identified dozens of individuals who are both interested and competent to undertake additional projects. Approximately 16,000 replies were received. Overwhelm ingly, response was that present compilations of data satisfy poorly or at best only moderately the requirements of the membership of ACS. The survey identified the properties which ACS workers most often sought in the literature as well as those data compilations most often consulted by respondents. Many worthwhile comments and suggestions were contributed as to approaches taken, compilation priorities and techniques of format and presentation.

Key Words: American Chemical Society, chemical and physical properties, compilation, data, NSRDS, Office of Standard Reference Data, questionnaire, survey, users.

Radiation and photochemistry, P. Ausloos, Ann. Rev. Phys Chem. 17, 205-236 (1966).

A critical review of major publications on Photochemistry and Radiation Chemistry published in 1965.

Key Words: Photochemistry, radiation chemistry.

Sublimation, E. C. Kuehner and R. T. Leslie, Encyclopedia of Industrial Chemical Analysis 3, 573-584 (1966).

Sublimation is considered analogous to distillation and their advan tages are compared. Methods of sublimation and types of sublimators are discussed. A section on sublimation analysis is included in which characteristics of a solid substance, such as condensation temperatures, are applied to the identification and quantitative analysis of material.

Key Words: Analogous distillation, analysis-sublimation, condensation temperatures, solid substance, sublimation, sublimators.

Simultaneous determination of copper and zine in human lung tissue by neutron activation analysis, R. G. Keenan, J. H. Marcus, and J. R. DeVoe, Am. Ind. Hygiene Assoc. J. 27, 128134 (Mar.-Apr. 1966).

Certain trace elements including copper and zinc are constituents of numerous enzymes and function as essential catalysts in biosyntheses. The expanded interest in these substances has supplied a demand for microanalytical techniques of increased sensitivity accuracy and precision if meaningful conclusions are to be derived from the analytical data. This paper shows that good precision may be realized in the activation analysis of complex biological specimens with only a few one-step chemical separations.

The nuclear reactions $\mathrm{Cu}^{63}(\mathrm{n}, \gamma) \mathrm{Cu}^{64}(12.8 \mathrm{~h})$ and $\mathrm{Zn}^{68}(\mathrm{n}, \gamma) \mathrm{Zn}^{69 m}$ (13.8h) were used for the analysis. The samples were irradiated in a thermal neutron flux of $10^{13} \mathrm{n} / \mathrm{cm}^{2} / \mathrm{sec}$. The copper was extracted as the acetylacetonate into chloroform from an acetate system buffered at a $p \mathrm{H}$ of 4.75 . The remaining aqueous phase was extracted with chloroform to remove most of the acetylacetone dissolved in 
the aqueous phase. The zinc was extracted as the dithizonate into chloroform and was back-extracted into $1 \% \mathrm{HCl}$ for counting. Careful internal standardization was used for correction of results for variation in chemical yields.

Applications of the method to the simultaneous determination of copper and zinc in lung samples provided values of the same order of magnitude as those reported by Tipton and Cook for U.S. adults using emission-spectrographic procedures which were between 7 and $10 \mathrm{ppm}$ for copper and 40 and $70 \mathrm{ppm}$ for zinc. Comparison of the precision of this method with that of emission spectroscopy indicates that this activation technique has at least three times better precision.

Key Words: Biosynthesis, catalysis in biosynthesis, copper, human lung tissue, lung tissue, neutron-activation analysis.

Systematic errors in "recovery" and "detection" efficiency as related to radiochemical analysis, L. A. Currie, Proc. 11th Annual Bio-Assay and Analytical Chemistry Meeting, Albuquerque, New Mexico, Oct. 7-8, 1965, AEC No. 651008, pp. 35 (Clearinghouse for Federal Scientific and Technical Information, Springfield, Va., 1967).

Evidence of systematic error in the assay of thorium arose when the chemical yield from a biological sample seemed to depend upon the detection method. When $\alpha$-counting and spectrophotometry were applied to different aliquots of the same sample, following chemical purification, the discordant chemical yields pointed to variations in detection efficiency. The difficulty arises because determination of the chemical yield is based upon the known disintegration rate of a "spike" which has been chemically processed, and upon the detection efficiency, which is generally determined by means of a standard which may not have been chemically processed. Thus, if the nature of the original sample or the resultant material in any way influences the final detection efficiency, the calculated recovery and its relative variance must be incorrect. Systematic errors in recovery and detection efficiency may be eliminated in one of two ways: (1) direct measurement of the "overall" yield - the product of chemical yield and detection efficiency, (2) accurate determination of both the chemical yield and the detection efficiency by such methods as isotope dilution and internal (efficiency) monitoring, respectively. Experimental illustrations are given for analyses of thorium and of carbon-14.

Key Words: Radiochemical analysis, bio-assay, systematic errors, random errors, thorium chemical yield, detection efficiency, "overall" yield, isotope dilution, carbon-14.

The erystal structure of sodium tetraborate, A. Hyman, A. Perloff, F. Mauer, and S. Block, Acta Cryst. 22, No. 6, 815-821 (June 1967).

Single crystals of sodium tetraborate, $\mathrm{Na}_{2} \mathrm{O} \cdot 4 \mathrm{~B}_{2} \mathrm{O}_{3}$, have been synthesized and studied. The structure has been determined using the method of symbolic addition. The space group is $\mathrm{P} 2_{1} /$ a with unit cell dimensions: $a=6.507 \pm 0.001, b=17.796 \pm 0.002, c=8.377$ \pm 0.001 , and $\beta=96^{\circ} 34^{\prime} \pm 2^{\prime} ; Z=4$. The structure consists of two infinite, independent, and interlinking boron-oxygen networks, each containing alternating single and double rings. The sodium atoms serve to hold the networks together through coordination with oxygen atoms.

Key Words: Boron-oxygen networks, double ring, sodium tetraborate.

Thermal decomposition of 4,4-dimethylpentene- 1 in a single-pulse shock tube, W. Tsang, J. Chem. Phys. 46, No. 7, 2817-2822 (Apr. 1, 1967).

4,4-Dimethylpentene-1 has been pyrolyzed in a single pulse shock tube. The initial process is apparently the breaking of the allylic carbon-carbon bond. The rate expression for the reaction,

$$
\mathrm{C}_{4} \mathrm{H}_{9}-\mathrm{C}_{3} \mathrm{H}_{5} \stackrel{k}{\rightarrow} t-\mathrm{C}_{4} \mathrm{H}_{9} \cdot+\mathrm{C}_{3} \mathrm{H}_{5} .
$$

has been found to be

$$
k=10^{15.8} \exp (-65,500 / R T) \mathrm{sec}^{-1} .
$$

Assuming no activation energy for the recombination process this leads to a value of $12 \mathrm{kcal}$ for the allylic resonance energy.
Key Words: 4,4-dimethylpentene-1, allyl radicals, $t$-butyl radicals, thermal decomposition, bond energy, allylic resonance energy, single pulse shock tube, 1-butene, 4-methylpentene-1, 1,5 hexadiene.

Two National Bureau of Standards data centers: chemical kinetics and mass spectrometry, D. Garvin and H. M. Rosenstock, J. Chem. Doc. 7, No. 1, 31-34 (Feb. 1967).

Two current information retrieval centers, one for chemical kinetics, the other for mass spectrometry are described. The methods and philosophies of operation of these programs are compared. The role of specialized information systems in promoting data evaluation, the evaluation of their usefulness as sources for reference material, the choice of techniques and possibilities for inter-center coordination are discussed.

Key Words: Chemical kinetics, mass spectrometry, information retrieval.

A new ultra-low-frequency bridge for dielectric measurements, W. P. Harris, 1966 Annual Report, Conf. Electrical Insulation and Dielectric Phenomena, National Academy of SciencesNational Research Council, Mount Pocono, Pennsylvania, 1966, pp. 72-74 (1967).

This is an abstract of a talk given at the NAS-NRC Conference on Electrical Insulation and Dielectric Phenomena at Pocono Manor. Pennsylvania, October 4, 1966. It is to be included in the Annual Report of the Conference.

Keys Words: Bridge, dielectrics, dielectric measurements, electrical measurements, low frequency measurements, electrical, measurements, dielectric, ultra low frequency.

A $100 \mathrm{Mc} / \mathrm{s} 2$ out of 3 gate, J. K. Whittaker, Nucl. Instr. Methods 45, No. 1, 138-140 (Nov. 1966).

A zero-crossing type of discriminator with a very wide dynamic range and a short dead-time is described. When used with a $56 \mathrm{AVP}$ photomultiplier with a linear dynode resistor chain, a light amplitude variation of at least 125:1 may be accommodated. The relative time shift of the output discriminator pulse is then only $200 \mathrm{p} . \mathrm{s}$.

Key Words: Discriminator, zero-crossing, wide-range, time-invariant, picosecond, resolution.

A single axis, two crystal $x$-ray instrument, R. D. Deslattes, Rev. Sci. Instr. 38, No. 6, 815-820 (June 1967).

Design features of a two crystal instrument capable of measurements of diffraction angles to of the order of 0.1 are second are presented. The instrument is of simple geometry, employs a stable and massive chassis and derives its precision from components of general availability. Diffraction angles are generated in $1^{\circ}$ increments by a pre cise indexing mechanism and interpolated by means of a sine arm driven by a micrometer.

Key Words: X-ray spectrometer, double crystal instrument, precise goniometry.

A testing and rating method for refrigerated trucks with respect to cooling load, P. R. Achenbach, C. W. Phillips, and R. W. Penny, Annex to Proc. Intern. Inst. Refrigeration, Comm. VII, pp. 29-35 (London, England, Sept. 1966).

A testing and rating method for refrigerated delivery trucks has been developed under the sponsorship of the U.S. Department of Agriculture and the Truck Body and Equipment Association. The method is applicable to insulated vehicles used for short-haul delivery of frozen food at a low temperature or fresh produce at a medium temperature. It involves a measurement of the steadystate transmission of heat from ambient air to cargo space under selected conditions of test and the use of a correction factor for the effect of solar radiation on a stationary vehicle. The essentials of the testing and rating procedure and of the laboratory studies carried out to develop the procedure are described.

Key Words: Air leakage, cooling load, refrigerated trucks, solar heating, testing and rating methods.

A two-crystal, vacuum monochromator, R. D. Deslattes, Rev. Sci. Instr. 38, No. 5, 616-620 (May 1967).

Design and construction of a vacuum two crystal instrument for 
high resolution spectroscopy at long wavelengths is reported. The instrument provides for coordinated rotations of both crystals source and detector. The usable scan range is $8^{\circ}$ in Bragg angle and is limited only by the characteristics of the tangent drive system.

Key Words: X-ray spectrometer, vacuum instrument, double crystal instrument.

Air-to-air heat pumps for military housing, P. R. Achenbach, Military Engr. 384, 270 (July-Aug. 1966).

The National Bureau of Standards has performed laboratory and field studies of electric air-to-air heat pumps as a part of the technical investigations sponsored by the three agencies of the Department of Defense. These studies have developed information on the coefficient of performance and heating and cooling capacities of typical systems used for residential applications, design data useful for estimating energy usage and maximum power demand for similar installations, some information relative to the unexpectedly high rate of motor-compressor failure, and comparisons of the annual cost of year-around air conditioning using heat pumps and gas heating systems combined with conventional air conditioners for cooling. The annual cost of heating and cooling these military houses with air-to-air heat pumps averaged about $\$ 100$ for a unit electric energy cost of $0.8 \phi / \mathrm{kWh}$.

Key Words: Air-to-air heat pumps, residential air conditioning, energy usage, annual energy cost.

An improved transportable 10 picofarad capacitor, R. D. Cutkosky and L. H. Lee, Proc. $11^{e}$ Session, Comite Con. D'Electricite, May 10-12, 1965, pp. 65-66 (May 1965).

By design modifications improvements have been achieved in the performance of $10-\mathrm{pF}$ capacitance standards with fused silica dielectric as regards voltage dependence, shock sensitivity, and stability of value. It is suggested that standards of the new design are suitable for interlaboratory comparisons of the unit of capacitance.

Key Words: Capacitance standards, fused silica dielectric, picofarad capacitor, shock sensitivity, stability of value, ten picofarad capacitor, transportable ten picofarad capacitor, unit of capacitance, volume dependence.

Comparison of the Hall-Petch parameters of zone-refined determined by the grain size and extrapolation methods, B. W. Christ and G. V. Smith, Acta Met. 15, 809-816 (May 1967). The dependence of the lower yield strength of zone-refined iron containing $0.0020 \mathrm{wt}$ \% (carbon plus nitrogen) on grain size has been investigated at room temperature. In spite of the rather limited grain size variation possible with such pure metal, a meaningful determination of the Hall-Petch parameters has been made by the grain-size method: friction stress $-2.5 \mathrm{~kg} / \mathrm{mm}^{2}$, Petch slope -2.4 $\mathrm{kg} / \mathrm{mm}^{3 / 2}$. It is shown that tensile data obtained where the grain diameter is comparable to the minimum specimen dimension should not be included in the grain size method of analysis.

Analysis of tensile data by the extrapolation method produces Hall-Petch parameters which (1) are internally inconsistent, and (2) compare unfavorably with results of the grain size method. It is concluded that the extrapolation method in its present form is not an adequate substitute for the grain size method of evaluating the Hall-Petch parameters of iron.

Key Words: Extrapolation methods, grain size, Hall-Petch parameters, iron, zone-refined, parameters, zone-refined iron.

Discussion of the paper "flow in culverts and related design philosophies," J. L. French, J. Hydraulics Div. Am. Soc. Civil Eng. 93, No. HY1, 85-91 (Jan. 1967).

An evaluation is made of certain conclusions advanced in a paper by Fred W. Blaisdell. The paper, entitled "Flow In Culverts And Related Design Philosophies" appeared in the Journal of the Hydraulics Division, American Society of Civil Engineers, March 1966. The present paper will form a discussion of Mr. Blaisdell's paper and will appear in a subsequent issue of the same publication.

The present discussion of Mr. Blaisdell's paper illustrates the use of tapered inlets in the design of culverts. The use of a minimum performance curve in the design of culverts is concluded to be acceptable, notwithstanding certain reservations advanced by $\mathrm{Mr}$. Blaisdell. The concept of "balanced design" as applied to culverts is discussed in terms of the assessment of the risks of hydraulic overloading to the various component parts of the structure and it is concluded that the design rate of flow for the culvert and a structure or channel immediately downstream of the culvert need not be identical. And finally it was suggested that the experimental data so far presented have not demonstrated, beyond reasonable question, that the performance assigned to the hood-inlet is applicable at prototype size as well as at model size.

Key Words: Culverts, hydraulics, tapered inlets, hood inlets.

Five years of VLF worldwide comparison of atomic frequency standards, B. E. Blair, E. L. Crow, and A. H. Morgan, Radio Sci. 2, No. 6, 627-636 (June 1967).

The VLF radio braodcasts of GBR( $(16.0 \mathrm{kHz}), \mathrm{NBA}(18.0$ or $24.0 \mathrm{kHz})$, and NSS $(21.4 \mathrm{kHz})$ have enabled worldwide comparisons of atomic frequency standards to parts in $10^{10}$ when received over varied paths and at distances up to 9000 or more kilometers. This paper summarizes a statistical analysis of such comparison data from laboratories in England, France, Switzerland, Sweden, Russia, Japan, Canada, and the United States during the 5-year period 1961-1965. The basic data are differences in 24-hr average frequencies between the local atomic standard and the received VLF radio signal expressed as parts in $10^{10}$. The analysis of the more recent data finds the receiving laboratory standard deviations, $\hat{\alpha}_{i}$, and the transmission standard deviation, $\hat{\tau}$, to be a few parts in $10^{11}$. Averaging frequencies over an increasing number of days has the effect of reducing $\hat{\alpha}_{i}$ and $\hat{\tau}$ to some extent. The variation of the $\hat{\alpha}_{i}$ with propagation distance is studied. The VLF-LF long-term mean differences between standards are compared with the recent portable clock tests, and they agree to parts in $10^{11}$.

Key Words: Analysis of variance, atomic frequency standard errors, portable clock, VLF propagation.

The Bi I-II transition pressure measured with a dead-weight piston gage, P. L. M. Heydemann, J. Appl. Phys. 38, No. 6, 2640 2644 (May 1967).

A dead piston gage was used to determine the Bismuth I-II transition pressure and the volume change at the transition. The transition pressure for one sample, believed to contain less than $.001 \%$ impurities, was found to be $25,306 \pm 60$ bars. With another sample, of substantially less purity and of larger grain size, a transition pressure of $25,500 \pm 60$ bars was measured. The average relative volume change was .035 .

Key Words: Free piston gage, bismuth, polymorphic phase transition, transition pressure, volume change, high pressure.

Performance criteria for building components and systems, P. R. Achenbach, Proc. Porcelain Enamel Institute Forum, University of Illinois, Urbana, Ill., Sept. 28-30, 1966, 28, 176-195 (1966). The Building Research Division has conducted a number of technical investigations which led to the development of new test procedures for evaluating the significant performance requirements of building components and systems. These investigations have typically produced performance data which could be used by appropriate organizations in establishing criteria of acceptability. Laboratory studies of this type have been completed on underground heat distribution systems, ducts for heating and air conditioning systems, and sanitary plumbing fixtures and a similar study is in progress on exterior wall systems for residential buildings. In each of these studies the Building Research Division has collaborated with multidiscipline task groups of the Building Research Advisory Board of the National Academy of Sciences-National Research Council in developing the list of important performance characteristics in qualitative language. The work done on these projects is used to illustrate the sequence of activities required in developing performance criteria, the importance of collaboration among representatives of industry, professional societies, codes and standards organizations. and government bodies in selecting acceptable performance levels, the problems involved in devising adequate laboratory test procedures for building components made of widelydiffering materials, and the incomplete state of administrative 
procedures for implementation of performance criteria on a national scale.

Key Words: Performance characteristics, performance criteria, building components, laboratory procedures, codes, standards, specifications.

Transistorized current stabilizer for $x$-ray tubes with directly heated cathodes, K. W. Yee and R. D. Deslattes, Rev. Sci. Instr. 38, No. 5, 637-638 (May 1967).

An instrument is described which stabilizes the emission current in $x$-ray tubes with directly heated cathodes. Transistors are used in the amplifier and loading circuits. Emission currents from $20 \mathrm{~mA}$ to $1 \mathrm{~A}$ are maintained constant to within $0.1 \%$ for periods of about a half-hour.

Key Words: Emission, current, regulator, x-ray tube, controlled impedance, stabilizer.

Computer aided typesetting, W. R. Bozman, Book, Advances in Computers, 7, ch. 4, 195-207 (Academic Press, Inc., New York, N.Y., 1966).

Several examples are given of typesetting prepared by a computer.

Key Words: Photocomposition, typesetting, computers, printing, automation, publication.

A comparator for thermal AC-DC transfer standards, R. S. Turgel, Proc. 21st Annual ISA Conference and Exhibit, New York, N.Y., Oct. 24-27, 1966, ISA Preprint 12.3-1-66 (Oct. 1966).

Thermal transfer standards play an important role in precision a-c measurements. They are calibrated by intercomparison with standards of known ac-de difference. A comparator is described that simplifies such routine calibrations. A sequence of null balances in the measuring circuit operates a simple analog computer which indicates the result of the intercomparison directly in parts per million of ac-dc difference.

Key Words: A-C, D-C, calibration, transfer standard, thermoelement, intercomparison.

Calibration of the NBS photoelectric pyrometer of 1961 , R. D. Lee, Proc. 7th session, Comite Con. de Thermometrie, Paris, France, pp. 74-78 (Sept. 24, 1964).

Factors affecting the reproducibility of the NBS Photoelectric Pyrometer are listed, and progress in reducing these factors are described. A calibration to realize the International Practical Temperature Scale (IPTS) above $1063{ }^{\circ} \mathrm{C}$ to $1256{ }^{\circ} \mathrm{C}$ is described. At present, the estimated uncertainty in realizing the IPTS is about 0.1 ${ }^{\circ} \mathrm{C}$ at $1063{ }^{\circ} \mathrm{C}, 0.2{ }^{\circ} \mathrm{C}$ at $1256{ }^{\circ} \mathrm{C}$, and is predicted to be $0.8{ }^{\circ} \mathrm{C}$ at 2400 ${ }^{\circ} \mathrm{C}$.

Key Words: Calibration-NBS photoelectric pyrometer of 1961, International Practical Temperature Scale, NBS photoelectric pyrometer, photoelectric pyrometer-NBS, pyrometer, photoelectricNBS.

On long-term stability of Zener reference diodes, W. G. Eicke, Jr., and H. H. Ellis, Proc. 11 ${ }^{e}$ Session, Comite Con. D'Electricite, May 10-12, 1965, pp. E-73-E-77 (May 1965).

This paper gives a summary of a three year study of the stability of Zener Diodes either when operated intermittently or continuously. The diodes that were studied under intermittent use were in use for periods of 5 to 10 minutes with periods of two to four weeks between measurements. The diodes studied had normal voltage ranging from 8.1 to 9.2 . The studies were conducted at $25.00 \pm{ }^{\circ} \mathrm{C}$. The studies indicated that the Zener voltage gave stable output voltage to within 3 to $10 \mathrm{ppm}$ over a three year period.

Key Words: Diodes-reference, long-term stability, reference diodes, Zener reference diodes.

Potential applications of the $x$-ray/density method for the comparison of atomic-weight values, $R$. D. Deslattes, H. S. Peiser, J. A. Bearden, and J. S. Thomsen, Metrologia 2, No. 3, 103111 (July 1966).

Without presenting experimental details, this report outlines and reappraises the principles involved in measurement of crystal lattice parameters and density for the determinations of atomicweight values.

Attention is drawn to the advantages to be derived from a comparison of densities and lattice spacings with those of a crystal of mononuclidic elements, rather than from absolute measurements of $x$-ray spacings and density.

Errors arising from physical and chemical imperfections are discussed as are the general techniques of adequate precision for density and lattice spacings measurements.

Recent literature data is used by way of illustration to derive the effective atomic weight of calcium appertaining to a group of calcite samples from that of a group of silicon crystals (really an unsuitable "standard"). The calcium value obtained is $40.0795 \pm 0.0019$ (probable error); it compares with IUPAC's adopted 40.08 and a "physical value" of 40.078 from nuclidic masses and isotopic abundance measurements. There are several elements for which the x-ray/ density method is judged to be potentially the most promising for atomic-weight redeterminations in the foreseeable future.

Key Words: Atomic weights, crystal densities, crystal perfection, experimental methods, lattice parameters.

Review of elementary theory of the photometry of projection apparatus, C. S. Douglas, Illum. Eng. 62, No. 4, 246-253 (Apr. 1967).

Equations based upon simple geometric relations are developed for the illuminance produced by a projector such as a searchlight, beacon, or floodlight at a distance from the projector. When the beam is rotationally symmetrical but not collimated and the image, virtual or real, subtends a smaller angle at the point of observation than does the objective of the projector, illuminance varies inversely as the square of the distance to the image. If the angle subtended by the image is larger than that subtended by the objective, the illuminance varies inversely as the square of the distance to the objective. The distance at which the two angles are equal is defined as the critical distance. Equations relating critical distance to the radius of the source, the radius of the objective, and the magnification of the system are developed. Approximations for use when the beam of the projector is asymmetric are developed. Very good agreement was found between the computed variation of illuminance with distance and the measured variation of illuminance with distance for a projector forming a virtual image 150 feet behind the objective.

Key Words: Critical distance, illumination, light projectors, photometry, photometric distance, signal lighting.

Statistical concepts in metrology, H. H. Ku, Book, Handbook of Industrial Metrology, ch. 2, pp. 20-54 (Prentice-Hall, Inc., Englewood Cliffs, N.J., 1967).

These two sections of the chapter, statistical concepts of a measurement process and statistical analysis of measurement data, are part of the textbook Handbook of Industrial Metrology sponsored by the American Society of Tool and Manufacturing Engineers.

Beginning with the differentiation between arithmetic and measurement numbers, the properties of the latter are developed and described, leading to a discussion of precision and accuracy at the end of the first section.

A basic kit of tools for the comparison and manipulation of means and variances are given in the second section, including a collection of propagation of error formulas. The use of control chart techniques for monitoring stability is emphasized. Examples are given using actual calibration data of NBS.

Selected references are given for topics introduced but not treated in detail.

Key Words: Industrial metrology, measurement process, statistical analysis, statistical concepts.

The photometry of colored light, A. C. Wall, Illum. Engr. 62 , No. 4, 239-242 (Apr. 1967).

The photosensitor of a photometer must be corrected to have a spectral sensitivity as close as possible to the CIE photopic luminous efficiency function. A correction-by-filter technique is described. applicable to photosensitors which are used in the measurement of "colored light." which, in this paper, designates light which has a spectral distribution different from that of the light with which the photometer is calibrated. Three types of photosensitors with their associated auxiliary filters were investigated, as well as one type 
of barrier-layer cell with an integral filter. The photosensitors were first calibrated by exposing them to illumination from a lamp operating at $2854{ }^{\circ} \mathrm{K}$. Then, to test the adequacy of the spectral correctionby-filter technique, twenty-two 2-by-2-inch squares of colored glass whose luminous transmittance was computed from spectrophotometric data were placed in turn in the light beam and readings proportional to the irradiance incident on each photosensitor were taken. If the spectral correction were perfect, the ratio of the reading obtained with the filtered light to the reading with the unfiltered light would be equal to $\tau_{s}$, the luminous transmittance of the filter obtained from the spectrophotometric measurements. Factors were calculated to convert the ratios obtained to $\tau_{s}$ for the color-corrected photosensitors and for five types of noncolor-corrected photosensitors.

Key Words: Photometry, photocells, spectral correction of phototubes, photometers, phototubes, filters.

Thermal converters used as transfer standards for the measurement of alternating current and voltage, $\mathrm{F}$. L. Hermach, Proc. $11^{e}$ Session, Comite Con. D'Electricite, May 10-12, 1965, pp. E-83-E-88 (May 1965).

This report to the Advisory Committee oulines recent progress at NBS in the development of ac-de transfer standards (comparators) for measurements of alternating current and voltage with $20 \mathrm{ppm}$ accuracy or better at audio frequencies. Electrothermic transfer standards of the thermocouple type offer good prospects of meeting this goal. Their ac-dc differences appear to be very stable. The standards can be read with high precision and are rugged and portable. Furthermore, they can readily be intercompared for ac-dc difference, to step up and down the current and voltage scale with a precision of a few ppm. They are thus worthy of consideration for international comparisons of the accuracy of alternating current and voltage measurements.

Key Words: Audio frequency, audio, standards, comparator, thermoelements, thermal converters, transfer standards, voltage comparator, voltage measurements.

Use of a laser for length measurement by fringe counting, K. E. Gillilland, H. D. Cook, K. D. Mielenz and R. B. Stephens, Metrologia 2, No. 3, 95-98 (July 1966).

The use of a 633-nm He-Ne laser of normal neon isotopic abundance as a light source for an automatic fringe counting interferometer was found to improve the counting precision and extend the usefulness of the interferometer to the full one meter limit of its carriage travel. A 91-mm length was measured in terms of $\mathrm{Hg}^{198}$ and laser fringes. From the fringe counts obtained and the wavelength of the $\mathrm{Hg}^{198}$ line, the laser vacuum wavelength was measured to be 632.99146 $\mathrm{nm}$ with a standard error of $1.1 \times 10-7$. With the laser wavelength so determined, wach decimeter interval of a one meter line standard was measured by counting laser fringes. All measured decimeter interval lengths agreed with the assigned values within the mutual limits of uncertainty, the largest discrepancy being less than $0.5 \mathrm{um}$. The result obtained for the total length of the line standard agreed with the assigned length of the line standard to 7 parts in $10^{8}$, which is well within the mutual limits of uncertainty.

This method is being applied to routine calibration of line standards using a stabilized isotopic He-Ne laser.

Key Words: Automatic fringe counting interferometer, fringe counting, interferometer, laser for length measurement, length measurement.

A note on thermal expansion coefficients of rare gas solids, R. D. Mountain, J. Phys. Chem. Solids 28, 1071-1073 (Dec. 29, 1966). Recent measurements of the thermal expansion coefficient of solid argon, krypton and xenon are shown to violate the law of corresponding states. The failure of the law of corresponding states is related to the different ways the lattice vibration spectra of these crystals change as pressure is applied to the lattice.

Key Words: Corresponding states, lattice vibration spectrum, solid argon, solid krypton, solid xenon, thermal expansion coefficient.

Annual report on spectroscopy, C. E. Moore, Astron. J. 71, No. 9, 796-797 (Nov. 1966).

This report is furnished annually to the Astronomical Journal in order to present to astrophysicists the spectroscopic work that they are particularly interested in. It is published with the Observatory Reports and provides a brief summary of activity at the National Bureau of Standards.

Key Words: Atomic spectra, rare-earth spectra, transition probabilities, solar spectrum.

Approximate eigenfunctions of the Liouville operator in classical many-body systems. II. Hydrodynamic variables, R. J. Nossal and R. Zwanzig, Phys. Rev. 157, No. 1, 120-126 (May 5, 1967).

A variational solution of the Liouville Equation is used to obtain collective coordinates for simple classical fluids. Comparison is made with macroscopic analogs determined from relevant hydrodynamic equations. Approximate eigenfunctions of the Liouville operator, when constructed from linear combinations of the spatial fourier transforms (fluctuations) of the mass, momentum, and energy density operators for the fluid, are found appropriate to low frequency disturbances. When time derivatives of fluctuations are included among trial functions the variational procedure provides fluid state counterparts of usual solid state phonons.

Key Words: Eigenfunctions, Liouville operator, many-body systems, hydrodynamic variables, irreversible processes.

Certificates of radioactivity standards, S. B. Garfinkel, A. P. Baerg, and P. E. Zigman, Report of the Subcommittee on the Use of Radioactivity Standards, Natl. Acad. Sci.-Natl. Res. Council, pp. 1-11 (Dec. 1966).

Recommendations for certificates of standards of radioactivity are presented. It is hoped that commercial producers of such standards in the United States of America will use these recommendations in the preparation of certificates which they supply with their standards.

Key Words: Certificates, commerical standards, radioactivity standards, standards accuracy, combination of errors, precision, measurements.

Deformation twinning in $\mathrm{Ni}$ and F.C.C. Fe-Ni alloys, R. P. Reed, Phil. Mag. 15, No. 137, 1051-1055 (May 1967).

Using electron and optical microscopy techniques, deformation twinning has been found in $\mathrm{Ni}$ and fec $\mathrm{Fe}-\mathrm{Ni}$ alloys at low temperatures $\left(76-4{ }^{\circ} \mathrm{K}\right)$

Key Words: Nickel, Fe-Ni alloys, deformation twinning, low temperature.

Development of the engineering method and some simplified methods of structure shielding analysis, C. Eisenhauer (Lecture Notes, OCD Summer Inst., Kansas State Univ., Manhattan, Kansas, 1962-1963, 1965), TR-40, Radiation Shielding-Analysis and Design Principles as Applied to Nuclear Defense Planning, V-1-V-iv (Supt. Docs. Govt. Printing Office, Washington, D.C., Nov. 1966).

These lecture notes describe the technical basis for the procedures currently being used by the Office of Civil Defense to evaluate fallout protection in structures. The notes describe in detail how the equations and charts used in these procedures were derived from fundamental calculations of radiation shielding. Examples are given for simple structures.

Key Words: Fallout protection in structures, radiation shielding, structures.

Dielectric constants of $\mathrm{PbWO}_{4}$ and CaWO, W. S. Brower and P. H. Fang, J. Appl. Phys. 38, No. 5, 2391 (Apr. 1967).

The dielectric constants $\left(\epsilon^{\prime}\right) \mathrm{PbWO}_{4}$ and $\mathrm{CaWO}_{4}$ were measured at $24.5{ }^{\circ} \mathrm{C}$ in air. Two specimens of each orientation were measured. The averages and deviations therefrom of the two measured when of the reflective dielectric constants are as follows:

$$
\begin{aligned}
& \mathrm{PbWO}_{4} \epsilon^{\prime}\left\|a 23.6 \pm 0.3 ; \epsilon^{\prime}\right\| c 31.0 \pm 0.4 ; \\
& \mathrm{CaWO}_{4} \epsilon^{\prime}\left\|a 11.7 \pm 0.1 ; \epsilon^{\prime}\right\| c \quad 9.5 \pm 0.2 .
\end{aligned}
$$

Key Words: Dielectric constant, single crystal, calcium tungstate, lead tungstate. 
Effect of oxygen on the photoelectron yield from tungsten in the vacuum ultraviolet, B. J. Waclawski, L. R. Hughey, and R. P. Madden, Appl. Phys. Letters 10,305 (1967).

The effect of adsorbed oxygen on the photoelectron yield of bulk polycrystalline tungsten was studied at photon energies of $7.7,10.2$ $11.8,16.9$, and $21.2 \mathrm{eV}$. Use of ultra-high vacua $\sim 3 \times 10^{-10}$ torr ensured sample cleanliness prior to oxygen exposure. The photoelectron yield decreases with oxygen exposure because of the increase in the electronic work function of the tungsten photocathode. However, at $h \nu=21.2 \mathrm{eV}$, an increase in photoelectron yield with oxygen exposure also appears and is believed to be due to photoelectron emission from the adsorbed oxygen atoms.

Key Words: Oxygen adsorption, photoelectric effect, tungsten, vacuum ultraviolet.

Effects of environment on the fracture of glass, S. M. Wiederhorn, Proc. RIAS Conf., Baltimore, Md., June 7-8, 1965, pp. 293-317 (Gordon and Breach, New York, N.Y., 1966).

This paper briefly reviews previous work on the topic of delayed fracture of glass, and then presents the results of a new experimental approach to the subject. Using the double-cantilever cleavage technique, it was possible to observe crack motion and to accurately measure crack velocities in glass. The temperature and stress dependence of the crack velocity indicates that the observed fracture is an activated process with an activation energy of 19,500 calories/ mole. The existence of a static fatigue limit is inferred from the experimental data. Experimental results will be discussed with reference to current theories of static fatigue.

Key Words: Glass, fracture, crack propagation, static fatigue, corrosion, cleavage.

Electron beams: National Bureau of Standards and the new technology, H. W. Koch, Science 156, No. 3773, 321-328 (Apr. 21, 1967).

High energy electron beams can now be generated with radiation powers of hundreds of kilowatts and can be measured with energy resolutions of several parts in $10^{4}$. The importance of this new tech nology to science, industry, and the public is related to the measurement research and services of the National Bureau of Standards.

Key Words: Electrons, x-rays, particle accelerators, radiation power, nuclear physics, radiation processing, radiation measurement standards.

Exposure rate measurements of $X$ - and gamma-rays with silicon radiation detectors, K. Scharf, Health Phys. 13, No. 6 , 575-586 (June 1967).

The steady-state d.c. current and voltage signals produced by $\mathrm{x}$ - or gamma-rays in silicon radiation detectors used either as photovoltaic cells or photodiodes are shown to be dependent on such circuit parameters as load resistance and bias voltage used in the respective exposure rate measurement. Non-linear exposure rate dependence of radiation-produced signals may result from choosing unsuitable circuit parameters and no singular value of sensitivity or signal per unit exposure rate can be ascribed to an individual detector without specifying the circuit parameters used. Measurements are reported with silicon detectors of the diffused $p$ - $n$ junction type illustrating these performance features, and a measuring method is suggested which makes it possible to measure with high precision the generated photocurrent at zero voltage applied at the detector which is independent of circuit parameters and proportional to exposure rate over a wide range. Measurements using this method are reported of exposure rates ranging up to $10^{5} \mathrm{R} / \mathrm{hr}$ of $30-\mathrm{kV}$-rays of $0.09 \mathrm{~mm} \mathrm{Al} \mathrm{HVL}$, and from approximately $1 \mathrm{R} / \mathrm{hr}$ to $30 \mathrm{R} / \mathrm{hr}$ of ${ }^{60} \mathrm{Co}$ gamma rays.

Key Words: X-rays, gamma rays, radiation detectors, silicon, semiconducting devices, exposure rate measurements, dosimetry, radiation monitoring, radiation detection devices.

Experimental evidence concerning the conduction band of $\mathrm{SrTiO}_{3}$, H. P. R. Frederiske, W. R. Hosler, and W. R. Thurber, (Proc. Inter. Conf. Physics of Semiconductors, Kyoto, Japan, Sept. 8-13, 1966) J. Phys. Soc. 21, Suppl., 32-36 (1966).

Experimental information about the conduction band of semiconducting $\mathrm{SrTiO}_{3}$ is compared with the calculated band structure.
Measurements of transport properties, magnetic susceptibility and plasma frequency yield rather high average effective masses. Lowfield magnetoresistance as well as piezoresistance experiments have been performed on $\mathrm{SrTiO}_{3}$. Although some disagreement remains, the weight of the evidence is in favor of a many-valley structure of the lowest conduction band as predicted by theory.

Key Words: Band structure, effective mass, electronic transport properties, semiconductor, strontium titanate.

Ferromagnetic iron alloys lacking a hyperfine field at the iron site, L. H. Bennett and L. J. Swartzendruber, Physics Letters 24A, No. 7, 359-360 (Mar. 27, 1967).

Although ferromagnetism has been reported for $\mathrm{TiFe}_{x} \mathrm{Co}_{x-1}$ when $0.3 \ll \times \ll 0.7$, the Mössbauer effect shows no evidence for the existence of a localized moment at the iron site. Thus the magnetization is most likely due to a diffuse moment associated with the $\mathrm{Ti}$ atoms, implying itinerant ferromagnetism.

Key Words: Alloys, ferromagnetism, superconductivity, hyperfine fields, moments, titantium, cobalt, Mössbauer effect, iron.

Future spectroscopy for late-type stars, C. E. Moore, Proc. Colloquium on Late-Type Stars, Trieste, Italy, June 13-17, 1966 , pp. 15-24 (Stampato Presso, Trieste, Italy, 1967).

The subject is reviewed with the idea of the application of spectroscopy to work on abundances. Two main topics are discussed: the general characteristics of the observed stellar spectra and the available data on laboratory spectra needed to identify the stellar lines. The impact of the developments in space technology has greatly expanded the observed range of stellar spectra. This is handled by regions, the Ultraviolet, the Visible, and the Infrared. More laboratory programs are needed to meet present needs for data on both atomic and molecular spectra. The existing programs are discussed. Encouraging progress on the analyses of selected rare-earth spectra is reported. These promise to be of great astrophysical interest.

Key Words: Spectra of late-type stars, atomic spectra, molecular spectra, solar spectra, sun-spot spectra, reference data programs, rare-earth spectra.

Report on international conference on spectroscopy, Bombay, 9-18 January 1967, C. E. Moore (Intern. Conf. Spectroscopy, Bombay, India, Jan. 9-18, 1967), Appl. Opt. 6, No. 5 , 836 (May 1967).

The First International Conference on Spectroscopy in India, was held in Bombay, January 9-18, 1967. Three International Unions, Astronomy, Physics, and Chemistry, supported the Organizing Committee in arranging for the Conference. Some 200 scientists from 13 countries attended. There were 30 invited papers and more than 100 contributed papers in all. Most of them dealt with molecular spectroscopy, but a few touched on interstellar spectra, solar spectroscopy, in the x-ray region and laser spectroscopy.

Key Words: Molecular spectroscopy, Indian Conference on Spectroscopy, International Conference on Spectroscopy.

Interpretation of the far infrared laser oscillation in ammonia, D. R. Lide, Jr., Physics Letters 24A, No. 11, 599-600 (May 1967).

The interpretation of the laser emission spectrum of ammonia in the far infrared is considered. The $\mathrm{P}$ branch of the $\mathrm{v}_{2}=3^{s} \rightarrow 2^{\prime \prime}$ transition is shown to coincide closely with the observed laser spectrum. However, only the low $K$ transitions are observed. Possible reasons for the absence of the expected strong $K=3$ lines are discussed.

Key Words: Ammonia, infrared, inversion, laser, molecular, spectrum.

Low-temperature heat capacity of $\mathrm{NdCl}_{3}$ and $\operatorname{PrCl}_{3}, \mathrm{~J} . \mathrm{H}$. Colwell and B. W. Mangum, J. Appl. Phys. 38, No. 3, 1468-1469 (Mar. 1, 1967)

Heat capacities of $\mathrm{PrCl}_{3}$ and $\mathrm{NdCl}_{3}$ have been measured between $0.3^{\circ} \mathrm{K}$ and $4{ }^{\circ} \mathrm{K}$. The dominant feature of the heat capacity curves is a broad anomaly indicating a region of extensive short-range magnetic ordering. The anomaly in $\mathrm{NdCl}_{3}$ has a maximum at 0.47 
${ }^{\circ} \mathrm{K}$ and fits closely that of a linear Ising chain model. In addition, two small peaks appear at the same temperatures as the sharp spikes found in the magnetic susceptibility. $\mathrm{PrCl}_{3}$ has a sharp peak in the heat capacity at $0.4^{\circ} \mathrm{K}$ which is presumably associated with longrange ordering. The broad anomaly in $\mathrm{PrCl}_{3}$ has a maximum at 0.8 ${ }^{\circ} \mathrm{K}$. The magnetic entropy change for the temperature region of the measurements is approximately $80 \%$ of $\mathrm{R} \log _{e} 2$ for both salts.

Key Words: Heat capacity, magnetic entropy, magnetic susceptibility, $\mathrm{NdCl}_{3}$ (neodymium trichloride), $\mathrm{PrCl}_{3}$ (praeseodymium trichlroide), temperature measurement.

Modulus of rupture of glass below room temperature, M. J. Kerper and T. G. Scuderi, Am. Ceramic Soc. Bull. 45, No. 9, 782-783 (Sept. 7, 1966).

The modulus of rupture of seven different commercial glasses was determined at $0{ }^{\circ} \mathrm{F}\left(-17.8{ }^{\circ} \mathrm{C}\right)$ and $-50{ }^{\circ} \mathrm{F}\left(-45.6{ }^{\circ} \mathrm{C}\right)$. The results showed that for all glasses and for all conditions of temper the modulus of rupture increased as the temperature decreased.

Key Words: Glass, strength, low temperature.

On the diffraction profiles of spectrograph slits of finite width, K. D. Mielenz, Optik 25, No. 3, 138-139 (May 17, 1967).

In an earlier paper, the author presented a measured curve of line intensity vs. slit width, for the case of partially coherent spectrograph slit illumination. The result of a theoretical calculation is now presented which supports the experimental curve.

Key Words: Diffraction, partial coherence, spectrograph slit.

Optical properties of $\mathrm{SrTiO}_{3}$ under applied stress and electric field, R. C. Casella, Phys. Rev. 154, No. 3, 743-749 (Feb. 15, 1967).

Motivated by recent experiments on the effects on uniaxial stress on the superconducting transition and normal-state transport properties of $\mathrm{SrTiO}_{3}$, we have carried out a symmetry analysis, obtaining the perturbed band structure and optical selection rules for the cases of uniaxial stress along the (111) and (001) axes and of static electric field along (001). A comparison of the last case with $\mathrm{BaTiO}_{3}$ in the $\mathrm{C}_{4 \mathrm{v}}$ ferroelectric phase suggests a model with a reversal in the order of the valence bands in $\mathrm{SrTiO}_{3}$ relative to that proposed earlier. Selection rules for polarized light are obtained for both models and criteria for deciding experimentally which is correct are stated. An example is given of how the sign of the relative energy shift of the conduction valleys with stress may be determined optically.

Key Words: Electro-optical effects, energy bands, selection rules, stress-optical effects, strontium titanate.

Oscillatory photoconductivity and luminescence in $\mathrm{SrTiO}_{3}$, L. H. Grabner, Proc. Cairo Solid State Conf., Cairo, Egypt, Sept. 3-8, 1966, Book, Interaction of Radiations with Solids, Ed. A. Bishay, pp. 155-160 (Plenum Press, Inc., New York, N.Y., 1967).

Photocurrents and luminescence in $\mathrm{SrTiO}_{3}$ oscillate at low temperatures $\left(\sim 4{ }^{\circ} \mathrm{K}\right)$ at a threshold of about 100 volts $/ \mathrm{cm}$. Voltage-current curves show negative differential resistance in the region of oscillation. We suggest that these effects are due to the field ionization, into the valence band, of a hole trapped $1 \mathrm{eV}$ from the valence band. The hole is ionized by the local field $\left(\sim 10^{6} \mathrm{~V} / \mathrm{cm}\right)$ which differs from the externally applied field of $10^{2} \mathrm{~V} / \mathrm{cm}$ because of the high dielectric constant of $\mathrm{SrTiO}_{3}\left(\sim 10^{4}\right)$ at low temperatures.

Key Words: Electric field quenching, luminescence, negative resistivity, photoconductivity, strontium titanate.

Photographic and spectroscopic studies of exploding wires in a sealed vessel, E. C. Cassidy and K. K. Neumann (Proc. 7th Intern. Cong. High-Speed Photography, Zurich, Switzerland, Sept. 12-18, 1965), Book, Kurzzeitphotographie, Ed. O. Helwich, pp. 178185 (Verlag Dr. Othmar Helwich, Darmstadt, West Germany, 1967). Investigations of the mixing process between exploding wires and a confined air environment are described. The various high-speed framing camera, combined framing camera and drum camera, drum camera, periodic still, and ultraviolet photographic techniques employed for time resolution of the explosion are described and illustrated. The photographic results are correlated with time-resolved (by photographic and photoelectric techniques) spectroscopic observations. Results have suggested a method and suitable intervals (during the explosion) for estimating the average temperature of the exploding vapor column. A phenomenon apparently due to reflecting shock waves was observed in a later stage of the explosion.

Key Words: High-speed, photographic, time-resolved, spectrographic, exploding wires, electrical discharge.

Piezo-optical effects in solids by sample rotation, A. Feldman, Physics Letters 23, No. 11, 627-628 (Dec. 12, 1966).

The differential absorption and reflection coefficients of uniaxially stressed $\mathrm{Si}$ and $\mathrm{SrTiO}_{3}$ were determined by rotating the samples in a linearly polarized light beam.

Key Words: Modulation technique, optical, piezo-optical, semiconductor, silicon, strontium titanate.

Radioactivity criteria for radiation processing of foods, H. W. Koch and E. H. Eisenhower, Book, Radiation Preservation of Foods, Advances in Chemistry Series 65 (American Chemical Society, Washington, D.C., 1967), ch. 7, pp. 87-108.

The high-dose-level processing of foods by high-energy electrons and $x$-rays can induce measurable radioactivity in foods. Such radioactivity might, but fortunately need not, present a food wholesomeness problem. The amount of induced radioactivity can be controlled and limited so as to be non-measurable by limiting the maximum energy of the radiation to $10 \mathrm{MeV}$. Therefore, non-measurability is one useful criterion. Another criterion may be developed from considerations of the maximum permissible concentration of radioactivity in foods and of the deliberate or chance nature of the occurrence of the activity. The bases of the various criteria and of possible future developments are detailed by a consideration of the characteristics of photonuclear radioactivities, the detection methods and capabilities, the influence of production parameters, and the maximum permissible concentrations.

Key Words: Detection, induced radioactivity, maximum permissible concentrations, photonuclear reactions, processing, radiation, threshold energies.

Reactor physics in the resonance and thermal regions, $D$. T. Goldman, J. Franklin Inst. 283, No. 5, 437-438 (May 1967).

A review of papers presented at a topic conference of the American Nuclear Society.

Key Words: Neutron, thermalization, resonance, absorption, reactor, review.

Spectroscope slit images in partially coherent light, K. D. Mielenz, J. Opt. Soc. Am. 57, No. 1, 66-74 (Jan. 1967).

The apparatus function of prism or grating spectroscopes with finite slits is derived for the general case of partially coherent illumination of the slit. Numerical results are presented for the border cases of coherent and incoherent slit illumination, as well as for full and partial illumination of the spectroscope aperture.

The dependence of line intensity and line width on slit width, as well as the optimum slit width, are determined for each of these cases. It is shown that the performance of the spectroscope reaches an optimum when the aperture is at least fully illuminated.

Key Words: Spectroscope slit, diffraction, partial coherence slit illumination, luminosity, resolution, optimal performance.

Status of the National Standards for physical measurement, R. D. Huntoon, Science 150, No. 3693, 169-178 (Oct. 8, 1965).

This article outlines various stages of sophistication in the development of a measurement system, from a "unit-standard" system to a consistent system in which standards are tied to atomic and molecular properties in an independently reproducible way. The present stage of development of our measurement system is discussed in this context, and predictions are made regarding its future development.

Key Words: Ampere, candela, current, degree Kelvin, International System of Units, kilogram, length, luminous intensity, mass, meter, metric system, second, standards for physical measurement, temperature, time. 
The basis of our measurement system, R. D. Huntoon, Phys. Teacher 4, No. 3, 113-120 (Mar. 1966).

This article outlines various stages of sophistication in the development of a measurement system, from a "unit-standard" system to a consistent system in which standards are tied to atomic and molecular properties in an independently reproducible way. The present stage of development of our measurement system is discussed in this context, and predictions are made regarding its future development.

Key Words: Degree Kelvin, kilogram, measurement system, meter, physical constant, second, standard, unit.

The elastic energies of non-regular hexagonal dislocation loops, R. DeWit and A. W. Ruff, Jr., Phil. Mag. 15, No. 137, 10651069 (May 1967).

The elastic energies of dislocation loops have been calculated as a continuous function of shape from equilateral triangle to hexagon A smooth decrease in energy is found in this sequence; a relatively rapid change is associated with truncation of the triangle corners. The results are compared with previous calculations for other geometric shapes. The effect of a stacking fault in the loop plane is also considered.

Key Words: Dislocation, elastic energy, loops, stacking fault.

Temperature dependence of the high-frequency moduli of vitreous $\mathbf{B}_{2} \mathbf{O}_{3}$, W. Capps, P. B. Macedo, B. O'Meara, and T. A. Litovitz, J. Chem. Phys. 45, No. 9, 3431-3438 (Nov. 1, 1966).

Measurements of ultrasonic velocity allowed the calculation of the high frequency shear and bulk moduli of $\mathrm{B}_{2} \mathrm{O}_{3}$ from $80{ }^{\circ} \mathrm{C}$ below to $300{ }^{\circ} \mathrm{C}$ above the glass transition. The temperature dependences of these moduli were found to be consistent with a semi-empirical extension of the theory of $\mathrm{Zwanzig}$ and Mountain.

Key Words: $\mathrm{B}_{2} \mathrm{O}_{3}$, high frequency moduli, ultrasonic velocity.

A determination of trace amounts of iron and cobalt in the same sample by substoichiometric radioisotopic dilution analysis, A. R. Landgrebe, L. McClendon, and J. R. DeVoe (Proc. 1964 Winter Meeting American Nuclear Society, San Francisco, Calif., Nov. 30-Dec. 3, 1964), Trans. Am. Nucl. Soc. 7, No. 2, 337-338 (Nov. 1964).

A method of analysis for iron and cobalt was developed for the concentration range of $10^{-3}$ to $10^{-8} \mathrm{M}$. The method involves using a limiting amount of EDTA to complex iron or cobalt. The noncomplexed ions were removed from solution with a cationic exchanger (Dowex 50-X8) leaving a constant amount of cobalt or iron EDTA complex in solution. Trace amounts of naturally occurring cobalt and iron were determined with good sensitivity as long as radioisotopes of high specific activity were used. N.B.S. standard reference material $(671,672$, and 673$)$ of nickel oxide were also analyzed for iron and cobalt.

Key Words: Iron, cobalt, EDTA, radioisotopic dilution, Dowex 50$\mathrm{X} 8$, nickel oxide, analysis, standard reference material.

Application of radiometric techniques to quantitative paper chromatography of iron, copper, manganese, and cobalt, A. R. Landgrebe, T. E. Gills, and J. R. DeVoe, Anal. Chem. 38, No. 9, 1265-1266 (Aug. 1966).

A radioactive reagent was used for the quantitative determination of iron, copper, manganese, and cobalt after separating them by paper chromatography. The method has been applied to the analysis of a sample of nickel oxide (NBS Standard Reference Material No. 671). With this method which is operable at the $\mu \mathrm{g} / \mathrm{ml}$ level, values of $0.37,0.19,0.14$, and 0.32 percent for $\mathrm{Fe}, \mathrm{Cu}, \mathrm{Mn}$, and $\mathrm{Co}$ respectively were found and the relative standard deviation of a single determination for $\mathrm{Fe}, \mathrm{Cu}, \mathrm{Mn}$, and $\mathrm{Co}$ were $7.1,6.8,3.8$, and 4.1 percent. Comparison of these results with those of other analytical techniques were made.

Key Words: Analysis, nickel oxide, paper chromatography, radiometric methods, NBS Standard Reference Material 671, Fe, Co, $\mathrm{Cu}, \mathrm{Mn}$.

A study of the heat of formation of oxygen difluoride, $\mathrm{R}$. C. King and G. T. Armstrong, Proc. Fifth Meeting ICRPG, Working Group on Thermochemistry 1, CPIA Publ. 146, May 1967.
The enthalpies of the reactions below $\Delta H_{303}^{\circ}$, were determined in a flow calorimeter operated at one atm. pressure, to be respectively, in keal mol-1. $-227.52(0.16),-153.38(0.06)$, and $-68.28(0.03)$. The numbers in parentheses are the standard deviations of the means for 13,5 , and 6 experiments, respectively. The enthaipy of formation of $\mathrm{OF}_{2}(\mathrm{~g}), \Delta H_{f 298}^{\circ}$

$$
\begin{aligned}
\mathrm{OF}_{2}(\mathrm{~g})+2 \mathrm{H}_{2}(\mathrm{~g})+99 \mathrm{H}_{2} \mathrm{O}(\mathrm{l}) & =2\left[\mathrm{HF} \cdot 5 \mathrm{OH}_{2} \mathrm{O}\right](\mathrm{l}) \\
\mathrm{F}_{2}(\mathrm{~g})+\mathrm{H}_{2}(\mathrm{~g})+100 \mathrm{H}_{2} \mathrm{O}(\mathrm{l}) & =2\left[\mathrm{HF} \cdot 50 \mathrm{H}_{2} \mathrm{O} \mid(\mathrm{l})\right. \\
\frac{1}{2} \mathrm{O}_{2}(\mathrm{~g})+\mathrm{H}_{2}(\mathrm{~g}) & =\mathrm{H}_{2} \mathrm{O}(\mathrm{l}) \\
\mathrm{F}_{2}(\mathrm{~g})+\frac{1}{2} \mathrm{O}_{2}(\mathrm{~g}) & =\mathrm{OF}_{2}(\mathrm{~g})
\end{aligned}
$$

was calculated from the measured enthalpy changes to be +5.86 $\mathrm{kcal} \mathrm{mol}-1$. The average bond energy $\mathrm{E}(\mathrm{O}-\mathrm{F})$ in the gaseous molecule of $\mathrm{OF}_{2}$ was calculated to be $45.72 \mathrm{kcal} \mathrm{mol}^{-1}$. The results of the second reaction are compared with other recently derived data on $\mathrm{HF}(\mathrm{aq})$.

Key Words: Fluorine, reaction with hydrogen; oxygen, reaction with hydrogen; oxygen difluoride, reaction with hydrogen; oxygen difluoride, heat of formation; hydrofluoric acid, heat of formation; hydrogen, reactions with fluorine, oxygen difluoride and oxygen; calorimetry, fluorine flame.

Crystal nucleation in polyethylene: the droplet experiment, F. Gornick, G. S. Ross, and L. J. Frolen, J. Polymer Sci. 18, Part C, 79-91 (1967)

The droplet technique was utilized to obtain estimates of the isothermal rate of homogeneous crystal nucleation in highly supercooled melts of unfractionated linear polyethylene. In a typica experiment a cell containing a suspension of several hundred micronsize spherical droplets of the polymer was placed on a microscope hot stage and quenched from a temperature well above the melting point of polyethylene to the desired crystallization temperature. When viewed between crossed polarizers, the droplets were initially invisible but, upon freezing, they appeared as visible birefringent spheres. The time dependence of the process was followed by time-lapse photography. Half times $\left(\tau^{1 / 2}\right)$ for the freezing of those droplets remaining unfrozen by the time the crystallization temperature was attained were thus obtained at a series of undercoolings and related to the desired nucleation rate constant

$$
I\left(\text { nuclei- } \mathrm{cm}^{-3}-\mathrm{sec}^{-1}\right)
$$

by the equation $I=\ln 2 / \tau^{1 /} 2 v$, where $v$ is the droplet volume The temperature dependence of $I$, as obtained by the above procedure, was analyzed in accord with current theories of homogeneous nucleation of chain-folded polymer crystals. From this analysis, an estimate, $14,960 \mathrm{ergs}^{3} \mathrm{~cm}^{-6}$ was made of the quantity $\left(\sigma^{2} \sigma_{e}\right)$, where $\sigma$ and $\sigma_{e}$ are respectively the lateral and end-surface free energies of the crystal.

Key Words: Crystallization, polyethylene, homogeneous nucleation, surface free energy, microscopy, kinetics.

Effects of temperature and of ultraviolet radiation on pyrene adsorbed on garden soil, A. J. Fatiadi, Environ. Sci. Technol. 1, No. 7, 570-572 (July 1967).

The chemical and photochemical changes of pyrene adsorbed on soil have been studied. It was found that pyrene adsorbed on soil and subjected to either heat or ultraviolet radiation underwent selfcoupling to $1,1^{\prime}$-bipyrene, apparently by free-radical mechanisms, this product was not found from pyrene adsorbed on a number of other particulates. Also formed in the pyrene-soil reaction were 1,6- and 1,8-pyrenediones, probably by a different reaction-path.

Key Words: Photochemical, reaction, photooxidation, particulates, polycyclic, aromatic, hydrocarbons, pyrene, 1,6- and 1,8-pyrenediones, $1,1^{\prime}$-bipyrene.

Electrolysis of nonaqueous systems, A. Brenner, Book, Advances in Electrochemistry and Electrochemical Engineering, Ed. C. W. Tobias, V, 205-248 (John Wiley \& Sons, Inc., New York, N.Y. 1967). A survey is presented of the electrodeposition from organic solutions of lithium, sodium, potassium, beryllium, magnesium, and 
aluminum. The attempts to electrodeposit the rare-earth metals are discussed. Also treated are the electrodeposition of metals from liquid ammonia and the electrolysis of essentially pure liquids, both organic and inorganic.

Key Words: Electrolysis, non-aqueous systems, electrolysis of, lithium, sodium, potassium, beryllium, magnesium, aluminum, liquid ammonia.

High purity powdered CsI as a high reflectance infrared diffuser, J. Geist, G. J. Kneissl, and V. R. Weidner, Appl. Opt. 6, No. 7, 1280-1281 (July 1967).

The spectral reflectance of powdered CsI is compared with that of flowers of sulfur between $2.5 \mu \mathrm{m}$ and $20 \mu \mathrm{m}$. The experimental procedure is described and room temperature data are presented. The reflectance of ultra pure powdered CsI was found to be appreciably higher than that of the flowers of sulfur beyond $7 \mu \mathrm{m}$.

Key Words: Body scatterer, cesium iodide, diffuse reflector, powdered cesium iodide and sulfur.

Internal friction in rutile containing $\mathrm{Ni}$ or $\mathrm{Cr}$, J. B. Wachtman, Jr., S. Spinner, W. S. Brower, T. Fridinger, and R. W. Dickson, Phys. Rev. 148, No. 2, 811-816 (Aug. 12, 1966).

Rutile containing $\mathrm{Ni}$ gives an internal-friction peak centered near $50{ }^{\circ} \mathrm{C}$ at $2 \mathrm{kHz}$ characterized by an activation energy $E=15.3 \pm 2.4$ $\mathrm{kcal} / \mathrm{mole}$ and a characteristic relaxation time $\tau_{0}=3 \times 10^{-15 \pm 1.7}$ sec; this peak occurs for tensile stress along [100] or [110]. A peak centered near $200^{\circ} \mathrm{C}$ with $E=21.4 \pm 2.1 \mathrm{kcal} / \mathrm{mole}$ and

$$
\tau_{0}=8 \times 10^{-15 \pm 1.0}
$$

sec occurs for stress along [100] but not for stress along [110]. Rutile containing $\mathrm{Cr}$ gives similar peaks characterized by $E=13.5 \pm 2.4$ $\mathrm{kcal} / \mathrm{mole}$ and $\tau_{0}=2 \times 10^{-14 \pm 1.6} \mathrm{sec}$ and by $E=22.2 \pm 1.5 \mathrm{kcal} / \mathrm{mole}$ and $\tau_{0}=4 \times 10^{-15 \pm 0.9} \mathrm{sec}$. Light reduction in vacuum decreases the amplitude of the low-temperature peak and enhances the hightemperature peak in both cases. Heavy reduction of rutile containing $\mathrm{Cr}$ removes both peaks but they reappear upon subsequent reoxidation. The evidence suggests that the motion of interstitial cations is involved and that reduction causes the formation of a compound defect. A tentative interpretation is given in terms of unpaired $\mathrm{Ni}^{3+}$ interstitials for the low-temperature peak and of interstitial pairs composed of $\mathrm{Ni}^{3+}-\mathrm{Ti}^{3+}$ for the high-temperature peak in $\mathrm{Ni}$ doped specimens; the corresponding peaks in Cr-doped rutile are tentatively interpreted in terms of $\mathrm{Ti}^{4+}$ interstitials and of interstitial pairs consisting of $\mathrm{Ti}^{4+-} \mathrm{Ti}^{3+}$. It is possible to have two chargecompensating $\mathrm{Cr}^{3+}$ on adjacent substitutional sites and preserve the last two models.

Key Words: Activation energy, internal friction, point defect, reduction, rutile, symmetry conditions.

Electron probe microanalysis, K. F. J. Heinrich, Book, Experimental Methods of Materials Research. Advances in Materials Research 1, 145-162, (John Wiley \& Sons, Inc., New York, N.Y. 1967).

This paper introduces the reader to the principles and techniques of electron probe microanalysis. After a brief description of the instrument, the characteristics of probe analysis, such as range of elements, spatial resolution, sensitivity, and conditions necessary for the specimen, are discussed. The corrections to be applied in quantitative analysis are enumerated and explained. Several signal evaluation systems, particularly for scanning microprobe analysis, are described, including the use of signals other than x-rays. The fields of application are briefly indicated.

Key Words: Characteristics of probe analysis, electron microanalysis, electron probe microanalysis, microanalysis, electron probe, probe.

Extraction-spectrophotometric determination of antimony as a ternary complex, R. W. Burke and O. Menis, Anal. Chem. 38, p. 1719 (Nov. 1966).

A critical examination is presented of the many parameters associated with the extraction-spectrophotometric determination of $\mathrm{Sb}^{+5}$ as the ternary chloro complex of brilliant green, a triphenylmethane dye. The basic problem of dissolving the sample without residue problems and without volatilization of antimony is also dis- cussed. A sealed tube dissolution procedure yields only $\mathrm{Sb}^{+3}$, the requisite form. The step-wise reactions that may preclude the formation of the colored complex are discussed in terms of the interaction of the following variables: Oxidation and hydrolysis mechanism, spectral dependency on final choice of oxidant, role of $\mathrm{H}^{+}$ and $\mathrm{Cl}^{-}$in the oxidation-extraction steps, the side reaction due to impurities in the dye, and the extraction characteristics of the ternary complex. The method has been applied to the analysis of both ferrous and non-ferrous standard reference materials with good success. The coefficient of variation is 2 percent.

Key Words: Extraction-spectrophotometric, antimony, brilliant green, sealed tube dissolution, mechanism, dye impurity, ferrous and non-ferrous alloys.

Gas phase photolysis and radiolysis of methane. Formation of hydrogen and ethylene, R. Gorden, Jr. and P. Ausloos, J. Chem. Phys. 46, No. 12, 4823-4833 (June 15, 1967).

The photolysis of $\mathrm{CH}_{4}$ and of $\mathrm{CH}_{4}-\mathrm{CD}_{4}$ mixtures has been investigated at $1236 \AA(10.0 \mathrm{eV})$ and at $1048-67 \AA(11.5-11.8 \mathrm{eV})$. The excited methane molecule dissociates to form $\mathrm{H}_{2}, \mathrm{H}, \mathrm{CH}_{3}, \mathrm{CH}_{2}$, $\mathrm{CH}$ and probably also $\mathrm{C}$. The $\mathrm{CH}$ and $\mathrm{CH}_{2}$ radicals insert into methane to form internally excited $\mathrm{C}_{2} \mathrm{H}_{5}{ }^{*}$ and $\mathrm{C}_{2} \mathrm{H}_{6}{ }^{*}$ species, respectively. Below one atmosphere all $\mathrm{C}_{2} \mathrm{H}_{5}$ radicals decompose to form $\mathrm{C}_{2} \mathrm{H}_{4}$, while the ethane molecules are partially stabilized. The relative quantum yield of $\mathrm{CH}$ increases about three-fold when the wavelength is reduced from $1236 \AA$ to $1048-67 \AA$. On the basis of an isotopic analysis of the hydrogen produced in the photolysis of $\mathrm{CD}_{4}-$ $\mathrm{H}_{2} \mathrm{~S}$ mixtures, it is concluded that at $1236 \AA$, D-atoms constitute at least 65 percent of the "molecular" deuterium yield.

In the radiolysis, ethylene is largely, although not exclusively formed by the insertion of $\mathrm{CH}$ into methane. It is demonstrated that addition of small concentrations of an unsaturated hydrocarbon to methane profoundly affects the ion-molecule reaction mechanism and, therefore, does not lead to a dependable value of the "initial" ethylene yield as suggested in earlier studies. Upon application of an electrical field, the production of $\mathrm{CH}$ and $\mathrm{CH}_{2}$ is augmented in the saturation current region. The importance of the latter two radicals in the direct and rare gas sensitized radiolysis is examined briefly. The formation of hydrogen in the radiolysis will be discussed on the basis of new information derived from $\mathrm{CD}_{4}-\mathrm{H}_{2} \mathrm{~S}$ experiments.

Key Words: Photolysis, radiolysis, free radical reactions, ionmolecule reactions.

Laser probe excitation in spectrochemical analysis. I. Characteristics of the source, S. D. Rasberry, B. F. Scribner, and M. Margoshes, Appl. Opt. 6, No. 1,81-86 (Jan. 1967).

A laser probe for spectrochemical anslysis is described. A high energy laser beam is focused onto a specimen to vaporize a sample from a small area, and the vapor thus formed is further excited by a spark discharge. The characteristics of emission spectra with and without auxiliary spark excitation are compared. Spectrograph illuminating-systems for qualitative and quantitative analysis were investigated. Some difficulties were encountered with the laser probe, and modifications were made to the instrument to alleviate some of these problems. Some typical analytical applications are discussed.

Key Words: Laser probe, qualitative, laser vaporization, Q-switched ruby laser, spectrochemical, high energy, spark excitation, illuminating system, analysis, high power, emission, emission spectra.

Laser probe excitation in spectrochemical analysis. II. Investigation of quantitative aspects, $S$. D. Rasberry, B. F. Scribner, and M. Margoshes, Appl. Opt. 6, No. 1, 87-93 (Jan. 1967).

A study has been made of quantitative analysis by a laser probe with spark excitation of the sample vapor. Random errors come largely from variations in laser energy and from photometric errors. The parameters of the spark circuit affect the line intensities; however, these factors are well controlled. Correlations have been established between the energy of the laser beam, the size of the pit formed, and spectral intensities. Single-spike laser operation has been found to be preferable for most purposes to multiple-spike operation. At present, the coefficients of variation for analysis are 15 to $40 \%$.

Key Words: Laser probe, spectrochemical analysis, quantitative, laser vaporization, spark excitation, high energy, high power, pit 
volume, spectral intensity, spark, photographic emulsion, Q-switched ruby laser.

pH determination, R. G. Bates, Encyclopedia of Industrial Chemical Analysis 3, 146-161 (John Wiley \& Sons, Inc., New York, N.Y. 1966).

Procedures for the determination of $p \mathrm{H}$ by both electrometric and indicator methods are set forth. The NBS reference standard solutions are described. Other topics discussed include the limitations of measured $p \mathrm{H}$ values, glass electrodes and reference electrodes, $p \mathrm{H}$ instrumentation, temperature effects, and the special requirements of industrial $p \mathrm{H}$ control.

Key Words: Glass electrodes, industrial analysis, $p \mathrm{H}$ determination, $p \mathrm{H}$ instrumentation, reference electrodes, temperature effect.

Surface studies of natural and synthetic bone mineral teeth, W. V. Loebenstein, (Proc. 2nd Workshop, Adhesive Restorative Dental Materials, University of Virginia, Charlottesville, Va., Dec. 8-9, 1965), Book, Adhesive Restorative Dental Materials, ch. $I V$. Surface Measurements-Synthesis and Evaluation of Dental Adhesives, pp. 213-223 (Dept. of Health, Education, and Welfare, Washington, D.C. 1966).

Low temperature nitrogen adsorption measurements have been performed using dentin and bone as well as synthetic calcium phosphate preparations. Surface areas ranging from about $1 \frac{1 / 2}{2}$ to nearly $150 \mathrm{~m}^{2} \cdot \mathrm{g}^{-1}$ have been found. Pore size distribution calculated from the isotherm data shows promise of being a valuable and sensitive tool for aiding in the comparison of crystallographic forms and for detection of subtle changes in structure not measurable by other means presently in use. The pore structure of bone mineral in the range 20-300 $\AA$ appears to be entirely independent of the collagen matrix.

Key Words: Adsorption, surface chemistry, pore size dsitribution, surface area, teeth, bone, hydroxyapatite, calcium phosphate, octacalcium phosphate, pore volume, anorganic bone mineral and dentin.

Testing scouring powder abrasion, W. C. Wolfe, Detergent Age 2, No. 10, p. 22 (Mar. 1966).

Five leading brands of household scouring powders were examined in order to establish a formulation for testing the abrasion or wear resistance of sanitary plumbing fixtures. A test abrasive of known composition and representative of commercial products was desired. The products examined all contained sodium dodecylbenzenesulfonate as the detergent, usually chlorine bleach, sometimes bactericide, and about 90 percent by weight of abrasive. The abrasive, in each case, was fine quartz powder, mostly less than 44 microns particle size, but containing some particles between 149 and 250 microns in diameter, which might scratch porcelain enamel or plastic.

Key Words: Abrasives, bathtubs, cleansers, detergents, particle, plumbing, plastic, porcelain, sieve, silica, sinks.

The estimation of molecular weights of vinyl acetate copolymers in latex paints, H. W. Berger, J. Paint Technol. 39, No. 508, 310-315 (May 1967).

A viscometric technique has been used for the estimation of the molecular weights of vinyl acetate copolymers used in manufacturing latex paints. The whole paint is diluted with boiling acetone and the dissolved polymer is separated from pigments by centrifuging. The intrinsic viscosity, $\lceil\eta]$, of the polymer in acetone at $25^{\circ} \mathrm{C}$ is obtained and used to calculate a quantity related to the molecular weight. The various values for $a$ and $K$, the constants in the Mark-Houwink Equation, that have been reported in the literature for PVA in acetone are used empirically to derive the equation, $\log \bar{M}=1.45 \log [\eta]+5.521$. This equation is used as the basis for the estimation of the molecular weights of PVA copolymers in experimental latex emulsions, experimental paints formulated with those latexes, and proprietary paints.

Key Words: Copolymer, intrinsic viscosity, latex, Mark-Houwink, molecular weight, polymer, polyvinyl acetate.

The National Standard Reference Data System program in atomic and molecular properties, S. A. Rossmassler, (Proc. Symp. Compilations of Data on Chemical and Physical Properties of Substances, 152nd National Meeting, Am. Chem. Soc., New York, N.Y., Sept. 12, 1966) J. Chem. Doc. 7, No. 1, 15-18 (Feb. 1967).

In general, atomic and molecular properties are taken to mean properties primarily characteristic of the individual atoms or molecules rather than of any system or state of aggregation. For operational convenience, the area includes also certain general and fundamental physical constants.

An Advisory Panel listed sixty-three specific properties and gave high priority to twenty-eight of these. The Office of Standard Reference Data is supporting or monitoring sixteen projects which are concerned with fourteen of these high priority topics. Most of the projects are continuing ones. Five of the activities perform data center or information center functions.

In several cases, joint support or cooperative programs have been developed, and we are seeking to extend this type of activity.

To provide reasonable current coverage of the general area, the number of projects should be doubled (high priority topics only) or trebled, (high priority plus related moderate priority topics) as rapidly as possible. Projects being initiated in other countries (cf. next paper by R.M.S. Hall) are already assuming some of this burden. Ten compilations of data and a similar number of bibliographies and secondary publications will have appeared by the end of calendar year 1966.

Key Words: Atomic, molecular, properties, data, compilation, data center.

The radiation-induced copolymerization of tetrafluoroethylene and 3,3,3-trifluoropropene at high pressure, D. W. Brown and L. A. Wall, (Proc. Symp. Compilations of Data on Chemical and Physical Properties of Substances, 152nd National Meeting, Polymer Preprint 7, No. 2, 1116-1132, (Sept. 1966).

A study was made of the gamma-ray induced copolymerization of tetrafluoroethylene (TFE) and 3,3,3-trifluoropropene (TFP). Copolymerizations were carried out at $100{ }^{\circ} \mathrm{C}$ and $5000 \mathrm{~atm}$ pressure and at $21{ }^{\circ} \mathrm{C}$ and various pressures up to $8000 \mathrm{~atm}$. The reactivity ratios calculated from the composition data indicate that the propagation rate constants favor addition of TFP by a factor of three to seven; individual values depended little on the polymerization pressure and temperature. Polymerization rates changed little with monomer composition between zero and $75 \%$ TFE; between 75 and $95 \%$ TFE they increased by a factor of ten. As many as 850,000 (molecules) were polymerized per 100 electron volts absorbed.

The copolymers are soluble in hexafluorobenzene at $29.6^{\circ} \mathrm{C}$ if they contain less than $70 \%$ TFE. Intrinsic viscosities range from 0.1 to about $10 \mathrm{dal} / \mathrm{g}$. From various considerations it appears likely that the degree of polymeriztion is about equal to the kinetic chain length in high pressure polymerizations at $21{ }^{\circ} \mathrm{C}$; at autogenous pressure or at $5000 \mathrm{~atm}$ and $100{ }^{\circ} \mathrm{C}$ monomer transfer reduces the value considerably.

Key Words: Tetrafluoroethylene, trifluoropropene, copolymerization, pressure, radiation, reactivity ratios.

A dual frequency VLF timing system, L. Fey and C. H. Looney, IEEE Trans. Instr. Meas. IM-15, No. 4, 190-195 (Dec. 1966).

The use of high precision portable clocks and radio signals is discussed in relation to synchronization of remotely located clocks. The demonstrated inherent phase stability, approximately two $\mu \mathrm{s}$ rms, of very-low frequency (VLF) propagation and its low attenuation rate with distance, have led to various approaches to exploit these virtues in timing applications. The system considered here employs two carrier frequencies with timing information contained in their difference frequency to permit identification of a specific cycle of one of the carrier frequencies. Such a system makes stringent demands on phase stabilities of the transmitted signals and of the receiving system as well as that of the propagation medium itself. The present system, whose development has been supported jointly by NBS and NASA, makes use of NBS radio station WWVL at Fort Collins, Colorado. Receivers are of the standard VLF phase tracking servo type. A special signal generator is used in conjunction with the local clock to simulate the transmitted signal in order to relate the local time scale to that at the transmitter.

One of the carrier frequencies is maintained at $20 \mathrm{kHz}$. With a second frequency $(500 \mathrm{~Hz}$ removed from this frequency), carrier cycle identification was achieved on about 90 percent of the days for over a month on the path from Fort Collins, Colorado, to Greenbelt, Maryland. Since January 4, 1966, the difference frequency has 
been $100 \mathrm{~Hz}$, with somewhat more fluctuation in results. However, lower precision is required for the initial synchronization. The results of averaging to improve this performance will be discussed.

Key Words: Worldwide clock synchronization; VLF propagation; portable clock; multiple VLF transmissions; standard time broadcasts.

An analysis of low information rate time control unit, L. Fey, J. A. Barnes, and D. W. Allan, Proc. 20th Annual Symp. Frequency Control, Atlantic City, N.J., Apr. 19-21, 1966 pp. 629-635 (1966).

Computer simulation has been used to study the feasibility of producing a synchronized time station requiring minimum attention to operate.

The device simulated consists of a multiloop servo system to correct the output phase of a quartz crystal oscillator and to simultaneously compensate for the linear frequency drift common to these oscillators. Upon the occurrence of an occasional phase comparison, such as propagated from VLF transmission during the time of day when propagation conditions are most stable, the servo incorporates a resulting phase correction and establishes a new linear frequency drift compensation rate based on the past history of the oscillatorallowing extrapolation of the phase of the reference signal until the next phase comparison occurs. This in effect results in a remote, phase locked system operating automatically with an intermittant reference.

The effect on such a system of flicker noise modulation, the characteristic type of noise associated with quartz crystal oscillators in the domain of interest, is treated, along with servo system time constant considerations.

The use of such a system is discussed in relation to applications such as unmanned standard time and frequency stations, meteor burst synchronization, and the operation of atomic time scales with intermittant frequency calibrations. From available data, one anticipates a synchronization precision of 1 microsecond at stations as remote as 1,500 kilometers using the meteor burst technique. The system would be both low in initial cost and in operation.

Key Words: Time synchronization, flicker noise, multi-loop servo, VLF propagation, meteor burst, oscillator correction.

An equation for the local thermal emissivity at the vertex of a diffuse conical or $\mathrm{V}$-groove cavity, F. J. Kelly, Appl. Opt. 5, 925-927 (June 1966).

An exact, closed-form expression is derived for the apparent local emissivity at the vertex of a diffuse conical or $V$-groove cavity. This expression is obtained by a substitution into an approximate equation for the apparent local emissivity of a point within a cavity of any shape. The exact expression depends only on the emissivity of the cavity wall material and the angle factor between the point at the cavity vertex and the cavity opening. Agreement is very good between the values predicted by the expression and those obtained from a numerical solution of the integral equation characteristic of a diffuse conical cavity.

Key Words: Diffuse conical or V-groove cavity, emissivity, vertex of a diffused conical or $V$-groove cavity, equation, apparent local emissivity, V-groove cavity, vertex of a diffused conical or $V$-groove cavity.

A precision current comparator, C. M. Allred and R. A. Lawton (Proc. Annual ISA Conf., New York, N.Y., Oct. 1966), ISA Preprint No. 12. 8-2-66 (Oct. 1966).

A technique capable of precise comparison of currents in different parts of a network or between currents in different networks is discussed. With proper conditions, this comparison can be done with negligible perturbation of the networks under measurement.

Experiments on a coaxial system at $30 \mathrm{MHz}$ are discussed.

Key Words: Antenna, attenuation, comparator, current, phase, precision.

Impedance measurements in coaxial waveguide systems, R. L. Jesch and R. M. Jickling, Proc. IEEE 55, No. 6, 912-923 (June 1967).

This article is a tutorial review of impedance measurements and standards in coaxial waveguide systems propagating a TEM wave. It describes the development of coaxial air lines as impedance standards, reviews representative measurement methods, and discusses the errors and measurement techniques of the slotted line in detail. A list of selected references to pertinent literature is included.

Key Words: Impedance, waveguide, transmission line, standards, coaxial, measurements, air lines.

International comparison of high frequency electromagnetic quantities, M. C. Selby, Proc. IEEE 55, No. 6, 745-747 (June 1967).

Activities to establish international agreement on measurements of high frequency electrical quantities have been in progress since 1957 at the initiative of the URSI (International Radio Scientific Union) and the International Committee of Weights and Measures (CIPM). Results accomplished and the overall up-to-date status are presented.

Key Words: Electrical quantities at high frequencies, measurement of high frequency electrical measurements, international agreement on electromagnetic measurements.

Field strength above $1 \mathrm{GHz}$ : Measurement procedures for standard antennas, R. R. Bowman, Proc. IEEE 55, No. 6, 981990 (June 1967).

To calibrate antennas for state-of-art field strength measurements, standard horns are needed with gain uncertainties well within $\pm 0.1 \mathrm{~dB}$. To attain this degree of accuracy for absolute gain measurements, the two-antenna method is recommended. This method is considered to be essentially an insertion loss measurement (with many additional problems and sources of error), and a working formula is derived that is suitable for gain measurements of high accuracy. The problems that appear to be most limiting in gain measurements, insufficient antenna separation and multi-path interference, are chosen for detailed discussion. (The discussion concerning multi-path interference has application to anechoic chamber evaluations and radar cross-section measurements as well as to gain measurements). It is concluded that error estimates of less than $\pm 0.1 \mathrm{~dB}$ for horm gain measurements have been somewhat optimistic. Several ambiguities and sources of error have been overlooked or inadequately discussed, and additional discussion is presented to provide a more complete basis for horn gain measurements of high accuracy.

Key Words: Field strength, high accuracy gain measurements, horn antennas, two-antenna method, gain corrections, multi-path interference, antenna range design.

Impedance measurements and standards for uniconductor waveguide, R. W. Beatty, Proc. IEEE 55, No. 6, 933-941 (June 1967).

A tutorial review is presented of the measurement of impedance and reflection coefficient in uniconductor waveguide. Impedance in a waveguide operating in a particular mode is defined and related to measured quantities such as the reflection coefficient and the VSWR.

Emphasis is given to the rectangular waveguide operating in its dominant mode and to the tuned reflectometer as an instrument for achieving the most accurate results. The evolution of the tuned reflectometer at NBS is outlined and recent techniques are discussed. Different types of standards of reflection coefficient are described and the advantages and limitations of each are mentioned.

Key Words: Impedance standard, reflection coefficient, reflectometers, standing-wave ratio, waveguide impedance.

Conference on burns and flame retardant fabrics, December 1966, New York, N.Y., A. F. Robertson, Fire Res. Abst. Rev. 9 , No. 2, 119-122 (1967).

A summary is presented of subject meeting which was held on 2 and 3 December 1966.

Key Words: Fire-retardant clothing, retardant treated fabrics, flame resistance, clothing, fire, accidents, clothing fires, burn injuries.

Doors as barriers to fire and smoke, H. Shoub and D. Gross, Proc. Symp. Fire Testing, Lancaster, Pa., June 24-25, 1965, pp. I-1-I-10 (Armstrong Cork Co., Lancaster, Pa., 1965). 
A study was made of means for improving dwelling unit entrance doors as fire and smoke barriers. Existing combustible doors and frames could be modified to enhance their fire resistance, but it did not appear practical to raise them to the level of rated commercial fire door assemblies. Fire retardant paints, except those consisting of heavy, reinforced, intumescent-type coatings, provided little or no increase in fire resistance.

Several modifications of existing doors were not effective in preventing the transmission of smoke. However, controlling the pressure levels on both sides of a door, as by suitable venting, appeared to offer a means of reducing smoke penetration into an area.

It is recommended that current methods of fire tests of doors, and criteria relating to their fire and smoke transmission be improved.

Key Words: Doors, dwelling, dwelling unit entrance doors, fire and smoke barriers.

Calorimetric measurement of pulsed laser output energy, D. A. Jennings, IEEE Trans. Instr. Meas. IM-15, No. 4, 161-164 (Dec. 1966).

One of the important parameters of pulsed laser systems is their output energy. The application of pulsed lasers requires knowing this output energy with varying degrees of accuracy depending on the application. There are several methods by which one may measure the energy output of the laser. However, the technique which seems to be promising as far as accuracy and precision are concerned is the calorimetric method. We have designed, built, and calibrated calorimeters for measuring the output energy of the pulsed ruby laser $(6943 \AA)$. The heart of the calorimeter is a small absorption cell containing an aqueous solution of $\mathrm{CuSO}_{4}$. The temperature of the absorption cell, as measured by a thermocouple, indicates the energy absorbed by the calorimeter. The calorimeter was calibrated in two different ways: (1) The known heat capacity of the absorption cell and the thermocouple sensitivity calibration gives a calorimeter calibration which agrees within 0.3 percent or 2) an electrical energy substitution calibration which is obtained via a heater wire contained in the absorption cell solution. A method has been devised by which two calorimeters may be intercompared. Calorimeters which we have built and calibrated agree with each other to about 0.7 percent. This specific calorimeter has been designed to measure energies up to 30 "Joules" and will take peak powers of up to $200 \mathrm{MW} / \mathrm{cm}^{2}$.

Key Words: Laser, calorimeter, energy, measurement.

Long-time effects of humidity change on the dielectric properties of certain polymers, A. H. Scott and W. P. Harris, (Proc. 1962 Annual Report Conf. Electrical Insulation, Hershey, Pa., Oct. 15-17, 1962), Natl. Acad. Sci.-Natl. Res. Council Publ. $1080, \mathrm{pp} .41-44$ (1963).

The results of a study of the long-time effects of humidity change on the dielectric properties are given for three materials, polyethylene, polystyrene, and polycarbonate. The polyethylene and polystyrene specimens were disks about $4 \mathrm{~cm}$. in diameter with gold electrodes. Measurements on polycarbonate specimens were made using the air-gap method without contact electrodes. The electrical properties of some specimens were still changing at the end of three years. The results are given in the form of graphs.

Key Words: Dielectric properties of certain polymers, humidity change, polycarbonate, polyethylene, polystyrene, properties of certain polymers, polymers.

Lumped parameter impedance measurements, L. E. Huntley and R. N. Jones, Proc. IEEE 55, No. 6, 900-911 (June 1967).

This paper is a tutorial presentation dealing with two and three terminal lumped parameter impedance measurements at radio frequencies. Included is a very brief historical discussion with particular emphasis upon more important recent developments such as precision coaxial connectors and coaxial air line standards. The relationship of impedance standards to standards of length and time is shown together with a discussion of instruments and measurement techniques in current use. Special attention is given to particular areas of measurement difficulty. Also included is a presentation of the state-of-the-art wherein commercial instrumentation is compared with best practices from the standpoint of accuracy. The paper concludes with comments and recommendations for improving measurement and measurement agreement.
Key Words: Capacitance, inductance, impedance and admittance, measurement, radio frequency, resistance, standards, state-of-theart.

Measurement of RF peak pulse power, P. A. Hudson, Proc. IEEE 55, No. 6, 851-855 (June 1967).

Methods for radio and microwave measurements of dielectric and magnetic properties of materials are categorized, referenced, and placed in perspective. The reference period extends to mid-1966. Measurement errors are analyzed for appropriate cases where possible.

Key Words: Review of radio materials, radio materials measurement, dielectric constant, dielectric loss, ferromagnetic resonance, permeability.

Micrometer U-tube manometers for medium vacuum measurements, A. M. Thomas and J. L. Cross, J. Vacuum Sci. Technol. 4, No. 1, 1-5 (Jan.-Feb. 1967).

A family of U-tube manometers, suitable for use as standard instruments, has been designed and constructed at the National Bureau of Standards to cover the range of pressures from 100 torr to $1 \times 10^{-2}$ torr. In these instruments the levels of the two liquid surfaces are measured by adjusting micrometers with conical points ground on the ends of the spindles. Four inch and two inch range mercury manometers, with spindles approaching the liquid surface from above, are used for differential or absolute pressure measurements up to 100 torr. Pressures less than 3.5 torr are measured with oil manometers, in which the micrometer spindles approach the surfaces from below. Measurements made with the mercury manometer have an uncertainty of about $4 \times 10^{-3}$ torr plus eight parts in one hundred thousand of the reading. Measurements made with the oil manometer have an uncertainty of about $4 \times 10^{-4}$ torr plus two parts in ten thousand of the reading.

Key Words: Vacuum measurement, manometers, U-tube, micrometer, oil, mercury, water.

NBS Field-strength standards and measurements $(30 \mathrm{~Hz}$ to $1000 \mathrm{MHz}$ ), F. M. Greene, Proc. IEEE 55, No. 6, 970-981 (June 1967).

A description is given of the various $\mathrm{CW}$ field-strength standards and associated measurement instrumentation and techniques developed over the past twenty-five or thirty years at the National Bureau of Standards. These are used for the calibration of both commercial and military field-strength meters in various frequency bands of the overall range from $30 \mathrm{~Hz}$ to $1000 \mathrm{MHz}$. The techniques used are applicable only for evaluating the strength of steady-state, ac fields varying sinusoidally in time, and are not intended for use in broadband applications of any kind.

Two principal types of field-strength standards and a prototype near-zone field-strength meter are described. These are as follows: (a) Magnetic-Field-Strength Standards used over the frequency range $30 \mathrm{~Hz}$ to $30 \mathrm{MHz}$ for the calibration of CW field-strength meters employing small-loop receiving antennas;

(b) Electric-Field-Strength Standards used over the frequency range 30 to $1000 \mathrm{MHz}$ for the calibration of $\mathrm{CW}$ field-strength meters employing half-wavelength self-resonant dipole receiving antennas; and

(c) Near-Zone Electric-Field-Strength Meter and Interim FieldStrength Standards used over the frequency range $150 \mathrm{kHz}$ to 30 $\mathrm{MHz}$ for the evaluation of hazards of high-level electromagnetic radiation to ordnance devices and other uses.

Key Words: Magnetic-field-strength standards, electric-field-strength standards, near-zone electric-field-strength standards, calibration of field-strength meters, standard-field calibration method, standardantenna calibration method.

Peak pulse voltage measurement (baseband pulses), A. R. Ondrejka, Proc. IEEE 55, No. 6, 882-885 (June 1967).

Several methods are presently being used for the measurement of pulse voltage. Oscilloscopes are particularly useful because they provide information concerning the shape of the pulse, besides a measure of the peak voltage. Besides the oscilloscope, several peak voltmeter circuits are mentioned. These include pulse stretching, sampling, and the slideback method. A standard pulse generator 
is described which provides a calibrated pulse voltage suitable for voltmeter calibration and other uses.

Key Words: Oscilloscope, peak voltage, pulse, sampling, slideback, standard.

Physical and performance properties of leather, J. R. Kanagy, Book, The Chemistry and Technology of Leather, 4, ch. 64, 369-416 (Reinhold Publ. Corp., New York, N.Y., 1965).

This chapter gives an outline of the properties of leather including both strength and mechanical properties such as compressibility and flexing. In addition its value as an insulator and its stability to temperature and atmospheric conditions are discussed. The nature of the hide is described with regard to fiber structure and chemical composition in order to give a better understanding of its properties and indicate how it might be modified. The information should be useful in developing further uses for leather and to stimulate further research in the study of its properties.

Key Words: Physical properties, mechanical properties, fiber structure, stability, insulator leather, hide.

Precision coaxial connectors in lumped parameter immittance measurements, R. N. Jones and L. E. Huntley, IEEE Trans. Instr. Meas. IM-15, No. 4, 375-380 (Dec. 1966).

Amid the concern surrounding the design and application of precision coaxial connectors for use in precise electrical measurements there is one area which has received very little attention. This has to do with the application of such connectors to measurements in the lumped-parameter region. This paper points out significant sources of error in lumped-parameter measurements which are attributable to connector uncertainties and shows how they can be greatly reduced through the application of precision coaxial connectors. Where these connectors are utilized in lumped-parameter immittance measurements, extensions of frequency, magnitude and accuracy are realized. Specific examples are discussed.

Key Words: Immittance, precision, lumped-parameter, measurement, coaxial, connectors, radio frequency.

Progress in the development of a thermal-shock-resistance factor for bituminous built-up roofing, W. C. Cullen and T. H. Boone, ASTM Spec. Tech. Publ. 409, 151-161 (Apr. 1967).

The resistance of bituminous built-up roofing membranes to thermally induced forces is considered in terms of their strength properties such as breaking load in tension, modulus of elongation and apparent linear thermal expansion coefficient. The development of a thermal-shock resistance factor is described and values are given for three bituminous built-up membranes at temperatures of $-30{ }^{\circ} \mathrm{F}\left(-34.4{ }^{\circ} \mathrm{C}\right), 0{ }^{\circ} \mathrm{F}\left(-17.8^{\circ} \mathrm{C}\right), 30^{\circ} \mathrm{F}\left(-1.1^{\circ} \mathrm{C}\right)$ and $73^{\circ} \mathrm{F}(22.8$ $\left.{ }^{\circ} \mathrm{C}\right)$. The apparent relation between the values obtained in the laboratory and the observed performance of roofing membranes in service is considered. The utilization of the thermal-shock resistance factor in the reduction of potential failures of bituminous built-up roofing membranes in service from thermally induced forces is also discussed.

Key Words: Development, roofing membrane, strength properties, thermally induced forces, thermal-shock resistance factor.

Radio frequency power measurements, A. Y. Rumfelt and L. B. Elwell, Proc. IEEE 55, No. 6, 837-850 (June 1967).

The need for improved accuracy in and understanding of all kinds of measurements has come with the recent rapid advances in modern technology. RF power measurement, the subject of this paper, is no exception to this requirement. The basic principles of bolometric, calorimetric, and certain other types of power meters are reviewed. The methods for making accurate $\mathrm{RF}$ power measurements are discussed in detail. Emphasis is given to the techniques for eliminating or accounting for the errors due to mismatch, de or LF substitution, and bolometer mount efficiency.

Key Words: Power meter, power measurement, mismatch error, substitution error, bolometer mount efficiency.

RF attenuation, D. H. Russell and W. Larson, Proc. IEEE 55, No. 6, 942-959 (June 1967).
A tutorial review of $r-f$ attenuation measurement methods and standards is presented.

Accepted and proposed definitions and attenuator models are discussed. Commonly used standards operating from d-c through most waveguide bands are compared with the "ideal" interlaboratory standard. Characteristics of fixed resistive, waveguide belowcutoff and rotary-vane standards are included.

Measurement methods are classified and described including comments concerning convenience and accuracy of various methods, and references are given which cover most of the basic and important research in the field.

Key Words: Attenuation, measurements, standards, coaxial, waveguide.

RF measurements of the speed of light, R. C. Baird, Proc. IEEE 55, No. 6, 1032-1039 (June 1967).

Modern RF measurements of the velocity of light are reviewed, with emphasis on those methods capable of attaining an accuracy of $1.0 \mathrm{~km} / \mathrm{s}$ or better. The geodimeter and microwave interferometer methods are discussed in some detail because of the significant role they have played in arriving at our present value for $c$. Serious limitations of the microwave resonant cavity method are pointed out and brief mention is made of the electrical units and band spectrum methods. A recent measurement by Karolus and Helmberger, who obtained the value $299792.1 \pm 0.2 \mathrm{~km} / \mathrm{s}$, is mentioned. Some experimental factors that should be considered in planning future velocity of light measurements are presented, and an experiment involving lasers, now in progress at NBS, is described briefly. The conclusion is that the presently accepted value of $299792 \pm 0.3 \mathrm{~km} / \mathrm{s}$ is still valid. Only two or three measurements have been completed since its adoption nearly ten years ago and they are not of sufficient accuracy to warrant a reevaluation of $c$.

Key Words: Velocity of light, review, methods and limitations, recent results.

Sampling of leather for physical and chemical examination, J. Mandel and J. R. Kanagy, Book, The Chemistry and Technology of Leather 4, ch. 59, 223-242 (Reinhold Publ. Corp., New York, N.Y. 1965)

A presentation of some general principles of sampling, with application to the sampling of leather.

The topics discussed in this chapter include:

1. General statistical principles of sampling: effect of sample size and of lot size;

2. formulas for the determination of sample size:

3. the selection of a sampling location on a leather side:

4. tables of the variability of physical and chemical tests between locations and between hides:

5. acceptance sampling; and

6 . a survey of the literature.

Key Words: Sampling, Leather, quality control, statistics, test variability, acceptance sampling.

Standards for galvanomagnetic devices, S. Rubin (Proc. Committee on Hall Effect Applications, Cambridge, Mass., Nov. 8-9, 1965), Book, Solid State Electronics 9, No. 65, 559-566 (Pergamon Press, Inc., New York, N.Y., 1966).

A summary is given of existing and "in-process" standards for galvanomagnetic devices. Controversial items in the IEC standard for Hall effect devices, 47(Secretariat)196, May 1965, are reviewed, and note is made of USA and Japanese comments on this document. Items in the USA document, 47(USA), September 1965, commenting on 47 (Secretariat)196, are reviewed, and particular emphasis is given to items relating to linearity error, particularly as a percent of reading, to residual voltages, and to sensitivity indices.

A summary of items in an "in-process" document for "Standard Definitions and Terminology for Magnetoresistive Devices," is given. The concept of compatibility between definitions for flux and temperature sensitive resistors (i.e., magnetoresistors, thermistors, and photoresistors) is introduced. Some overlapping areas of application are noted. The linear input-output characteristics obtainable from a device which has a square law characteristic is noted and appropriate definitions for both characteristics are introduced. Copies of four documents dealing with standard terminology and definitions for Hall effect devices are included as appendices. 
Key Words: Hall effect device, magnetoresistive device, magnetoresistor, Hall element, standard terminology, galvanomagnetic device.

Some accuracy limiting effects in an atomic beam frequency standard, R. J. Harrach, Proc. 20th Annual Symp. Frequency Control, Atlantic City, N.J., Apr. 19-21, 1966, pp. 424-435 (1966).

The accurate resonance frequency of the transition

$$
\left(\mathrm{F}, \mathrm{M}_{\mathrm{F}}\right)=(4,0) \leftrightarrow(3,0)
$$

in the ground state of cesium-133 is expressed in the form of an operational equation for an atomic beam spectrometer. Emphasized are the terms in this equation which correct for the beam direction dependence and radiation field dependence of measured resonance frequencies: $1 / 2\left(\nu_{\text {res }_{i}}\left(P_{1}\right)+\nu_{\text {res }_{j}}\left(P_{1}\right)\right)-1 / 2\left(S_{i}+S_{j}\right) P_{1}$, where $i$ and $j$ refer to opposite beam directions through the apparatus, $P_{1}$ is the microwave power exciting the transition, and $S_{i}$ and $S_{j}$ are rates of linear frequency shift. The results of a detailed theoretical analysis are given which specify the contribuicions to these terms by various apparatus and fundamental shift-inducing effects.

This approach to accuracy specification is applied to the United States frequency standard, a National Bureau of Standards atomic beam machine designated NBS III, through a set of experiments using an atomic hydrogen maser as a highly stable reference frequency source. The corrections determined are $-3.2 \times 10^{-12}$ for beam direction dependence, $-2.2 \times 10^{-12}$ for power dependence and $+0.4 \times 10^{-12}$ for second-order Doppler shift. The uncertainties in these corrections and contributions from other sources give a present $1 \sigma$ estimate of accuracy capability of $\pm 1.1 \times 10^{-12}$ for NBS III. This figure should be reducible by one order of magnitude through efforts to eliminate systematic errors in the measurements of $\nu_{\mathrm{res}_{i}}$ and $\nu_{\mathrm{res}_{j}}$.

Key Words: Accuracy, cesium beam, frequency shifts, frequency standard.

Superconducting devices, T. M. Flynn and K. D. Timmerhaus (Proc. Intern. Inst. Refrigeration Meeting of Comm. 1, Boulder, Colo., June 15-17, 1966), Book, Liquid Helium Technology, Bull. IIR Annexe 1966-5, pp. 459-490 (Paris, France, 1967).

Superconductors may be treated as engineering materials having three unusual properties: (1) a transition occurs between two different states which depends upon external parameters, (2) zero resistivity is exhibited in one state, and (3) perfect diamagnetism is exhibited.

This paper views superconductors in this way, as engineering materials, and examines applications of these properties. Examples include applications of superconductors to thermometry, bolometery, level gauging, rectifiers, magnets (briefly), bearings, motors, electron microscope lenses, and a helium pump.

Key Words: Bearings, bolometer, electron microscope, helium, hydrogen, level gauging, liquid level, magnet, motor, pump, rectifier, solenoid, superconductivity, switch, temperature, thermometer.

The Measurement of baseband pulse risetimes of less than $10^{-9}$ seconds, N. S. Nahman, Proc. IEEE 55, No. 6, 855-864 (June 1967).

This is a review paper dealing with the measurement of fractional nanosecond pulse rise time in which the following subjects are discussed: oscillographic systems, pulse comparison techniques, a basic instrumentation system, and the distortion of pulses by transmission lines. Extensive references are provided. Included in the discussion is a delineation of equivalent time oscillographic sampling systems and a classification into three sampling categories: sequen tial, random, and multiple. Also considered are single transient oscil lographic systems employing either traveling wave deflection structure cathode ray tubes or multiple sampling methods. In order to clearly present the rise time limitations caused by TEM transmission lines, attention is given to the distortion incurred by pulses upon passing through such lines. Some suggestions and predictions relating to future work are presented.

Key Words: Baseband pulse rise-times, basic instrumentation system, fractional nanoseconds pulse rise-times, oscillographic systems, pulse comparison techniques, pulse rise-times.
The measurement of current at radio frequencies, W. W Scott, Jr. and N. V. Frederick, Proc. IEEE 55, No. 6, 886-891 (June 1967).

The state-of-the-art of radio-frequency current measurements is reviewed with emphasis on what the authors consider are the most useful current standards. In particular, thermocouple and electrodynamic ammeters are discussed in detail. Reference is made to photoammeters, air thermometer ammeters, and other types of current measuring apparatus, some of which deserve additional development. Extensive referencing is included for the convenience of investigators interested in an intensive review of radio-frequency current measurements.

Key Words: Ammeter, calibration, current, electrodynamic, measurement, radio-frequency, standards, thermocouple.

The role of the CCRL, J. R. Dise, Construct. Specifier 20, 54-60 (June 1967).

The history and methods of operation of the Cement and Concrete Reference Laboratory are described together with the benefits which can be derived from the inspection of cement and concrete testing laboratories.

Key Words: Cement and concrete testing laboratories, inspection of cement and concrete testing laboratories.

Transistorized UHF marginal oscillator and its application for the measurement of the magnetic flux density, $S$. Rubin, Proc. IEEE Letter 53, No. 9, 1249-1250 (Sept. 1965).

A transistorized marginal oscillator operating in the UHF region has been used to measure magnetic flux density in a Helmholtz coil at $17.5 \mathrm{mT}$, with an accuracy of better than a part in $10^{3}$. The instrument uses plug-in oscillator modules to simplify frequency changing. The results achieved indicate the feasibility of such a device for measurement of magnetic flux density in the 1 to $50 \mathrm{mT}$ range in industrial environments and with accuracies approaching a part in $10^{4}$.

Key Words: Density, magnetic flux, flux density, magnetic flux density, marginal oscillator, oscillator, marginal, UHF marginal oscillator.

UHF and microwave phase shift measurements, D. A. Ellerbruch, Proc. IEEE 55, No. 6, 960-969 (June 1967).

A phase shift standard, a measurement system and the techniques for determining the corresponding limit of uncertainty are all required for obtaining the phase shift characteristics of UHF and microwave components. Differential phase shift standards, measurement techniques and measurement uncertainties are all discussed in a general sense and a comprehensive bibliography is included to supplement the general discussion.

Key Words: UHF, microwave, phase shift, measurements, standards, uncertainties.

Voltage measurement at high and microwave frequencies in coaxial systems, M. C. Selby, Proc. IEEE 55, No. 6, 877-882 (June 1967).

The progress and up-to-date state of the art in measuring voltages at frequencies to $10 \mathrm{GHz}$ and higher at three accuracy echelons is briefly described. The trend toward higher frequencies in voltmeter design is indicated. Justifications for this trend are listed. Advantages of voltage measurements and standards over computation of voltages from power and impedance measurements are briefly discussed. Some pending development problems are indicated and major steps are proposed to improve the application of voltmeters at frequencies above $30 \mathrm{MHz}$.

Key Words: Voltage measurement, high frequency voltages, microwave voltages, standards of $\mathrm{rf}$ voltage.

Computer languages and their use, S. N. Alexander, Am. Mgmt. Assoc. Mgmt. Bull. 79, 8-12 (1966).

Three levels of computer programming languages are discussed in terms of their effectiveness as tools for solving the man/machine interface problem. In this respect, the least effective of the three is the assembly level language which in general is used only when maximum system performance is required. At the next level of 
effectiveness are the procedure-oriented languages such as FOR TRAN, COBOL and ALGOL. In general, these are at a level of abstraction considerably above that of machine commands, but are still not at the working level of the average application analyst. The third level, problem oriented languages, are generally much closer to the specific mode of expression used by the analyst in describing the solution to a given problem. Several examples of this type of language are given including some that make use of ordered or graphical arrangements of inputs to facilitate the external mode of expression. The paper concludes with brief discussions of software documentation and the economic aspects of software development and utilization.

Key Words: Problem-oriented languages, software usage, man/ machine interface problems, economics of software, documentation of software.

Representations of discrete groups, J. Lehner, Proc. Symp. Pure Mathematics, California Institute of Technology, Pasadena, Calif., Nov. 21-22, 1963, ch. VIII, Theory of Numbers, pp. 203-208 (American Mathematical Society, Providence, R.I., 1965).

It is shown that certain properties of a class of finitely generated abstract groups known as $F$-groups are preserved when the $F$-group is imbedded in $\operatorname{SL}(2$, reals) as a discrete matrix subgroup. Thus the abstract structure of the $F$-group determines to a certain extent the topological properties of the matrix group.

Key Words: Abstract groups, discrete groups, $F$-groups, matrix groups.

The mathematical representation of physical entities, C. H Page, IEEE Trans. Educ. E-10, No. 2, 70-74 (June 1967).

Mathematics comprises abstract operations upon abstract elements. For the application of mathematics to the sciences, we must not only know the rules for manipulating symbols, but must also define the correspondences between the mathematical abstractions and the concepts to which application is made.

Certain basic postulates about physical observables yield the structure of their mathematical representation. An understanding of this structure yields an inderstanding of measure equations, quantity equations, measurements units, abstract units, and the mathematical nature of domensional analysis. Writing equations in a dimensionally homogeneous form is often convenient, but not necessary; sometimes an inhomogeneous formulation is more useful.

Key Words: Abstract unit, angle, dimensional analysis, measurement unit, numeric, quantity calculus, quantity equation.

Noise standards, measurements, and receiver noise definitions, C. K. S. Miller, W. C. Daywitt, and M. G. Arthur, Proc. IEEE 55, No. 6, 865-877 (June 1967).

This paper covers four topics: (1) basic principles of noise measurement, (2) the switching radiometer, (3) a survey of noise sources, and (4) concepts of noise factor and noise temperature. The first section presents basic formulas used in analyzing radiometers. The second discusses the switching radiometer briefly tracing its development and usage in the standards field. The third section surveys the development of hot and cold thermal noise sources, noise diodes, and gas-discharge noise generators. The last section presents and discusses the basic definitions of receiver noise performance.

Key Words: Radiometer, noise source, noise factor, noise temperature, error analysis.

On the problems of measuring transient temperature in cryogenic fluids, C. E. Miller and T. M. Flynn, ISA Trans. 6 , No. 2, 133-138 (Apr.-June 1967).

The complex and frequently unpredictable energy exchange mechanisms that govern the dynamic behavior of cryogenic sensors makes the measurement of transient temperatures extremely difficult. Without suitable models by which to predict and evaluate sensor performance, considerable measurement errors can and do occur. The intent of this paper is simply to delineate in detail those factors which give rise to this situation. The validity of using notions based on the performance of the "ideal" thermometer for characterizing the cryogenic case is also discussed.
Key Words: Cryogenic, instrumentation, measurement, metrology, response time, sensor, temperature, thermometer, time constant.

The use of semiconductors for the study of boiling heat transfer to low temperature liquids, G. G. Harman and L. H. Gordy, Cryogenics 7, 89-92 (Apr. 1, 1967).

It is shown that semiconductors, such as silicon and germanium, can be advantageously used to study boiling heat transfer from solıds to low temperature liquids. Measurements can be made quickly and automatically. Widely different types of resistance versus tem perature characteristics can be obtained from these materials and such characteristics can influence the nature of the nucleate to film-boiling transition. Because these materials have large positive temperature coefficients of resistance, the transitions are thermally self-regulating. All heat flux data obtained from such samples lie well within normal experimental values.

Key Words: Semiconductors, cryogenic heat transfer, measurements.

Diffusion and the Kirkendall shift in binary alloys, J. R Manning, Acta. Met. 15, 817-826 (May 1967).

In alloys, the directions of successive vacancy jumps are correlated to one another. This tends to reduce the net vacancy flux in a Kirk endall shift experiment. The magnitude of the vacancy flux, in cluding correlation effects, is calculated assuming that vacancies are not bound to any particular atoms and that fluctuations in average local composition can be ignored. New equations for the in trinsic diffusion coefficients, Kirkendall shift, and interdiffusion coefficient in binary alloys are obtained. The Kirkendall shift and interdiffusion coefficient given by these equations are larger than those predicted by Darken but smaller than those obtained when vacancy correlations are neglected. The appearance of cross terms and additional diagonal terms in the general thermodynamic equations is discussed.

Key Words: Diffusion, vacancies, Kirkendall shift, diffusion co efficients, binary alloys, thermodynamic equations for diffusion.

Digital computers, E. W. Cannon, Book, Encyclopedia of Physics, Ed. R. M. Besancon, pp. 124-125 (Reinhold Publ. Corp., New York, N.Y., 1966).

A general description of analog and digital computers is provided

Key Words: Analog digital computers, computers-analog, digital computers.

Effect on chromatic aberration on the resolving power of photographic objectives, F. E. Washer, J. Opt. Soc. Am. 57, No. 5, 625-629 (May 1967).

An empirical method for the estimation of the probable resolving power of a lens affected by longitudinal chromatic aberration is discussed. Values of the resolving power at a series of values of the $f$-number are calculated for selected values of longitudinal chromatic aberration, $d_{c}$. The variation of resolving power with $f$-number is presented graphically for selected values of longitudinal chromatic aberration and relative contrast. Indication is given of a critical aperture for which the resolving power is a maximum for a given set of values of chromatic aberration and relative contrast. The variation of relative contrast with resolving power is presented graphically for several values of the $f$-number for a lens having selected amounts of longitudinal chromatic aberration. A method for predicting the resolving power of a given lens-film combination is also indicated.

Key Words: Chromatic aberration, resolving power, critical aperture, relative contrast.

Hamilton's mixed and angle characteristic functions and diffraction aberration theory, A. B. Shafer, J. Opt. Soc. Am. 57, No. 5, 630-639 (May 1967).

The use of Hamilton's mixed and angle characteristic functions in wave and diffraction aberration calculations is theoretically examined. The relation of Hamilton's mixed and angle characteristic functions to the wave aberration function is shown. From this relation a wave aberration function is derived. The mixed and angle characteristic functions as utilized in diffraction theory via the Luneberg-Debye integrals are examined. The mathematical and 
physical approximations are discussed. The use of the LunebergDebye diffraction integrals for image evaluation is examined and some difficulties are pointed out. It is concluded that the above methods are poor approximations to more rigorous methods.

Key Words: Hamilton's characteristic functions, diffraction, aberration.

Lectures on critical phenomena, M. S. Green (Proc. Summer School of Theoretical Physics, Cargese, Corsica, Summer 1964), Book, Cargese Lectures in Theoretical Physics-Statistical Mechanics, Ed. B. Jancovici, pp. 59-88 (Gordon and Breach Publ., New York, N.Y., 1964).

Some speculative ideas on the theory of critical phenomena in liquid vapor systems are presented. As a background for these fundamental maximum principles of statistical mechanics, thermodynamics of phase changes in the activity temperature plane and sequence of Legendre transformations are discussed. It is suggested that critical phenomena will be simpler when expressed in term distribution functions rather than the potentials and that the critical points correspond to the existence of the zero eigenvalue of the derivative matrix of the transport from potentials of average force to potentials.

Key Words: Critical phenomena in liquid vapor systems, liquid vapor systems, statistical mechanics, thermodynamics of phase changes.

Light scattering from time-dependent molecular orientations at Raman frequencies in liquids, M. McClintock, D. A. Jennings, and M. Mizushima, Bull. Am. Phys. Soc. 12, Series II, No. 5, 711 (May 1967).

The profiles of several Raman lines arising from nontotally symmetric molecular vibrations in liquid benzene and carbon tetrachloride have been measured using $4880 \AA$ radiation from an argon ion laser as a source of illumination. These profiles have been analyzed on the assumption that scattering occurs from timedependent molecular reorientations of small angle in the liquid, analagous to those producing depolarized scattering at the Rayleigh line. On this basis, the half width at half maximum of the $606 \mathrm{~cm}^{-1}$ Raman line in benzene was found to be $3.3 \mathrm{~cm}^{-1}$, and the half width of the "orientation" line underlying this Raman line was found to $24.3 \mathrm{~cm}^{-1}$. The rotational relaxation time calculated for the $\nu_{18}$ vibrationally excited molecule is therefore $1.38 \times 10^{-12}$ seconds. This is short compared with a period of rotation and supports the assumption of rotational Brownian motion. It is also shorter than the rotational relaxation time for the molecule in the ground vibrational state, and indicates that there is weaker rotational coupling between molecules in the ground state than between vibrationally excited molecules and those in the ground state. The depolarization ratios of the Raman and the orientation components of the $606 \mathrm{~cm}^{-1}$ line for linearly polarized incident light were found to be 0.748 and 0.749 , respectively, in agreement with the theoretically predicted 0.750 .

\section{Key Words: Benzene, carbon tetrachloride, Raman scattering.}

Measurements in a turbulent boundary layer maintained in a nearly separating condition, W. G. Spangenberg, W. R. Rowland, and N. E. Mease (Proc. Symp. Fluid Mechanics of Internal Flow, General Motors Research Labs., Warren, Mich., 1965), Book, Fluid Mechanics of Internal Flow, Ed. G. Sovarn, pp. 110-151 (Elsevier Publ. Co., Amsterdam, The Netherlands, 1967).

A turbulent boundary layer on a smooth, flat wall was investigated where the pressure was increasing with increasing distance down stream such as to maintain the boundary layer in the condition of near separation. The investigation was conducted with air flowing in a channel having the boundary-layer wall as the bottom. The width was sufficient to permit realization of two-dimensional boundary-layer flow. Venting and sloping incorporated in the upper wall provided the control of pressure gradient by progressively decreasing the velocity within the duct with increasing distance downstream. The maximum free-stream velocity was always about $84 \mathrm{ft}$ per sec. The depth was sufficient to realize a free stream above the boundary layer except at the farther downstream positions where the boundary-layer flow itself reached the upper wall and escaped through the vents. Measurements of turbulence as well as of mean flow are made in order to reveal more of the mechanics of such flows than hitherto known. Measurements of turbulence were made with hot-wire instrumentation, and these comprised turbulence intensity, transverse integral scale, and turbulent shearing stress. Mean velocities were measured both with the hot-wire anemometer and total-head tube. Skin friction was estimated from mean-velocity profiles. Results were obtained for two slightly different pressure distributions, one yielding a closer approach to separation and vanishing skin friction than the other.

Key Words: Boundary layer, adverse pressure, turbulence, nearseparating flow, skin friction near-zero, turbulent boundary layer.

Neutron cross section evaluations-past, present, and future, K. Parker, D. T. Goldman, and L. Wallin (Proc. Intern. Atomic Energy Agency Conf. Reactors, Vienna, Austria, 1966), Book, Nuclear Data for Reactors II, 292 (1967).

A listing in computer output of all known neutron cross-section evaluations performed throughout the world is given.

Key Words: Neutron, cross section, evaluation, compilation, nuclear reactions.

NBSR converter tube, C. F. Kupiec and C. O. Muehlhause, Trans. Am. Nucl. Soc. 9, No. 2, 582-583 (Nov. 1966).

There are plans to incorporate a high-power-density fast-neutron converter tube in the National Bureau of Standards 10-MW Research Reactor, the NBSR. The purpose of such a facility would be for radiation effects studies where the flux is free from a thermalneutron component. A converter of this type would allow the experimenter to irradiate relatively large samples without allowing them to become excessively radioactive or appreciably perturb pile reactivity.

Key Words: Fast neutron, converter tube, research reactor, radiation effects, thermal neutron, radioactive, pile reactivity, NBSR.

Photographic standardization and research at the National Bureau of Standards, C. S. McCamy, Appl. Opt. 6, No. 1, 27-30 (Jan. 1967).

The Photographic Research Section of NBS provides physical standards of measurement and calibration services, cooperates with national and international standardizing organizations, and conducts research related directly to the utilization of photographic materials and processes. Standardization and research in sensitometry, standard light sources, emulsion making, preservation of photographs, precise densitometry, and image evaluation have spanned a half century.

Key Words: Photography, standardization, densitometry, NBS.

Radiation-field-dependent frequency shifts of atomic beam resonances, R. J. Harrach, J. Appl. Phys. 38, No. 4, 1808-1819 (Mar. 15, 1967).

Radiation field dependent frequency shifts arising in atomic beam spectroscopy are treated theoretically and experimentally. Shifts due to fundamental and unavoidable interactions between the radiation field and the atoms comprising the beam are distinguished from those due to various "apparatus effects." Precise measurements of frequency shifts are made for a cesium beam experiencing Ramsey-type excitation. For the magnetic field-sensitive transition $\left(\mathrm{F}, \mathrm{M}_{\mathrm{F}}\right)=(4, \pm 1) \leftrightarrow(3, \pm 1)$ the magnitude of the shifts is about 1 part in $10^{10}$ of the resonance frequency value, per milliwatt variation of input power to the radiation field. The shifts vary with input intensity in a non-monotonic fashion, and are shown to result from non-uniformity in the static magnetic $c$-field of the apparatus. Much smaller shifts of about 5 parts in $10^{13}$ per milliwatt are observed for the magnetic field-insensitive transition $\left(F, M_{F}\right)=(4,0) \leftrightarrow(3,0)$ The major features of these shifts are shown to arise from spectral impurities in the radiation exciting the transition and a small phase difference between the pair of separated radiation fields. The bearing these results have on evaluating the accuracy of an atomic beam frequency standard is discussed.

Key Words: Frequency shifts, atomic beam, radiation field, cesium beam, and frequency standard. 
Report on International Conference on Crystal Growth (ICCG), R. L. Parker (Proc. Intern. Conf. Crystal Growth, Boston, Mass., Dec. 1966), Phys. Today 19, No. 12, 109-111 (Dec. 1966).

An International Conference on Crystal Growth (ICCG) took place June 20-24, 1966 in Boston. The purpose of the Conference was to further the science and art of crystal growth by providing a forum for reporting and discussing recent original research in this field. The present report gives a brief summary of certain of the technical subjects dealt with at the Conference.

Key Words: Crystal, crystal growth, international conference, ICCG. report, 1966 ICCG.

Scaling-law equation of state for gases in the critical region, M. S. Green, M. Vincentini-Missoni, and J. M. H. L. Sengers, Phys. Rev. Letters 18, No. 25, 1113-1117 (June 19, 1967).

The Widom-Kadanoff scaling-law equation of state has been confirmed for a variety of gases in a range of $\pm 50 \%$ of the critical density and within a few percent above and below the critical temperature. Using a new procedure motivated by the scaling law the exponent $\delta$ describing the shape of the critical isotherm was found to be close to 5 while the compressibility exponents $\gamma$ and $\gamma^{\prime}$ were found to be both equal to about 1.4.

Key Words: Scaling law, critical region, gases, critical exponents, critical isotherm, compressibility, density gradients, gravity effect, equation of state.

Shubnikov-de Haas effect in $\mathrm{SrTiO}_{3}$, H. P. R. Frederiske, W. R. Hosler, and W. R. Thurber, Phys. Rev. 158, No. 3, 775-778 (June 15, 1967).

The magnetoresistance of semiconducting $\mathrm{SrTiO}_{3}$ has been investigated in high magnetic fields (up to $150 \mathrm{kOe}$ ). In the temperature range 1.4 to $2.1^{\circ} \mathrm{K}$, for fields of more than $50 \mathrm{kOe}$, well developed oscillations have been observed. The data support a conduction band consisting of spheroids along the $<100\rangle$ crystalline axes, having 3 minima at the points $X_{3}$. The periods of oscillation as well as the temperature dependence of the amplitude and the magnetic field saturation lead to the following values for the transverse and longitudinal effective masses: $m_{t}=1.5 m_{0} \pm 15 \%, m_{l}=6.0 m_{0} \pm 30 \%$.

Key Words: Bandstructure, high magnetic field, oscillatory mag netoresistance, Shubnikov-de Haas effect, strontium titanate.

Some characteristic of commonly used time scales, G. E. Hudson, Proc. IEEE 55, No. 6, 815-821 (June 1967).

The conception that time or duration is the ability of systems to experience events in a time sequence and to assign the same order to event sequences caused by other time sequences of events is examined. Time scales are defined ideally as the numerical measures which can be assigned to specific time sequences of events according to the theoretical analysis applicable to specific physical systems. Discussion of these ideas leads to the notions of phase and frequency and frequency standards, and to the theoretical and experimental basis for realizing a time scale. Examples of such realizations occur with the universal scales, the atomic scales, and the ephemeris scale, which are all defined ideally and then realized by the observations of specific physical systems and the use of the corresponding physical theories. There is a problem in the independent co-existence of gravitational and atomic scales which leads to the need for continued comparison, observation, and theoretical study.

Since 1958, several atomic clocks following various time scales have been maintained and are used in the control of standard frequency and time signal emissions from various radio stations. Several broadcast systems involving different time scales have evolved and are being studied. Two of these, designated as universal coordinated time (UTC) and stepped atomic time (SAT) are coordinated internationally and are useful in making the universal time information on the UT2 scale available to a certain approximation. Offsets in carrier frequencies and time pulse rates, and steps in pulse sequence epochs are used to derive the auxiliary approximating scales from a uniform atomic one. Statistical studies indicate some, but not much, difference in the choice of such systems. The CCIR is attempting to stimulate further investigations of the need and use of uniform scales of time on broadcasts, better ways to present universal scale information of use in navigation and in studying and knowing about earth rotation rates, the more efficient use of the electromag- netic spectrum for these broadcasts, and the international definition of a composite, uniform, reference scale of time.

Key Words: Time, time scales, broadcast time signals, time and frequency standards, standard frequency and time signals.

The calculation of nuclear cross-sections by the optical model, D. T. Goldman (Proc. Intern. Atomic Energy Agency Conf. Nuclear Data for Reactors, Vienna, Austria, 1966), Book, Nuclear Data for Reactors I, 339-364 (1967).

It is well recognized that there will always be limitations to the amount and certainty of microscopic nuclear cross-section data which are available for direct input into reactor design calculations. Therefore, scattering models for the interaction between incident nucleons and the target nucleus have been proposed and used to obtain appropriate values of necessary cross-sections, both where experimental data are lacking and to differentiate between conflicting data. The generic term for such computations is conveniently "optical model calculations" wherein the two-body internucleon potential is replaced by an effective nuclear potential.

This paper presents a systematic derivation of nuclear cross-sections beginning with the interaction between an incident particle and the target nucleons. The replacement of the exact potential by an effective potential results, to first order, in the ordinary timeindependent Schrödinger equation. This equation, including a complex and spin-orbit potential is solved for the resultant wave function. By writing the wave function in its scattering solution form, it is possible to compute the shape elastic cross-section and the polarization directly in Lengendre moment expansions. The compound nucleus cross-section, as given originally by the statistical model of Hauser and Feshbach, arises naturally by examining the total wave function. By using the entire solution, including the complete interaction potential, it is possible to generalize these calculations to include the effect of non-spherical potentials and to derive the distorted wave Born approximation. The equations derived in this manner have been used in writing ABACUS-1 and OPTIC, two widely utilized optical model programmes developed by colleagues and the author at Knolls Atomic Power Laboratory. The results obtained from calculations with suitably adjusted potential parameters, have provided confidence for further use of these optical model techniques in providing cross-section information.

Key Words: Calculations, cross section, nuclear cross sections, nucleus, neutron, optical model, scattering.

The effect of other metallic ions on the electrocrystallization of silver from nitrate solutions, J. P. Young, Plating, pp. 1-4 (Mar. 1967).

Silver dendrites of various configuration and forms were grown electrolytically on small cathode surfaces in silver nitrate solutions to which small amounts of other metal ions had been added to alter the characteristics of the non-epitaxial silver formations.

Key Words: Dendrite, electrocrystallization, silver, crystal growth, electrodeposited crystals, electrodeposited dendrites.

The effects of rotor deceleration on equilibrium sedimentation experiments, I. H. Billick, M. Dishon, M. Schulz, G. H. Weiss, and D. A. Yphantis, Proc. Natl. Acad. Sci. 56, No. 2, 399 (Aug. 1966).

It is the purpose of this note to present some results of a combined numerical and theoretical analysis of rotor deceleration, applicable to equilibrium sedimentation experiments. These results indicate the magnitude of errors in the data from sedimentation experiments where rotor slowing occurs. Of possibly greater interest is the conclusion that artificially induced rotor slowing can be used to substantially speed up equilibrium sedimentation experiments. We have developed the theory for the rectangular approximation to the Lamm equation, and concurrently solved the Lamm equation numerically by a method already described. Detailed accounts of both the theoretical analysis and the numerical results will be presented elsewhere.

Key Words: Centrifuge, sedimentation, rotor deceleration, equilibrium sedimentation, Lamm equation. 
The momentum autocorrelation function in a Bernoulli chain, R. J. Rubin and P. Ullersma, J. Math. Phys. 7, No. 10, 1877-1885 (Oct. 1966).

This paper is devoted to the study of the statistical dynamics of the small amplitude coplanar vibrations of a compound pendulum consisting of $N+1$ particles suspended in series by weightless strings in a gravitational field. All particles have the same mass $m$, except for the top particle whose mass is $n(1+2)$ : and all strings are of equal length. The behavior of this system in the limit in which $N \rightarrow \infty$ is of particular interest because the maximum normal mode frequency is proportional to $N^{1 / 2}$. In the limit $N \rightarrow \infty$, asymptotic formulas with error estimates are obtained for the time-dependence of the momentum autocorrelation function of: (1) the top particle when $\mathscr{2}=0 ;(2)$ the bottom particle when $2=0$; and (3) the top particle when $N \gg 2 \gg 1$

Key Words: Statistical dynamics, coupled harmonic oscillators, momentum autocorrelation function, statistical mechanics.

The production and use of monoenergetic electron beams, J. A. Simpson, Proc. 8th Annual Electron and Laser Beam Symp., University of Michigan, Ann Arbor, Mich., Apr. 6-8, 1966, pp. 437447 (1966)

The generation of dense electron beams of energy half-width below $0.1 \mathrm{eV}$ presents special problems. Among these are generation of tightly collimated beams of very low energy space charge effects in deflectors and anomalous energy spreads. A discussion of one successful attack on these problems will be given together with examples of the uses of such beams in electron optics.

Key Words: Electrons, electron beams, electron energy distributions, space charge.

Two-mirror systems with spherical reflecting surfaces, $\mathrm{O} . \mathrm{N}$. Stavroudis, J. Opt. Soc. Am. 57, No. 6, 741-748 (June 1967).

An analysis is made of two-mirror systems consisting of spherical refracting surfaces. Solutions are found for those systems having zero third order spherical aberration. It is shown that no practical solution exists for the configuration resembling the Gregorian telescope. For the configuration resembling the Cassegrainian telescope three one-parameter families of solutions obtain. These are given by

$$
\begin{gathered}
c_{1}=(q-1) / 2 t_{0} \quad t_{1}=\left(t_{0}-f\right) / q \quad c_{2}=q / 2 f \\
t_{0}=\frac{27 f}{32} \sec ^{2} \theta \quad q=-3\left[1+4 \cos \frac{2}{3}(\theta+\pi r)\right]^{-1}
\end{gathered}
$$

where $c_{1}$ and $c_{2}$ are the two curvatures; $t_{1}$, the axial separation of the two reflecting surfaces; $t_{0}$, the distance from a focus to the corresponding surface; and $f$, the focal length. The free parameter is $\theta$ and $r=0,1,-1$.

Key Words: Optical design, reflecting systems, collimators, cubic equations, third order spherical aberration, Cassegrainian systems.

X-ray diffraction measurement of stacking faults in alpha silver-tin alloys, C. J. Newton and A. W. Ruff, Jr., J. Appl. Phys. 37, No. 10, 3860-3868 (Sept. 1966).

Stacking fault probabilities and dislocation densities were studied by means of x-ray diffraction and transmission electron microscopy in both filed and compressed bulk specimens from a series of dilute silver alloys. In the filed samples the observed stacking fault probabilities increased smoothly from $3 \times 10^{-3}$ for pure silver to $66 \times 10^{-3}$ for 10.3 at.\% tin. The compressed bulk specimens led to values of $6 \times 10^{-3}$ and $95 \times 10^{-3}$ respectively. Direct determinations of the dislocation densities were made in the bulk specimens $\left(1\right.$ to $5 \times 10^{11}$ $\mathrm{cm}^{-2}$ ) leading to computed values for the stacking fault energy in the range 2 to $6 \mathrm{ergs} / \mathrm{cm}^{-2}$, with a slight dip for pure silver. Values for the dislocation density in the filed samples were also calculated. The effect of directed residual stresses measured on the bulk specimens was shown to be negligible with respect to the low angle diffraction line shifts attributed to faulting.

Key Words: X-ray diffraction, electron microscopy, stacking faults, dislocations, silver-tin alloys.
Distribution of standard frequency and time signals, A. H Morgan, Proc. IEEE 55, No. 6, 827-836 (June 1967).

This paper reviews the present methods of distributing standard frequency and time signals (SFTS), which include the use of high frequency, low frequency, and very low frequency radio signals, portable clocks, satellites, and $\mathrm{RF}$ cables and lines. The range of accuracies attained with most of these systems are included along with an indication of the sources of error. Information is also included on the accuracy of signals generated by frequency dividers and multipliers.

Details regarding the techniques, the propagation media, and the equipment used in the distribution systems described are not included. Also, the generation of the signals is not discussed.

Key Words: Standard frequency, time signals, standard frequency broadcasts, portable clocks, satellite timing.

Measurement of RF properties of materials-A survey, H. E. Bussey, Proc. IEEE 55, No. 6, pp. 1046-1053 (June 1967). This paper is a survey of the principal methods developed during the past twenty years for the measurement of $\mathrm{RF}$ peak pulse power. The basic principles involved for each method are described together with accuracies attainable under normal operating conditions. General techniques for pulse power measurement and precautions to be observed are also given.

Key Words: Measurement, peak pulse power, pulse modulation, RF power.

Of time and frequency, D. H. Andrews, Book, How to Listen to the World, pp. 3-7 (World Publ., Hellerup, Denmark, Jan. 1967). Following a short historical background of timekeeping, the author proceeds to describe Universal Time and how it is approximated by Atomic Time with corrections prescibed by the International Time Bureau. The use of radio broadcasts by various nations to disseminate time signals, standard radio frequencies and standard audio frequencies is described. Other services are also noted. The article includes an extensive listing of worldwide radio stations broadcasting standard frequencies and/or time signals. This tabulation is divided into two parts, Table I listing stations using frequencies above 1 megahertz, and, Table II listing stations using frequencies below 1 megahertz.

Key Words: Atomic time, frequency and time, international time bureau, standard audio frequencies, standard radio frequencies, time and frequency, worldwide radio stations.

Preliminary results of some new measurements of phase velocity at VLF, G. Kamas, A. H. Morgan, and J. L. Jespersen, Radio Sci. 1, No. 12, 1409-1410 (Dec. 1966).

A new measurement of the phase velocity of VLF radio waves is described. The measured value of the phase velocity at $18.6 \mathrm{kc} / \mathrm{s}$, for distances greater than 2400 kilometers from the transmitter, was $-0.0021 \pm 0.0006$ in the form $v_{p} / c-1$. For both 18.6 and 20.0 $\mathrm{kc} / \mathrm{s}$, at distances less than 2400 kilometers, the phase velocity varied with distance from the transmitter.

Key Words: Phase velocity, VLF, ionosphere.

\section{Other NBS Publications}

J. Res. NBS 71 A (Phys. and Chem.), No. 6 (Nov.-Dec. 1967), $\$ 1.00$.

\section{Guest Editor: Charles H. Corliss}

William Frederick Meggers, A Tribute. K. G. Kessler.

The second spectrum of ytterbium (Yb II). W. F. Meggers. (Edited by C. E. Moore.)

An improved description of technetium spectra (Te I and Te II), 2000 to $9000 \AA$ A. W. R. Bozman, W. F. Meggers, and C. H. Corliss.

Lifetimes of energy levels in neutral iron. C. H. Corliss and J. L. Tech.

Transition probabilities in argon I. C. H. Corliss and J. B. Shumaker, Jr.

The fifth spectrum of praseodymium. V. Kaufman and J. Sugar. 
Fundamental energy levels of neutral promethium (Pm I). J. Reader and S. P. Davis.

Analytical coordination chemistry; titrimetry, gravimetry, flame photometry, spectrophotometry, gas evolution and isotopic preparations, July 1965 to June 1966, Ed. O. Menis, Tecri. Note 402 (July 21, 1967), 50 cents.

Bibliography of Liesegand rings (second edition), K. H. Stern, Misc. Publ. 292 (Sept. 1, 1967), 40 cents.

Directory of United States standardization activities, J. E. Hartman, Misc. Publ. 288 (Aug. 1, 1967), \$2.00. (Supersedes Misc. Publ. 230).

Drawings of micrometer U-tube manometers for the ranges up to $100 \mathrm{~mm}$ of mercury, A. M. Thomas and J. L. Cross, Tech. Note 420 (Aug. 26, 1967), 15 cents.

Effects of finite lattice heat capacity on spin-lattice relaxation theory and numerical analysis, R. L. Peterson, Mono. 102 (Aug. 1, 1967), 25 cents.

Grading of abrasive grain on coated abrasive products, PS8-67 (Jan. 9, 1967), 15 cents. (Supersedes CS217-59.)

Hardboard, CS251-63, reprinted April 1967 with amendments (Nov. $15,1966), 10$ cents.

NBS standard frequency and time services, radio stations WWV WWVH, WWVB, WWVL, Misc. Publ. 236, 1967 Edition (1967), 15 cents.

Nuclear science and technology for ceramists, Proceedings of the American Ceramic Society Symposium Washington, D.C., April 7-12, 1966, Misc. Publ. 285 (May 26, 1967), \$1.75.

Proceedings of the 1966 Standards Laboratory Conference, Misc. Publ. 291 (July 13, 1967), \$1.00.

Revision of the NBS tables of spectral-line intensities below $2450 \AA$, C. H. Corliss, Mono. 32 Supplement (July 7, 1967), 30 cents.

Standard Reference Materials: Mössbauer spectroscopy standard for the chemical shift of iron compounds, J. J. Spijkerman, D. K. Snediker, F. C. Ruegg, and J. R. DeVoe, Misc. Publ. 260-13 (July $28,1967), 40$ cents

Standard Reference Materials: Recommended method of use of standard light-sensitive paper for calibrating carbon arcs used in testing textiles for colorfastness to light, E. Passaglia and P. J. Shouse, Misc. Publ. 260-15 (July 21, 1967), 20 cents.

Tables relating to Mathieu functions. Characteristic values, coefficients, and joining factors, AMS 59 (Aug. 1, 1967), \$3.25. (A reissue, with additions, of Columbia University Press 13).

Thermal-shock resistance for built-up membranes, W. C. Cullen and T. H. Boone, Bldg. Sci. Series 9 (Aug. 21, 1967), 20 cents.

The single-engine Claude cycle as a $4.2{ }^{\circ} \mathrm{K}$ refrigerator, $\mathrm{R}$. C. Muhlenhaupt and T. R. Strobridge, Tech. Note 354 (June 1, 1967), 45 cents.

Charge-transfer spectrum of the tetrachlorocuprate ion, M. Sharnoff and C. W. Reimann, J. Chem. Phys. 46, No. 7, 2634-2640 (Apr. 1, 1967).

Correlation of some Precambrian rocks and metamorphic events in parts of Wyoming and Montana, E. J. Catazaro, Mt. Geol. 4, No. 1, 9-21 (1967)

Erratum: Mass-spectrometric study of the reactions of $\mathrm{O}$ atoms with $\mathrm{NO}$ and $\mathrm{NO}_{2}$, F. S. Klein and J. T. Herron, J. Chem. Phys. 44, No. 9, 3645-3646 (May 1, 1966).

Magnetic and optical spectra of two dimeric copper-chloride pyridine-N-oxide complexes, G. F. Kokoszka, H. C. Allen, Jr., and G. Gordon, J. Chem. Phys. 46, No. 8, 3020 (Apr. 1967).

Mass spectrometric study of the photoionization of small molecules, V. H. Dibeler, R. M. Reese, and M. Krauss (Proc. 3rd Intern. Conf. Mass Spectrometry, Paris, France, Sept. 1964), Book, Advances in Mass Spectrometry 3, 471-488 (Institute of Petroleum, London, England, 1966).

Measurement of the direct $l$-doublet transitions in carbonyl sulfide, A. G. Maki, J. Mol. Spectry. 23, No. 1, 110-111 (May 1967).

Microwave spectrum of excited vibrational states of FCN, W. J. Lafferty and D. R. Lide, Jr., J. Mol. Spectry. 23, No. 1, 94-96 (May 1967).

Microwave spectrum, structure, dipole moment, and barrier to internal rotation of phosphorus trifluoride-borane, R. L. Kuczkowski and D. R. Lide, Jr., J. Chem. Phys. 46, No. 1, 357-365 (Jan. 1967).

Microwave studies of rotational isomerism, D. R. Lide, Jr., Trans. Am. Cryst. Assoc. 2, 106-116 (1966).
Monomer-polymer equilibria of deuterated alpha-methylstyrenes, L. J. Fetters, W. J. Pummer, and L. A. Wall, J. Polymer Sci. 4, Part A-1, 3003-3011 (1966).

Nuclear magnetic relaxation studies of $\left(\mathrm{CD}_{3} \mathrm{O}\right)_{2}^{11} \mathrm{BH}$, N. Boden, H. S. Gutowsky, J. R. Hansen, and T. C. Farrar, J. Chem. Phys. 46, No. 7, 2849 (Apr. 1, 1967).

Photolysis of cyclopentane at 1470, 1236, and 1048-67 A, R. D. Doepker, S. G. Lias, and P. Ausloos, J. Chem. Phys. 46, No. 11, 4340-4346 (June 1, 1967).

Symposium on problems of small information groups. Introductory remarks, M. B. Henderson (Div. Chem. Lit. Symp. Problems of Small Information Groups, 151st Natl. Meeting Am. Chem. Soc., Pittsburgh, Pa., Mar. 25, 1966), J. Chem. Doc. 6, 143 (Aug. 1966). Systematic errors in "recovery" and "detection" efficiency as related to radiochemical analysis, L. A. Currie, Proc. 11th Annual Bio-Assay and Analytical Chemistry Meeting, Albuquerque, New Mexico, Oct. 7-8, 1965, AEC No. 651008, pp. 35 (Clearinghouse for Federal Scientific and Technical Information, Springfield, Va., 1967).

The chain decomposition of propane initiated by vacuum ultraviolet photolysis, A. H. Laufer and J. R. McNesby, J. Phys. Chem. 70, 4094-4096 (1966).

The determination of bound styrene soluble high styrene-butadiene resins, M. A. Post, J. Paint Technol. 38, No. 497, 336-342 (June 1966).

The microwave spectrum and dipole moment of pyrazole, W. H. Kirchhoff, J. Am. Chem. Soc. 89, No. 6, 1312-1316 (Mar. 1967).

The microwave spectrum, structure, dipole moment, and quadrupole coupling constants of trans-nitrous acid, A. P. Cox and R. L. Kuczkowski, J. Am. Chem. Soc. 88, No. 22, 5071-5074 (Nov. 1966).

Vacuum-ultraviolet photolysis of solid propane at $20^{\circ}$ and $77^{\circ} \mathrm{K}$. R. E. Rebbert and P. Ausloos, J. Chem. Phys. 46, No. 11, 4333 4339 (June 1967).

Vapor deposition of tungsten by hydrogen reduction hexafluoride process variables and properties of the deposit, J. F. Berkeley, A. Brenner, and W. E. Reid, Jr., J. Electrochem. Soc. 114, No. 6, 561-568 (June 1967).

Anniversaries in 1966-67 of interest to statisticians. Part II: Tercentennials of Arbuthnot and De Moivre, C. Eisenhart and A. Birnbaum, Am. Stat. 21, No. 3, 22-29 (June 1967).

Comparison of three spin algebras employed in $\mathrm{SU}(6)$ theories, R. C. Casella, Phys. Rev. 147, No. 4, 962-964 (July 29, 1966).

Fundamental polygons for Fuchsian groups, L. Greenberg, J. Anal. Math. 18,99-105 (1967).

Fundamental polyhedra for kleinian groups, L. Greenberg, Ann. Math. 84, No. 3, 433-441 (Nov. 1966).

Invariance of the homology of a lattice, J. Mather, Proc. Am. Math. Soc. 17, No. 5, 1120-1124 (Oct. 1966).

On a theorem of Ahlfors and conjugate subgroups of kleinian groups, L. Greenberg, Am. J. Math. LXXXIX, No. 1. 56-68 (Jan. 1967). Calibration of germanium thermometers from $2^{\circ}$ to $20^{\circ} \mathrm{K}$, G. Cataland and H. H. Plumb (Proc. Intern. Inst. Refrigeration, Commission 1, Boulder, Colorado, 1966, Annexe 1966-5), Suppl. Bull. Inst. Intern. Froid. pp. 153-163 (Louvain, Belgium, 1966).

Cryogenic thermocouple thermometry, L. L. Sparks and R. L. Powell, Meas. Data 1, No. 2, 82-90 (Mar--Apr. 1967).

International standardization and expanded world trade, A. V. Astin, Mag. Std. 37, No. 7, 191-194 (July 1966).

A simple and accurate method of calibration by photopeak efficiencies, J. M. R. Hutchinson and D. H. Walker, Intern. J. Appl. Radiation Isotopes 18, No. 1, 86-89 (Jan. 1967).

Additional stopping power and range tables for protons, mesons and electrons, M. J. Berger and S. M. Seltzer, NASA-SP-3036 (1966).

Alpha gamma angular correlations in three heavy odd-A nuclides, J. M. R. Hutchinson, Phys. Rev. 157, No. 4, 1093-1098 (May 1967).

Autoionizing D States in He below the $n=2$ level of He, J. W. Cooper, S. Ormonde, C. H. Humphrey, and P. G. Burke, Proc. Phys. Soc. 91, 285-287 (1967).

Cold-neutron study of hindered rotations in solids and liquid methyl chloroform, neopentane and ethane, J. J. Rush, J. Chem. Phys. 46. No. 6, 2285-2291 (Mar. 1967).

Conformation of adsorbed polystyrene measured by attenuated total reflection in the ultraviolet region, P. Peyser and R. R. Stromberg, J. Phys. Chem. 71, No. 7, 2066-2074 (June 1967). 
Correction of some erroneous calculations of the Einstein A coefficient for the $18 \mathrm{~cm}$ transition of OH. D. R. Lide, Jr., Nature 213 , No. 5077, 694-695 (Feb. 18, 1967).

Dependence of 50 and $100 \mathrm{keV}$ bremsstrahlung on target thickness, atomic number, and geometric factors, R. C. Placious, J. Appl. Phys. 38, No. 5, 2030-2038 (Apr. 1967).

Eigenchannel theory of nuclear reactions, M. Danos and W. Greiner, Phys. Rev. 146, No. 3, 708-712 (June 1966).

Irradiation-induced colot centers in magnesium fluoride, R. F. Blunt and M. I. Cohen, Phys. Rev. 153, No. 3, 1031-1038 (Jan. 15, 1967).

Lineshapes due to anisotropic interactions in magnetic resonance experiments, R. A. Forman and A. H. Kahn, J. Chem. Phys. 45, No. 12, 4586-4588 (Dec. 1966).

Mean lives of atomic levels excited by electron impulse, J. Z. Klose, Proc. Intern. Conf. Electronic Excitation of an Atomic VaporApplication to Spectroscopy, Grenoble, France, May 23-26, 1966, pp. 191-192 (Centre Natl. de la Recherche Scientifique, Paris, France, 1967).

Microwave line shape and the inversion spectrum of $\mathrm{ND}_{3}$ and $\mathrm{ND}_{3}$. argon mixtures, A. A. Maryott and S. 3. Kryder, J. Chem. Phys. 46, No. 7, 2856-2857 (Apr. 1967).

Molecules in the sun, C. E. Moore-Sitterly, Proc. Symp. "Sun Spots" honoring Galileo, Florence, Italy, Sept. 9-12, 1964, Ed. G. Righini. pp. 181-185 (G. Barbera, Editore, Florence, Italy, 1966).

Multichannel photo-ionization of atomic systems, R. J. W. Henry and L. Lipsky, Phys. Rev. 153, No. 1, 51-56 (Jan. 1967).

Multichannel resonances in the inelastic scatterin $q$ of electrons by helium, G. E. Chamberlain, Phys. Rev. 155, No. 1, 46-51 (Mar. 5, 1967)

Newly measured and calculated wavelengths in the vacuum ultra violet spectrum of neutral nitrogen, V. Kaufman and J. F. Ward, Appl. Opt. 6, No. 1, 43-46 (Jan. 1967).

Nuclear magnetic resonance of nitrogen-14 in potassium azide, R. A. Forman, J. Chem. Phys. 45, No. 4, 1118-1123 (Aug. 13, 1966).

Nuclear magnetic resonance of ${ }^{7} \mathrm{Li}$ and ${ }^{1} \mathrm{H}$ in solid lithium imide, lithium amide, and lithium nitride, P. J. Haigh, R. A. Forman, and R. C. Frisch, J. Chem. Phys. 45, No. 3, 812-816 (Aug. 1, 1966).

Nuclear-resonance spin-echo study of ${ }^{61} \mathrm{Ni}$ hyperfine fields in ferromagnetic Ni-Al, Ni-V, and Ni-Cr systems, R. L. Streever and G. A. Uriano, Phys. Rev. 149, No. 1, 295-301 (Sept. 9, 1966).

Reflective scattering from substrates and evaporated films in the far ultraviolet, R. G. Johnston, L. R. Canfield, and R. P. Madden, Appl. Opt. 6, 719 (Apr. 1967).

Resonances in the photo-ionization continuum of Ne I $(20-150 \mathrm{eV})$, K. Codling, R. P. Madden, and D. L. Ederer, Phys. Rev. 155, No. 1, 26-37 (Mar. 5, 1967)

Scattering of cold neutrons in ammonium carbonate, ammonium citrate, and ammonium acetate, V. Myers, J. Chem. Phys. 46, No. 10, 4034-4035 (May 1967).

Spectral distribution of scattered light in a simple fluid, R. D. Mountain, Rev. Mod. Phys. 38, No. 1, 205-214 (Jan. 1966).

Stretch scheme, a microscopic description of rotations in nuclei, M. Danos and V. Gillet, Phys. Rev. Letters 1 7, No. 13, 703-705 (Sept. 26, 1966).

Structure of the alkali hydroxides. I. Microwave spectrum of gaseous CsOH. D. R. Lide and R. L. Kuczkowski, J. Chem. Phys. 46, No. 12, 4768-4774 (June 1967).

$\mathrm{SU}(3)$ reaction inequalities at high energies, S. Meshkov and G. B. Yodh, Phys. Rev. Letters 18, No. 12, 474-481 (Mar. 1967).

The photonuclear effect in heavy deformed nuclei, H. Arenhovel, W. Greiner and M. Danos, Phys. Rev. 157, No. 4, 1109-1125 (May 1967).

The standardization of cobalt-57, S. B. Garfinkel and J. N. R. Hutchinson, Intern. J. Appl. Radiation Isotopes 17, No. 10, 587-593 (Oct. 1966).
Transactions of the triple commission for spectroscopy, Subcommittee D-Atomic Spectra, C. E. Moore, J. Opt. Soc. Am. 55, No. 6 , 745 (1965).

Treatment of nuclear reactions above the two-particle threshold, M. Danos and W. Greiner, Z. Phys. 202, 125 (1967).

Triple-filament method for solid-sample lead isotope analysis, E. J. Catanzaro, J. Geophys. Res. 72, No. 4, 1325-1327 (Feb. 15, 1967).

$\mathrm{V}$ acuum ultraviolet wavelength standards and improved energy levels in the first spectrum of silicon, L. J. Radziemski, Jr., K. L. Andrew, V. Kaufman, and U. Litzen, J. Opt. Soc. Am. 57, No. 3, 336-340 (Mar. 1967).

W spin for any spin, H. Harari, D. Horn, M. Kugler. H. J. Lipkin, and S. Meshkov, Phys. Rev. 146., No. 4, $1052-1057$ (June 24, 1966).

Free rotation of methyl groups in dimethyltin difluoride, J. J. Rush and W. C. Hamilton, Inorg. Chem. 5, No. 12, 2238-2239 (Dec 1966).

Rate constants and the mechanism for the transfer of triplet excitation energy, R. A. Keller and L. J. Dolby, J. Am. Chem. Soc. 89, 2768-2770 (May 1967).

Study of low-frequency motions in several ferroelectric salts by the inelastic scattering of cold neutrons, J. J. Rush and T. I. Taylor, Proc. 3rd Symp. Inelastic Scattering of Neutrons, Bombay, India, 1965, II, 333 (1965).

Volume change on formation of native collagen aggregate, J. Cassel and R. G. Christensen, Biopolymers 5, 431-437 (1967).

Technological innovation: its environment and management, D. V De Simone, U.S. Department of Commerce Cl.2:T22 (Supt. Docs., Govt. Printing Office, W ashington, D.C.. Jan. 1967).

The innovator, D. V. De Simone, Engineer 8, No. 1, 8-9 (Jan.-Feb. 1967).

Progress report for O.S.A. committee on uniform color scales, D. B. Judd, Die Farbe 14, 287-295 (1965).

Almost "head-on" collisions in the scattering of fast argon atoms by hydrogen isotopes, J. E. Jordan and I. Amdur, J. Chem. Phys. 46, No. 10, 4145-4146 (May 1967).

Anomalous specific heat and viscosity of binary van der Waals mixtures. J. M. Deutch and R. Zwanzig, J. Chem. Phys. 46, No. 5 1612-1620 (Mar. 1, 1967).

Detachment of electrons from $\mathrm{H}^{-}$by electron impact, $\mathrm{G}$. C. Tisone and L. M. Branscomb, Phys. Rev. Letters 17, No. 5, 236-238 (Aug. 1, 1966).

Electron impact dissociation of $\mathrm{H}_{2}^{+}$, G. H. Dunn and B. Van Zyl, Phys. Rev. 154, No. 1, 40-51 (Feb. 1967).

Exponential operators and parameter differentiation in quantum physics, R. M. Wilcox, J. Math. Phys. 8, No. 4, 962-982 (Apr 1967).

Energetic ions from $\mathrm{N}_{2}$ produced by electron impact, L. J. Kieffer and R. J. Van Brunt, J. Chem. Phys. 46, No. 7, 2728-2734 (Apr. 1967).

Experimental transition probabilities for the Ar I $4 s-4 p$ array, J. B. Shumaker, Jr. and C. H. Popenoe, J. Opt. Soc. Am. 57, No. 1, 8-10 (Jan. 1967).

Formal theory of nonlinear response, R. L. Peterson, Rev. Mod Phys. 39, No. 1, 69-77 (Jan. 1967).

$g_{I} / g_{J}$ ratios in $\mathrm{Rb}^{87}$ and $\mathrm{Rb}^{85}$, L. C. Balling, Bull. Am. Phys. Soc. 12 Series II, No. 4, 508 (Apr. 1967).

NBS to dedicate Gaithersburg facility, W. K. Wilson, J. Wash. Acad. Sci. 56, No. 7, 165-167 (Oct. 1966).

Observation of two intrinsic nuclear relaxation rates in antiferromagnetic $\mathrm{KMnF}_{3}$, R. J. Mahler, A. C. Daniel, and P. T. Parrish, Phys. Rev. Letters 19, No. 2, 85-87 (July 10, 1967).

Short-range order in the Weiss molecular field approximation, R. L. Peterson, Bull. Am. Phys. Soc. 12, Series II, No. 4, 502 (Apr. 1967). 


\section{CORRIGENDA FOR THE PAPER}

Realistic Evaluation of the Precision and Accuracy of Instrument Calibration Systems, Churchill Eisenhart, Journal of Research of the National Bureau of Standards, Volume 67C, No. 2, 161-187 (April-June 1963)

Page 177, Eq. (16). Should read

$$
\sigma_{\bar{x}}^{2}=\frac{\sigma_{\bar{x}}^{2}}{n}=\frac{\sigma^{2}}{n}
$$

Page 178, Eq. (18). Insert " =" between " $s_{w}^{2} "$ and the formula that follows it.
Page 179, Eq. (20). Should read

$$
s_{\bar{x}}=\frac{\sum_{i=1}^{k}\left(\bar{x}_{i}-\bar{x}\right)^{2}}{k-1}
$$

Page 184. Roy H. Wampler of the Statistical Engineering Laboratory, NBS, has recomputed the entries of Table 1 and has found a number of errors in the original, especially in the two "Binomial" columns, that necessitate changes in the second column of the text. A corrected Table 1 , and revision of the affected text in column 2 follow.

TABLE 1. Limits of error of a sum of $n$ items indicated by various methods of

\begin{tabular}{|c|c|c|c|c|c|c|c|c|c|c|c|}
\hline \multirow{2}{*}{$n$} & \multirow{2}{*}{$\begin{array}{c}\text { Absolute } \\
\pm\end{array}$} & \multicolumn{2}{|c|}{ Binomial* } & \multicolumn{2}{|c|}{ Uniform } & \multicolumn{2}{|c|}{ Triangular } & \multicolumn{2}{|c|}{ Normal. $2 \sigma=0.5$} & \multicolumn{2}{|c|}{ Normal. $3 \sigma=0.5$} \\
\hline & & $0.95 \pm$ & $0.99 \pm$ & $0.95 \pm$ & $0.99 \pm$ & $0.95 \pm$ & $0.99 \pm$ & $0.95 \pm$ & 0.99 & $0.95 \pm$ & $0.99 \pm$ \\
\hline 1 & 0.50 & 0.50 & 0.50 & 0.48 & 0.50 & 0.39 & 0.45 & 0.49 & 0.64 & 0.33 & 0.43 \\
\hline 2 & 1.00 & 1.00 & 1.00 & 0.78 & 0.90 & 0.56 & 0.71 & 0.69 & 0.91 & 0.46 & 0.61 \\
\hline 3 & 1.50 & 1.50 & 1.50 & 0.97 & 1.19 & 0.69 & 0.88 & 0.85 & 1.12 & 0.57 & 0.74 \\
\hline 4 & 2.00 & 2.00 & 2.00 & 1.12 & 1.41 & 0.80 & 1.03 & 0.98 & 1.29 & 0.65 & 0.86 \\
\hline 5 & 2.50 & 2.50 & 2.50 & 1.25 & 1.60 & 0.89 & 1.15 & 1.10 & 1.44 & 0.73 & 0.96 \\
\hline 6 & 3.00 & 2.00 & 3.00 & 1.38 & 1.76 & 0.98 & 1.29 & 1.20 & 1.58 & 0.80 & 1.05 \\
\hline 7 & 3.50 & 2.50 & 3.50 & 1.49 & 1.91 & 1.06 & 1.39 & 1.30 & 1.70 & 0.86 & 1.14 \\
\hline 8 & 4.00 & 3.00 & 3.00 & 1.59 & 2.05 & 1.13 & 1.49 & 1.39 & 1.82 & 0.92 & 1.21 \\
\hline 9 & 4.50 & 2.50 & 3.50 & 1.69 & 2.18 & 1.20 & 1.58 & 1.47 & 1.93 & 0.98 & 1.29 \\
\hline 10 & 5.00 & 3.00 & 4.00 & 1.78 & 2.31 & 1.27 & 1.56 & 1.55 & 2.04 & 1.03 & 1.36 \\
\hline 15 & 7.50 & 3.50 & 4.50 & 2.19 & 2.88 & 1.55 & 2.04 & 1.90 & 2.49 & 1.27 & 1.66 \\
\hline 20 & 10.00 & 4.00 & 6.00 & 2.53 & 3.33 & 1.79 & 2.35 & 2.19 & 2.88 & 1.46 & 1.92 \\
\hline 25 & 12.50 & 4.50 & 6.50 & 2.83 & 3.72 & 2.00 & 2.63 & 2.45 & 3.22 & 1.63 & 2.15 \\
\hline 30 & 15.00 & 5.00 & 7.00 & 3.10 & 4.07 & 2.19 & 2.88 & 2.68 & 3.53 & 1.79 & 2.35 \\
\hline 40 & 20.00 & 6.00 & 8.00 & 3.58 & 4.70 & 2.53 & 3.33 & 3.10 & 4.07 & 2.07 & 2.72 \\
\hline 50 & 25.00 & 7.00 & 9.00 & 4.00 & 5.26 & 2.83 & 3.72 & 3.46 & 4.55 & 2.31 & 3.04 \\
\hline 60 & 30.00 & 8.00 & 10.00 & 4.38 & 5.76 & 3.10 & 4.07 & 3.80 & 4.99 & 2.53 & 3.33 \\
\hline
\end{tabular}
evaluation

*The results are not monotonic due to the discreteness of the distribution.

might "allow" a maximum error of \pm 50 cents per check, but consider it reasonable to regard their signs as being equally likely to be plus or minus. In this way one would be led to conclude "with probability
0.95 " that the total error lies between $\pm \$ 4.00$; or "with probability 0.99 ," between $\pm \$ 6.00$, as shown in the column headed "binomial" in table 1 , for $n=20$. 